UNIVERSIDADE DE SÃO PAULO

ESCOLA DE ENGENHARIA DE SÃO CARLOS

DEPARTAMENTO DE ENGENHARIA DE ESTRUTURAS

TITO JOSÉ RODRIGUES BALABUCH

\title{
ANÁLISE NUMÉRICA DAS DEFORMAÇÕES DO CONCRETO SUJEITO À REAÇÃO ÁLCALI-AGREGADO CONSIDERANDO OS EFEITOS DE RETRAÇÃO E FLUÊNCIA
}

SÃO CARLOS - SP

JULHO/2018 

TITO JOSÉ RODRIGUES BALABUCH

\title{
ANÁLISE NUMÉRICA DAS DEFORMAÇÕES DO CONCRETO SUJEITO À REAÇÃO ÁLCALI-AGREGADO CONSIDERANDO OS EFEITOS DE RETRAÇÃO E FLUÊNCIA
}

\author{
VERSÃO CORRIGIDA \\ A versão original encontra-se na Escola de Engenharia de São Carlos \\ Dissertação apresentada ao Departamento de \\ Engenharia de Estruturas da Escola de Engenharia de \\ São Carlos, da Universidade de São Paulo, como \\ requisito para obtenção do título de Mestre em \\ Engenharia Civil (Engenharia de Estruturas). \\ Área de Concentração: Estruturas de Concreto \\ Orientador: Prof. Dr. Rogério Carrazedo
}

SÃO CARLOS - SP

JULHO/2018 
AUTORIZO A REPRODUÇÃO TOTAL OU PARCIAL DESTE TRABALHO, POR QUALQUER MEIO CONVENCIONAL OU ELETRO̊NICO, PARA FINS DE ESTUDO E PESQUISA, DESDE QUE CITADA A FONTE.

Ficha catalográfica elaborada pela Biblioteca Prof. Dr. Sérgio Rodrigues Fontes da EESC/USP com os dados inseridos pelo(a) autor(a).

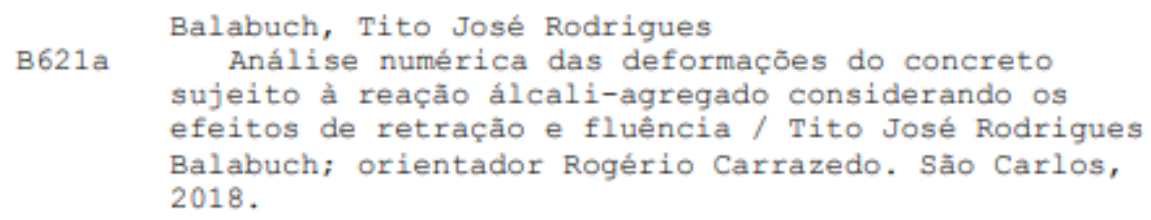

Dissertação (Mestrado) - Programa de Pós-Graduação em Engenharia Civil (Engenharia de Estruturas) e Área de Concentração em Estruturas -- Escola de Engenharia de São Carlos da Universidade de São Paulo, 2018.

1. Concreto. 2. Reação Alcali-Agregado. 3. Retração. 4. Fluência. 5. Método dos Elementos Finitos Posicional. I. Título.

Eduardo Graziosi Silva - CRB - 8/8907 


\section{FOLHA DE JULGAMENTO}

Candidato: Engenheiro TITO JOSÉ RODRIGUES BALABUCH.

Título da dissertação: "Análise numérica das deformações do concreto sujeito à reação álcali-agregado considerando os efeitos de retração e fluência".

Data da defesa: 05/07/2018

Comissão Julgadora:

Resultado:

Prof. Dr. Rogério Carrazedo (Orientador)

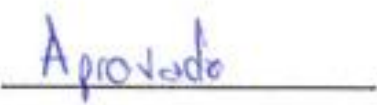

(Escola de Engenharia de São Carlos/EESC)

Profa. Dra. Edna Possan

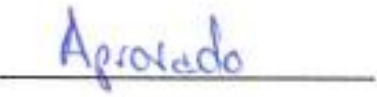

(Universidade Federal da Integração Latino-Americana/UNILA)

Prof. Dr. Luiz Alkimin de Lacerda

(Universidade Federal do Paraná/UFPR)

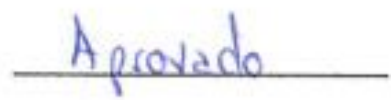

Coordenador do Programa de Pós-Graduação em Engenharia Civil (Engenharia de Estruturas):

Prof. Titular Humberto Breves Coda

Presidente da Comissão de Pós-Graduação:

Prof. Associado Luís Fernando Costa Alberto 

Dedico à minha família 



\section{AGRADECIMENTOS}

Ter chegado ao fim de mais uma etapa da minha vida acadêmica não seria possível se não tivesse em meu caminho a presença de pessoas maravilhosas. Foram tantos os percalços, porém maior do que eles foram as pessoas que me apoiaram, cada um a seu jeito.

Agradeço ao meu pai, José, que a seu modo sempre me incentivou aos estudos, e tenho consciência de que não chegaria até aqui se não fosse por isso. Agradeço à minha mãe, Lourdes, pelo seu amor, pela sua compreensão, pela sua abdicação em prol da família, buscando sempre me dar o suporte que precisava. Ao meu irmão, Timóteo, por demonstrar uma empatia e apoio além do que eu esperava, por me lembrar como são fortes os laços de família. À minha irmã, Lídia Carolina, por ser minha melhor amiga, pelo seu afeto, por me compreender, por me ouvir e compartilhar comigo os seus momentos.

À Rafaela Rondon, minha amiga, minha irmã de consideração, que cedeu não só sua casa quando precisei, bem como sua família. É claro que este agradecimento se estende a sua irmã, Fernanda, e sua mãe, Márcia. Não consigo expressar em palavras o quanto eu sou grato a cada uma de vocês.

À Monique Vogado, que me incentivou a me inscrever no mestrado, que comigo passou desde as dificuldades da conclusão da graduação até o fim da dissertação, sendo presente mesmo à distância. Sempre disposta a me ligar e conversar durante horas quando eu mais precisava, fosse para desabafar, fosse para jogar conversa fora. Por me inspirar a ser uma pessoa melhor.

À Rafaella Resende, minha amiga de mestrado e roommate, por me aconselhar quando estava confuso, me ouvir quando precisei conversar, me consolar quando precisei chorar, ou, simplesmente, por rir comigo mesmo da minha piada mais idiota.

Ao Emerson Félix, pela amizade e parceria desde os primeiros dias de mestrado, por sempre se fazer presente, sempre disposto a me ajudar, me auxiliando a passar pelas fases mais difíceis, e dividindo comigo os momentos mais alegres.

Aos amigos Felipi Pablo, Fabiana Moritani e Francielle Rodovalho, por me aturarem, por se importarem, por serem solícitos, gentis, e sempre, mas sempre, companheiros.

Aos amigos Giovane Avancini, Yagho Simões e demais amigos que fiz no SET, por tornarem os meus dias mais prazerosos. 
À Mariana Posterlli, pela sua amizade, e pela sua colaboração no entendimento da modelagem da $R A A$.

Aos funcionários do SET pela prestatividade, especialmente Daniane Prataviera e Marcela Bassoli, sempre tornando o momento do cafezinho mais agradável.

Aos professores da UFMT que contribuíram para minha formação, em especial ao Professor Alex Neves, que se dedicou em tornar possível a conclusão da graduação em tempo hábil.

Aos professores Luiz Alkimin de Lacerda e Edna Possan pelas contribuições na etapa de defesa desta dissertação, e aos professores Alessandra Lorenzetti e Vladimir Haach, pela colaboração na etapa de qualificação.

Ao meu orientador e professor, Rogério Carrazedo, pela disposição, preocupação, compreensão e paciência durante todo o período do mestrado.

E, por fim, ao Conselho Nacional de Desenvolvimento Científico e Tecnológico - CNPq pela bolsa de mestrado. 
"I'll tell you what freedom is to me... NO FEAR!" 

BALABUCH, T. J. R. Análise numérica das deformações do concreto sujeito à reação álcaliagregado considerando os efeitos de retração e fluência. 2018. 114 p. Dissertação (Mestrado em Engenharia Civil (Estruturas)) - Escola de Engenharia de São Carlos, Universidade de São Paulo, São Carlos, 2018.

As deformações derivadas da retração e da fluência estão entre os principais fatores que afetam a integridade e facilidade de manutenção das estruturas de concreto a longo prazo. Outro fator que corrobora para a deterioração do concreto é a Reação Álcali-Agregado (RAA), que devido à sua característica expansiva é considerada uma manifestação patológica de difícil tratamento, sendo necessário medidas mitigadoras para evitar sua ocorrência. A retração, a fluência e a RAA são deformações expressivas em estruturas com grandes volumes de concreto, em que as deformações devido à retração e à fluência potencializam o efeito da RAA, criando um ciclo de degradação do concreto de difícil controle. Deste modo, este trabalho tem como objetivo a análise numérica que possibilite a previsão do comportamento da retração e da fluência quando associadas à RAA. 0 código computacional é baseado no Método de Elementos Finitos Posicional considerando o elemento de chapa com elementos triangulares de ordem cúbica e utilizando a lei constitutiva de Saint-Venant-Kirchhoff. Para a modelagem da RAA utiliza-se o estudo desenvolvido por Carrazedo \& Lacerda (2008). A fluência e a retração são modeladas implementando-se os modelos FIB, JSCE e B4. Os resultados deste trabalho demonstram a eficiência da modelagem e da análise numérica para a previsão do comportamento das deformações do concreto sujeito à RAA, considerando os efeitos de retração e fluência.

Palavras-chaves: Concreto. Reação Álcali-Agregado. Retração. Fluência. Método dos Elementos Finitos Posicional. 

BALABUCH, T. J. R. Numerical analysis of concrete affected by alkali-aggregate reaction considering the effects of shrinkage and creep. 2018. 114 p. Dissertation (M. Sc. in Structural Engineering) - São Carlos School of Engineering, University of São Paulo, São Carlos, 2018.

Shrinkage and creep strains are among the main factors that affect the integrity and serviceability of concrete structures in long term. Another corroborating factor for the concrete deterioration is the Alkali-Aggregate Reaction (AAR), which due to its expansive characteristic is considered a pathological manifestation of difficult treatment, and mitigating measures are necessary to avoid its occurrence. Shrinkage, creep and AAR are expressive strains in structures with large volumes of concrete, in which strains due shrinkage and creep enhance the effect of AAR, creating a concrete degradation cycle that is difficult to control. Thus, this work has the aim of numerical analysis that allows the prediction of the shrinkage and creep behavior when associated with AAR. The computational code is based on the Positional Finite Elements Method considering the element of plate with triangular elements of cubic order and using the constitutive law of Saint-Venant-Kirchhoff. For the modeling of AAR is used the study developed by Carrazedo \& Lacerda (2008). The creep and shrinkage are modeled by implementing the FIB, JSCE and B4 models. The results of this work demonstrate the efficiency of modeling and numerical analysis for the prediction of the strains behavior of concrete subject to AAR, considering the effects of shrinkage and creep.

Key-words: Concrete. Alkali-Aggregate Reaction. Shrinkage. Creep. Positional Finite Elements Method. 



\section{LISTA DE FIGURAS}

Figura 1.1 - (a) Ponte Koror-Babeldaob (b) Colapso da Ponte. ...............................................................24

Figura 1.2 - Fissuração na barragem de Minas Gerais...............................................................................26

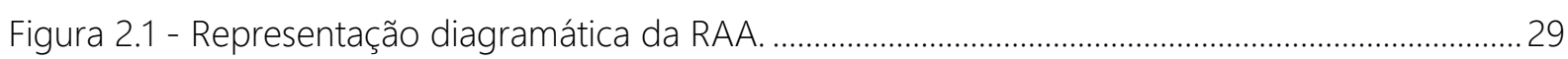

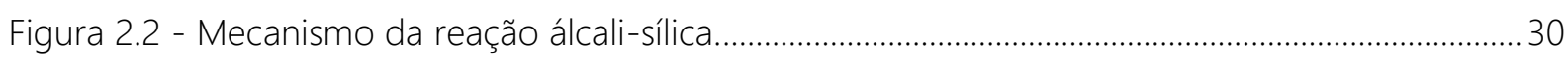

Figura 2.3 - Interpretação petrográfica da evolução da RAS. ............................................................... 31

Figura 2.4 - Efeito do tamanho e proporção do agregado na expansão por RAA.................................32

Figura 2.5 - Potencialidade do concreto em desenvolver a RAS em função do teor de álcalis e

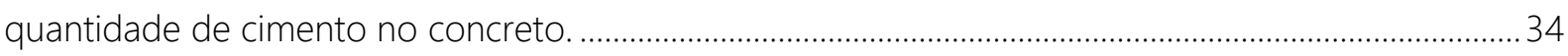

Figura 2.6 - Influência da umidade relativa na expansão por RAS. ………………………………............. 35

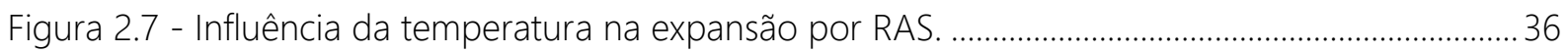

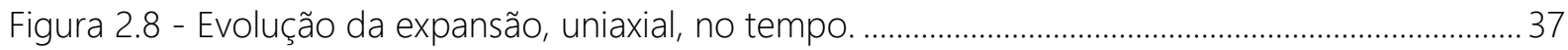

Figura 2.9 - Modelos numéricos para simulação da RAA. .........................................................................

Figura 2.10 - Representação das escalas macroscópica, mesoscópica e microscópica............................40

Figura 2.11 - Fatores que influenciam a expansão do concreto por RAA..................................................44

Figura 2.12 - Fatores de influência e coeficientes de calibração..................................................................46

Figura 2.13 - (a) Modelo sólido-padrão (b) Relação deformação vs tempo............................................ 47

Figura 2.14 - Curva de expansão de uma amostra de concreto sujeita à expansão livre.......................48

Figura 2.15 - Fatores de influência e coeficiente de calibração com relação a porosidade. .................49

Figura 3.1 - Fissuração por retração plástica.............................................................................................. 52

Figura 3.2 - Reversibilidade da retração por secagem. ……………………………………………............53

Figura 3.3 - Deformação do concreto submetido à carga constante....................................................... 55

Figura 3.4 - Deformação total do concreto ao longo do tempo. ................................................................55

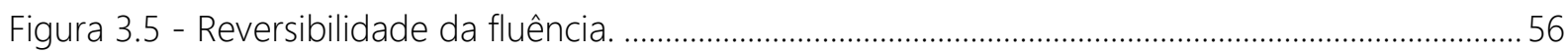


Figura 3.6 - Influência da relação água/cimento sobre a fluência.

Figura 3.7 - Influência da relação água/cimento e teor de agregados sobre a retração. .57

Figura 3.8 - Efeito da substituição de cimento por adições sobre a retração. .59

Figura 3.9 - Efeito da substituição de cimento por sílica ativa sobre a fluência. 60

Figura 3.10 - Influência das condições do ambiente sobre a retração. 61

Figura 3.11 - Influência das condições do ambiente sobre a resistência à compressão. 62

Figura 3.12 - Influência da espessura teórica na fluência e retração. 63

Figura 4.1 - Configuração de um corpo em equilíbrio. 74

Figura 4.2 - Formulação de um elemento finito posicional 2D. 76

Figura 4.3 - Fluxograma esquemático da rotina computacional desenvolvida. 84

Figura 5.1 - (a) Problema do quadro carregado (b) Malha discretizada do quadro. 85

Figura 5.2 - Deformações do quadro carregado à (a) Compressão e (b) Tração. 86

Figura 5.3 - Deformações do quadro carregado à compressão. 87

Figura 5.4 - Deformações do quadro carregado à tração.

Figura 5.5 - (a) Esquema do prisma de concreto (b) Malha discretizada do prisma 88

Figura 5.6 - Comparação entre o modelo numérico e os resultados experimentais para e expansão longitudinal.

Figura 5.7 - (a) Esquema do cilindro de concreto (b) Malha discretizada do cilindro. .89

Figura 5.8 - Correlação entre as expansões modeladas e observadas. 90

Figura 5.9 - Deslocamentos (a) horizontais (em cm) e (b) verticais (em cm) obtidos aos 450 dias.....91

Figura 5.10 - (a) Esquema de ensaio do cilindro (b) Malha discretizada do cilindro. 92

Figura 5.11 - Comparação entre os modelos numéricos e os resultados experimentais para deformação longitudinal do cilindro submetido tensão de compressão de $12 \mathrm{MPa}$. 93

Figura 5.12 - Comparação entre os modelos numéricos e os resultados experimentais para deformação radial do cilindro submetido tensão de compressão de $12 \mathrm{MPa}$. 93

Figura 5.13 - Comparação entre os modelos numéricos e os resultados experimentais para deformação longitudinal do cilindro submetido a expansão livre. 94 
Figura 5.14 - Comparação entre os modelos numéricos e os resultados experimentais para deformação radial do cilindro submetido a expansão livre.

Figura 5.15 - Comparação entre os modelos numéricos e os resultados experimentais para deformação do cilindro submetido tensão de compressão de $10 \mathrm{MPa}$.

Figura 5.16 - Comparação entre os modelos numéricos e os resultados experimentais para deformação do cilindro submetido tensão de compressão de $20 \mathrm{MPa}$.

Figura 5.17 - Comparação das deformações longitudinais considerando cada fenômeno isoladamente 98

Figura 5.18 - Deformação longitudinal do concreto sujeito à RAA, retração e fluência sob diferentes regimes de tensão.

Figura 5.19 - Deformação radial do concreto sujeito à RAA, retração e fluência sob diferentes regimes de tensão. 100

Figura 5.20 - Deformação (a) longitudinal e (b) radial do concreto sujeito à RAA, retração e fluência sob diferentes umidades relativas. 101

Figura 5.21 - Deformação (a) longitudinal e (b) radial do concreto sujeito à RAA, retração e fluência sob diferentes temperaturas 102 


\section{LISTA DE QUADROS}

Quadro 1 - Diferenças relativas entre o modelo numérico e os resultados de Mattiasson (1981)...... 86 


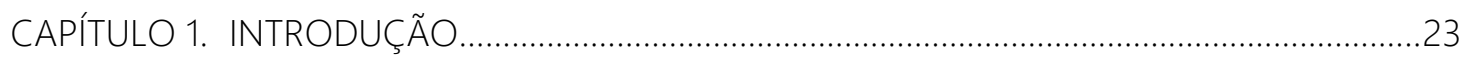

1.1 OBJETIVOS

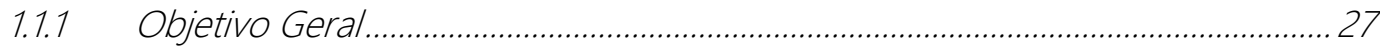

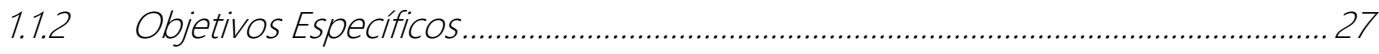

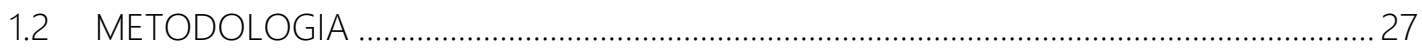

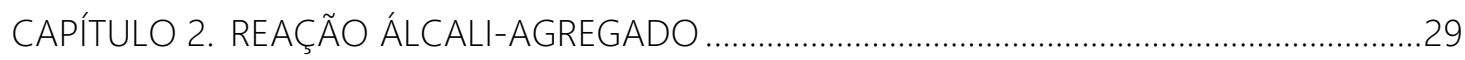

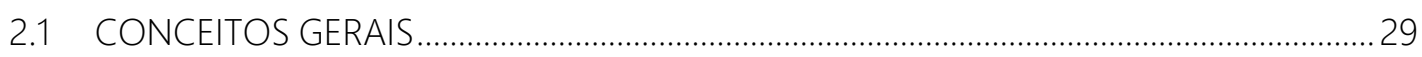

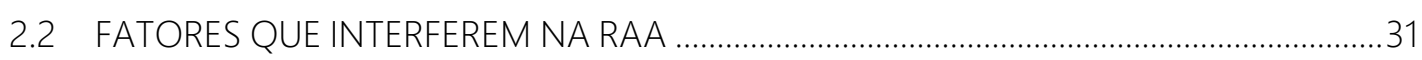

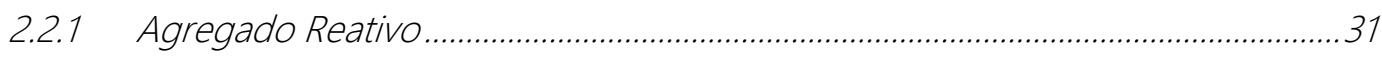

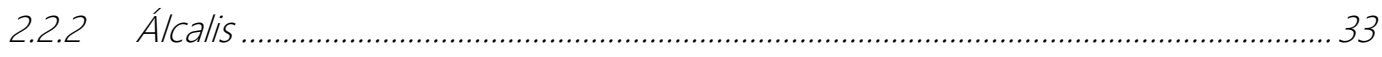

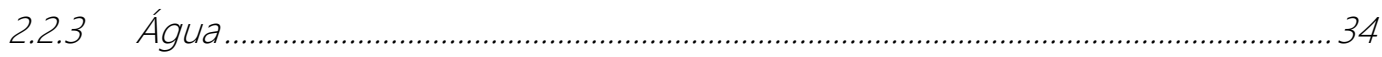

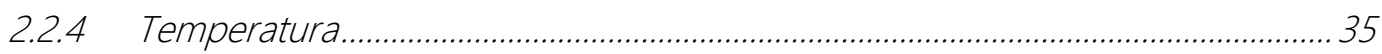

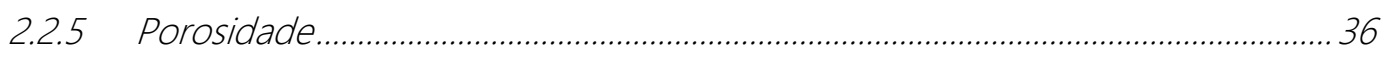

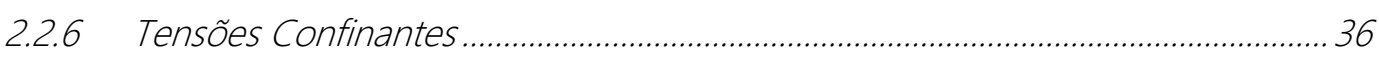

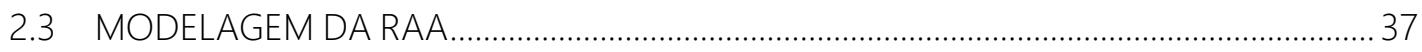

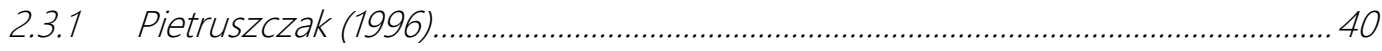

2.3.2 Léger, Côté \& Tinawi (1996) .................................................................................. 42

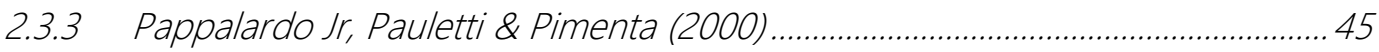

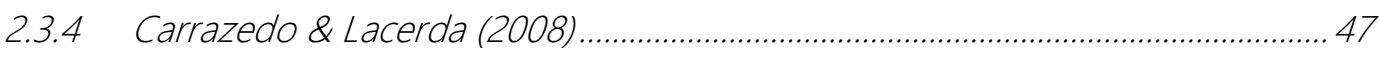

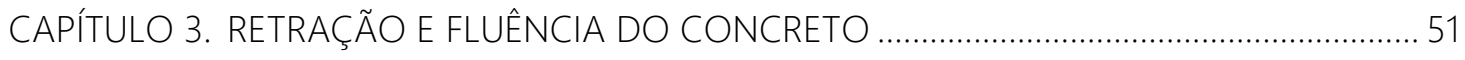

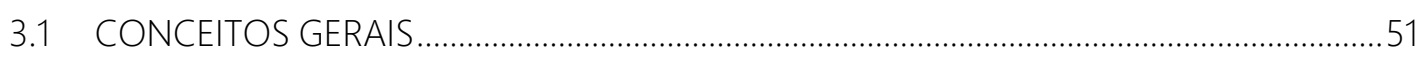

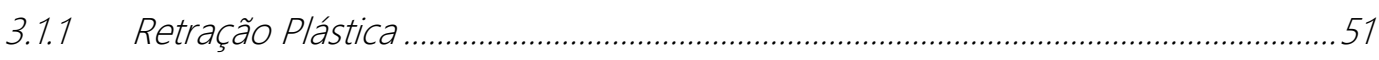

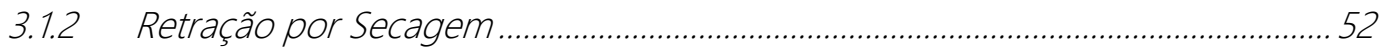

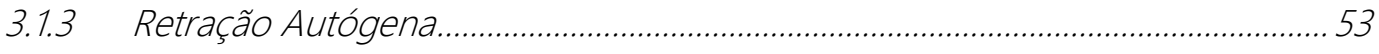

3.1.4 Deformação Elástica.............................................................................................. 54

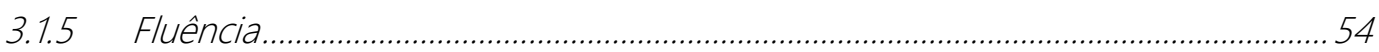

3.2 FATORES QUE INTERFEREM NA FLUÊNCIA E RETRAÇÃO ............................................56

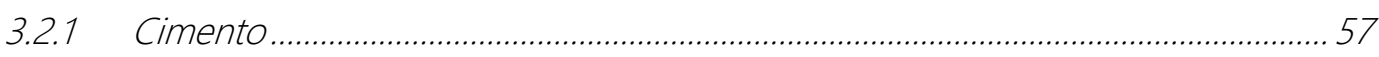




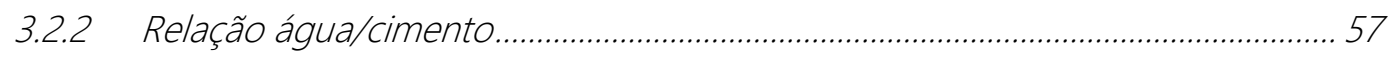

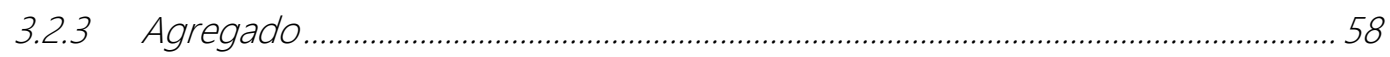

3.2.4 Umidade do Ar e Temperatura.........................................................................59

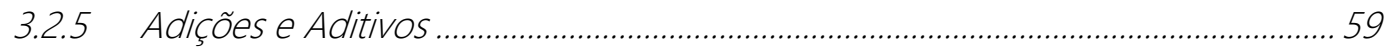

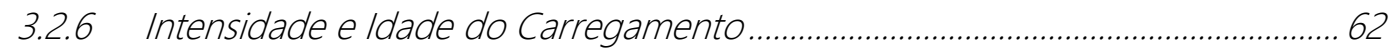

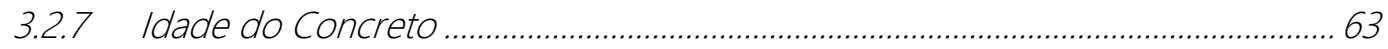

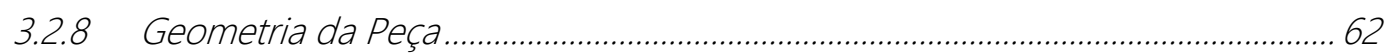

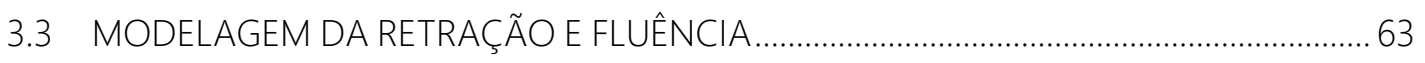

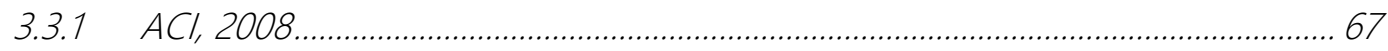

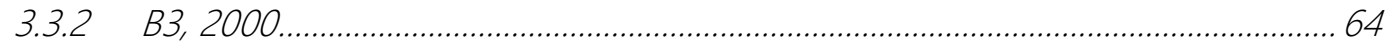

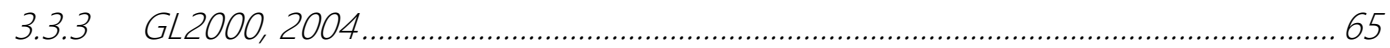

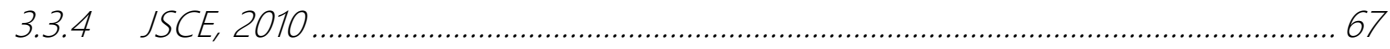

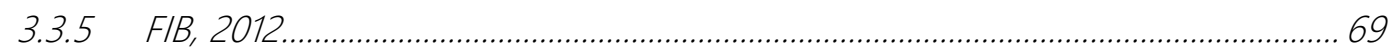

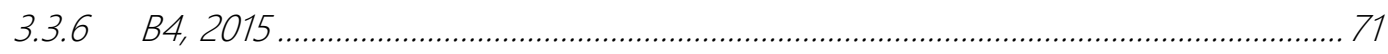

CAPÍTULO 4. MODELAGEM DO CONCRETO POR MEIO DO MEFP .......................................... 73

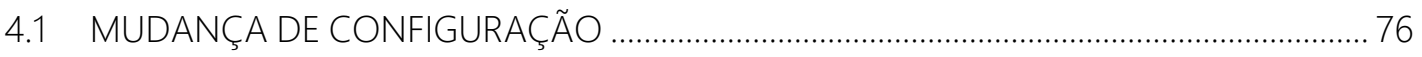

4.2 TENSOR DE DEFORMAÇÃO DE GREEN-LAGRANGE ……………………...................... 78

4.3 LEI CONSTITUTIVA DE SAINT-VENANT-KIRCHHOFF ................................................... 79

4.4 TENSOR DE TENSÃO DE PIOLA-KIRCHHOFF DE SEGUNDA ESPÉCIE …….................... 79

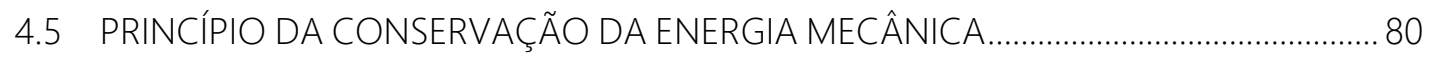

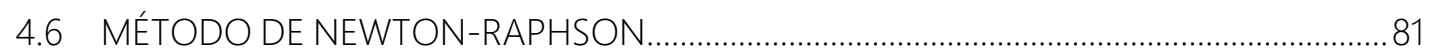

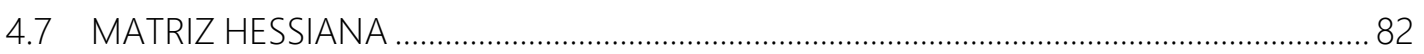

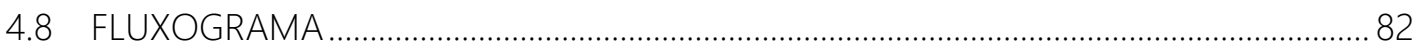

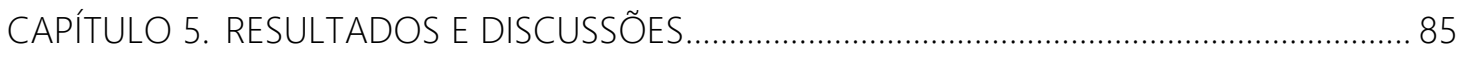

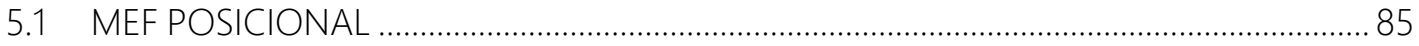

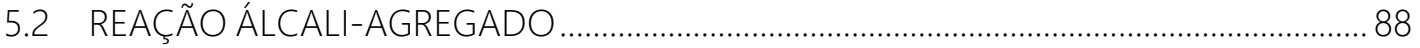

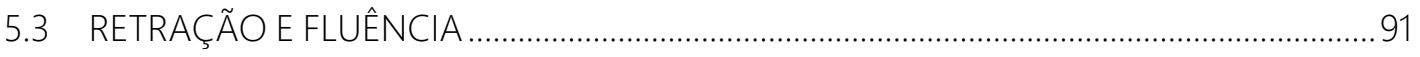

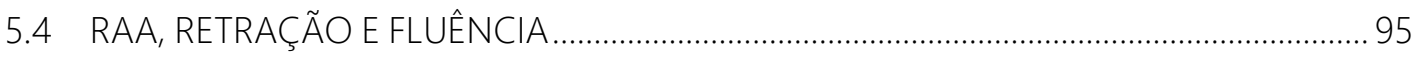

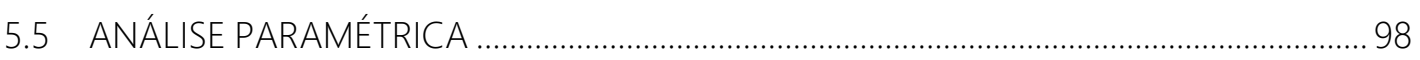

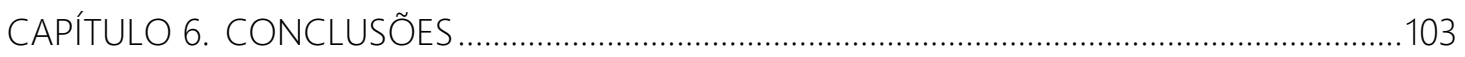

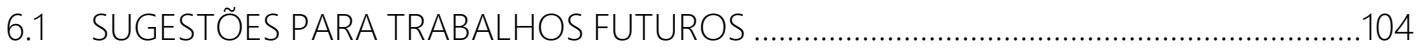

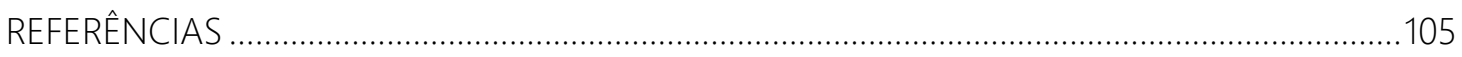




\section{CAPÍTULO 1 \\ INTRODUÇÃO}

O concreto, em seu comportamento, apresenta viscosidade, elasticidade e plasticidade, caracterizando-se como um material do tipo elasto-viscoplástico. As deformações do concreto podem ser da seguinte forma (LEONHARDT \& MÖNNING, 1977):

- Elásticas: causadas pelo carregamento ou temperatura, estas deformações desaparecem por completo após o fim da ação que as causou;

- Plásticas: causadas por carregamentos elevados de curta duração, estas deformações não desaparecem por completo após o fim do carregamento.

As deformações podem ser também em função do tempo e de condições climáticas. Devido à alteração da pasta de cimento no concreto, classifica-se essas deformações como:

- Retração e Expansão: são independentes do carregamento e causadas devido à variação de umidade e temperatura no concreto;

- Deformação lenta ou fluência: são causadas pela variação de volume do concreto, que dependem da aplicação ou remoção de carregamentos.

Após o carregamento da estrutura de concreto, tem início a deformação lenta, o que dificulta a verificação de deformações puramente elásticas. Deste modo, nas medições feitas em ensaios de estruturas, determina-se o tempo entre o carregamento e a medição, além da temperatura e da umidade ambiente (POLETTO, 2015).

As deformações derivadas da retração e da fluência são conhecidas como os dois maiores fatores que afetam a integridade e facilidade de manutenção das estruturas de concreto a longo prazo, sendo mais intensas em estruturas com grandes volumes de concreto. Para que houvesse compreensão da forma como ocorre a retração e fluência ao longo do tempo, foram elaborados diferentes formulações e programas experimentais, com o intuito de fornecer um conjunto de dados que fossem adequados ao estudo do presente problema. Foram também desenvolvidos modelos a fim de prever o comportamento do concreto (ABDELLATEF et al., 2015). 
O mais recente estímulo para o avanço na engenharia estrutural quanto ao estudo da fluência foi dado devido ao caso em 1996 da Ponte Koror-Babeldaob, de 241 m, em Palau (Figura 1.1a). A deflexão prevista em projeto era de $481 \mathrm{~mm}$, ficando abaixo da relação 1/500. Além disso, por ser uma deflexão de projeto, um desvio de $30 \%$ seria considerado tolerável, de modo que estavam preparados para uma deflexão de $625 \mathrm{~mm}$. No entanto, a ponte sofreu deflexões de fluência que alcançaram 1,61 m, mais do que o dobro do previsto já considerando um desvio de 30\%. Quando tentou-se realizar um pré-esforço corretivo, a ponte entrou em colapso (Figura 1.1b), alcançando apenas 18 anos de vida-útil, enquanto a maioria das grandes pontes são projetadas para uma vida-útil de pelo menos 100 anos (BAŽANT, YU \& LI, 2012; TANG, 2014).

Figura 1.1 - (a) Ponte Koror-Babeldaob (b) Colapso da Ponte.
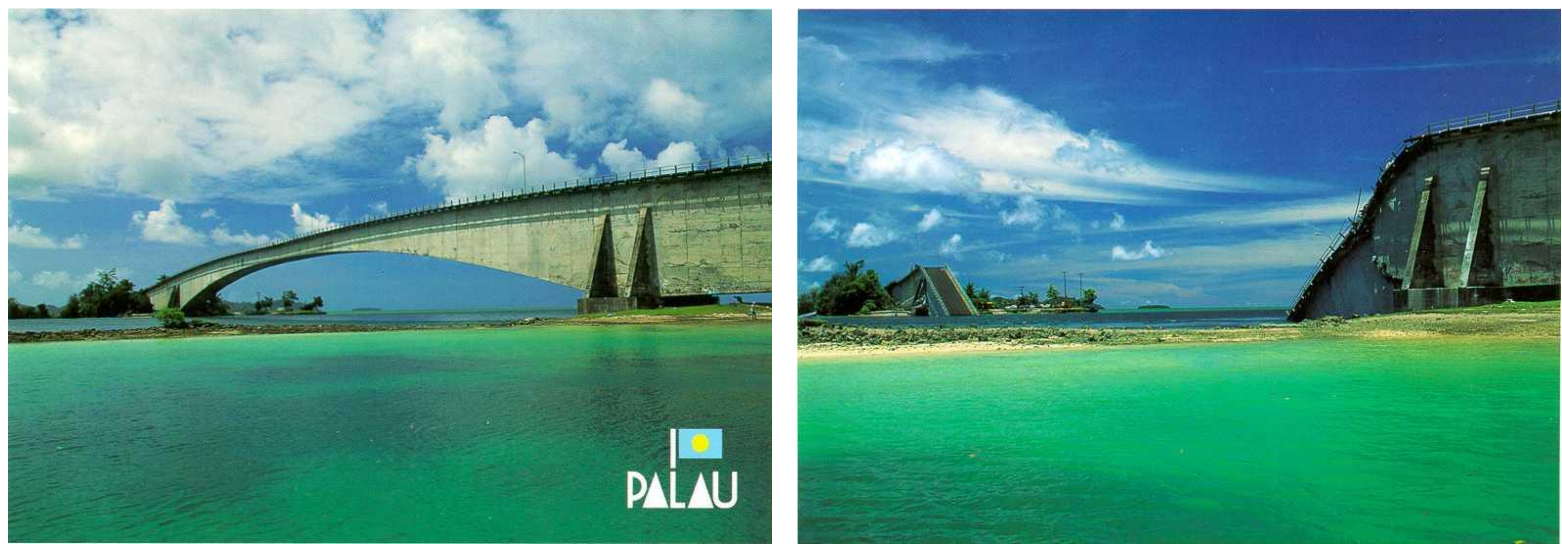

Fonte: Tang (2014).

Além da retração e da fluência, a expansão é outro tipo de deformação do concreto. Os processos expansivos físico-químicos acionados por determinadas condições ambientais podem produzir degradação significativa da resistência e rigidez do concreto em diferentes tipos de estruturas. Dentre esses processos, pode-se citar a Reação Álcali-Agregado (RAA), segunda forma mais prevalente de degradação do concreto, após a corrosão da armadura, e causa principal da deterioração do concreto em estruturas como pontes e barragens. Com o passar do tempo, cada vez mais estruturas são diagnosticadas com o fenômeno da RAA (SCRIVENER, 2009; COMI \& PEREGO, 2011; PAN et al., 2013).

A Reação Álcali-Sílica, uma das classificações da RAA, sendo a mais recorrente no Brasil, é a reação química que ocorre no concreto entre a pasta de cimento alcalino e o dióxido de silício, também conhecido como sílica amorfa, presente nos agregados. 0 principal produto da reação entre o álcali e a sílica amorfa é um gel que se expande na presença de água livre e, deste modo, produz fissuras extensivas na matriz de concreto, afetando a durabilidade e reduzindo a vida útil das estruturas de concreto. A deterioração das propriedades mecânicas 
é consequência da ação combinada das tensões internas devido à expansão do gel, e das tensões macroscópicas causadas pela redundância estrutural que impedem a livre expansão da estrutura (HASPARYK, 2011; COMI \& PEREGO, 2011; PAN et al., 2013).

A reação álcali-agregado sempre foi e sempre será uma preocupação para a indústria da construção porque não há, atualmente, nenhuma maneira de interromper completamente o problema antes que este pare por si próprio, o que pode levar décadas para acontecer, depois que um dano extensivo se desenvolveu. Tem-se criado programas de investigação, monitoramento e reparo da RAA a um custo excessivo, que em muitos casos não são efetivos. Há casos de estruturas lesadas pela RAA que não apresentam perigo estrutural, mas por fins estéticos são feitos reparos, por se tratarem de obras com apelo público. A importância dada a esse problema depende da estrutura afetada. Em casos onde os movimentos relativos, deformações e aberturas de fissuras não podem ser tolerados devido ao risco de perda na integridade estrutural ou perigo para o público, a RAA pode ser tomada como um problema grave (FOURNIER \& BÉRUBÉ, 2000).

Nos anos de 1920 a 1930, na Califórnia, foram observadas diversas estruturas de concreto com intensa fissuração, mesmo nas obras em que se havia adotado boas práticas de engenharia. Mas foi somente em 1940 que Thomas Edson Stanton identificou a existência da RAA como um processo deletério intrínseco dos constituintes do concreto, sendo causa dos problemas mencionados. Após a detecção do fenômeno nos EUA, a RAA foi constatada em diversas regiões do mundo: em 1950 na Dinamarca, em 1960 no Brasil e na Alemanha, em 1970 no Reino Unido, em 1980 no Japão e, desde então, vem sendo identificada em todo o mundo, sendo objeto de estudos por diversos pesquisadores (BATTAGIN, 2016).

Um exemplo é caso da ponte de Elgeseter, na Noruega, construída entre 1949 e 1951, custando na época kr\$ 1,5 milhões. Em 1985 a única junta de dilatação da ponte precisou ser reparada. Entretanto, mesmo após a reparação, em 1989 a ponte já estava danificada, em que foram observadas fissuras nas vigas e placas da estrada, "fissuras de retração", lascamento e corrosão da armadura das colunas de concreto armado. No início da década de 1990 foi investigada a RAA como causa para as fissuras observadas no concreto. Devido aos danos causados pela RAA foi necessária a reparação da ponte no prazo de 5 anos, cujo custo estimado foi de kr\$ 6,8 milhões (JENSEN, 2004).

Outro exemplo é caso do Aeroporto Regional do Noroeste de Arkansas (XNA) nos EUA. Trata-se de um aeroporto comercial com início de funcionamento em 1998, e que apenas quatro anos depois foram detectados sinais precoces de RAA, resultando em deterioração 
significativa ao longo dos anos. Consequentemente, após 14 anos da construção da pista, XNA se envolveu em um grande projeto de melhoria do aeródromo para reconstruir a pista. A RAA foi tão extensa que a pista precisou ser demolida e substituída. Antes de construir a nova pista, foi necessário construir uma superfície alternativa de aterrissagem, que custou US\$38,5 milhões, e o custo da nova pista foi de US\$ 37,9 milhões, resultando em um gasto final de US\$ 76,4 milhões (HEYMSFIELD et al., 2016).

No Brasil pode-se citar o caso de uma pequena barragem hidroelétrica localizada no estado de Minas Gerais (Figura 1.2), que apresenta um estado avançado de fissuração devido à reação álcali-agregado no concreto. A barragem foi concluída em 1946, com capacidade de geração de energia de 9,4 MW, possui $46 \mathrm{~m}$ de altura, com uma crista de $85 \mathrm{~m}$, teve suas primeiras fissuras no arco observado em 1966, cerca de 20 anos após sua construção. Após as primeiras fissuras, a avaliação da ombreira esquerda de concreto revelou que a expansão estava em torno de $120 \mu \varepsilon$ por ano, enquanto a ombreira direita e o arco se expandiam em torno de $20 \mu \varepsilon$ por ano. Uma nova avaliação foi realizada em 1997, revelando expansão de cerca de $65,3 \mu \varepsilon$ por ano na ombreira esquerda e $8,9 \mu \varepsilon$ por ano na ombreira direita e no arco. Alguns extensômetros foram instalados permitindo medições ao longo do tempo. As medições até 2008 mostraram expansão de 50,5 $\mu \varepsilon$ na ombreira esquerda e 12,5 $\mu \varepsilon$ no arco. Algumas amostras foram recentemente extraídas e submetidas a testes específicos, que demonstraram ainda existir potencial reativo (CARRAZEDO et al., 2018).

Figura 1.2 - Fissuração na barragem de Minas Gerais.

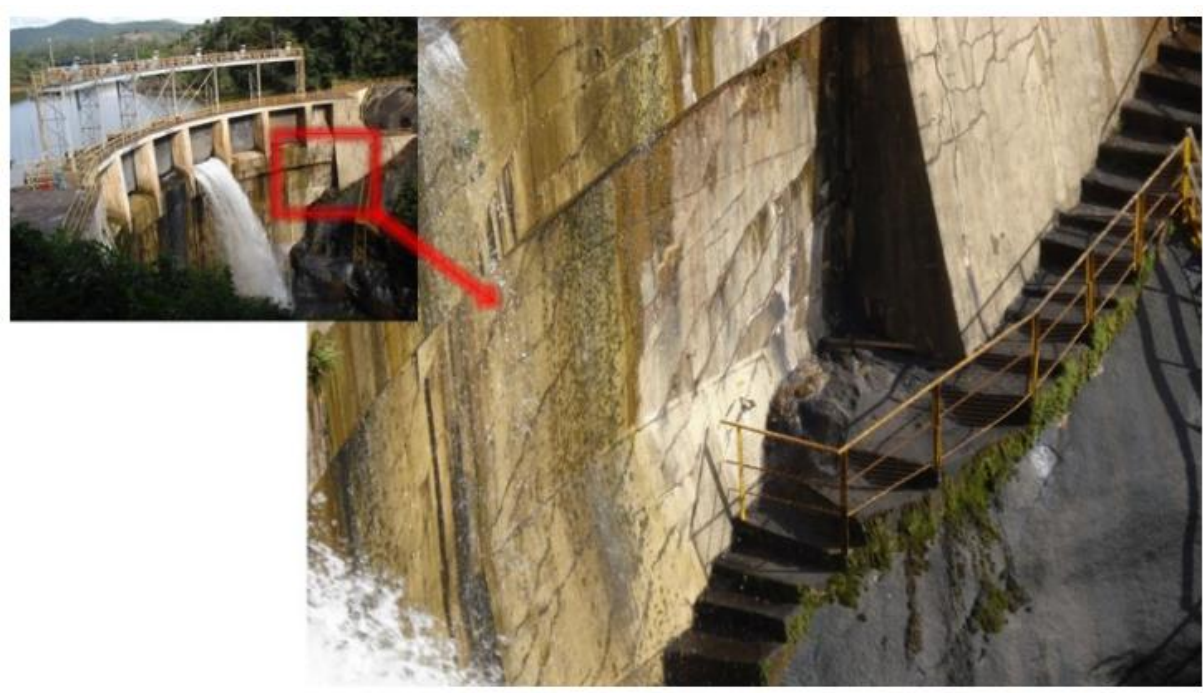

Fonte: CARRAZEDO et al. (2018).

Como se trata de um fenômeno que leva anos para produzir danos visíveis, é importante prever o comportamento das deformações causadas no concreto pela RAA, de 
modo que seja possível avaliar a estabilidade das estruturas. Entretanto, as simulações numéricas de estruturas de concreto afetadas pela RAA, de modo geral, negligenciam as interações entre RAA, fluência e retração (GRIMAL et al., 2008; COMI \& PEREGO, 2011; PAN et al., 2013).

Neste sentido, este trabalho vem com o intuito de desenvolver um modelo numérico em que seja possível prever o comportamento das deformações devido à reação álcaliagregado, considerando os fenômenos da retração e da fluência. Assim, permite-se a manutenção e avaliação de estruturas de maneira mais otimizada, sendo possível o ganho de vida útil das estruturas de concreto.

\subsection{OBJETIVOS}

\subsubsection{Objetivo Geral}

Desenvolver um modelo numérico que possibilite a previsão do comportamento de estruturas de concreto sujeitas à reação álcali-agregado, considerando os efeitos de retração e fluência.

\subsubsection{Objetivos Específicos}

- Implementar a formulação de chapa por meio do Método dos Elementos Finitos Posicional (MEFP);

- Modelar a expansão do concreto sujeito a reação álcali-agregado;

- Modelar as deformações por fluência e retração do concreto;

- Avaliar numericamente as deformações do concreto considerando a RAA, retração e fluência, com base em ensaio experimental;

- Analisar parâmetros relacionados aos três fenômenos em conjunto de modo a tentar verificar a interferência dos fenômenos entre si.

\subsection{METODOLOGIA}

Para o desenvolvimento deste trabalho, foi feito, primeiramente, uma pesquisa bibliográfica, a fim de buscar embasamento teórico a respeito da RAA, retração e fluência, bem 
como avaliar quais modelos de retração e fluência são mais eficazes para implementação no modelo de RAA de estruturas de concreto.

Além do referencial teórico, foi implementado um código computacional de um elemento de chapa, considerando a lei constitutiva de Saint-Venant-Kirchhoff, modelada por meio do método de elementos finitos posicional com elementos triangulares proposto por Coda (2003). Após criado o código computacional, foi feita a modelagem da RAA. Para este ponto, foi usada a modelagem desenvolvida por Carrazedo \& Lacerda (2008), com as contribuições de Oliveira (2013), Salomão (2017) e Posterlli (2017). Uma vez modelada a RAA, foi feita a modelagem da retração e fluência.

O comportamento médio, dependente do tempo, para estruturas de concreto, quando relacionado com os fenômenos físicos da fluência e da retração, é normalmente previsto usando modelos recomendados pelos códigos de projeto, como por exemplo, Model Code 2010 (FIB, 2012) e JSCE (JSCE, 2010), ou modelos acadêmicos, por exemplo, B4 (BAŽANT \& RILEM, 2015). Estes modelos foram desenvolvidos e calibrados com base em um grande número de resultados experimentais. Os modelos citados foram avaliados e implementados no código computacional a fim de definir qual deles é mais eficaz para o escopo deste trabalho.

Finalizado o código computacional que contemple a RAA, a retração e a fluência, foram gerados exemplos com o propósito de validar o programa criado, cujos resultados foram comparados com resultados de ensaios experimentais existentes na literatura. E, por fim, uma vez validado o código computacional, foi feita uma análise paramétrica dos três fenômenos associados. 


\section{CAPÍTULO 2}

\section{REAÇÃO ÁLCALI-AGREGADO}

Neste capítulo é apresentada uma breve fundamentação teórica do conceito de reação álcali-agregado, bem como os fatores que influenciam a sua ocorrência. Esse entendimento é necessário para melhor compreensão dos modelos numéricos que são apresentados em seguida, utilizados para a modelagem da expansão por RAA, bem como dos parâmetros utilizados por cada um deles.

\subsection{CONCEITOS GERAIS}

A Reação Álcali-Agregado, de modo geral, pode ser considerada como a reação química que se dá no interior de uma estrutura de concreto, que envolve minerais reativos presentes nos agregados, álcalis presentes na solução dos poros de concreto, e água (Figura 2.1).

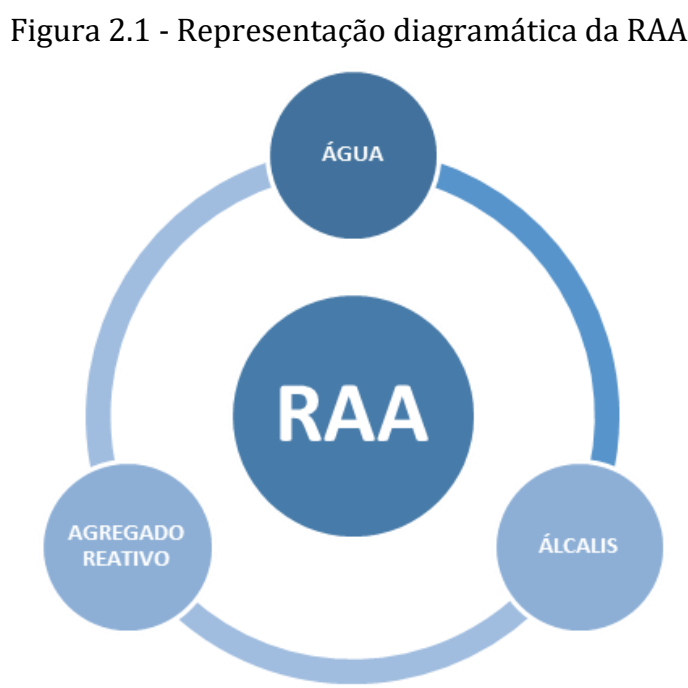

O produto que resulta dessa reação gera expansão, causando a fissuração do concreto, e interferindo na durabilidade da estrutura (HASPARYK, 2011). 0 processo químico de deterioração pela RAA é classificado pela NBR 15577-1:2008 (ABNT, 2008) de acordo com o tipo e a mineralogia do agregado reativo, sendo elas a Reação Álcali-Sílica (RAS), a Reação Álcali-Silicato (tipo específico de RAS) e a Reação Álcali-Carbonato (RAC). 
A RAS é uma das formas de RAA mais conhecidas e estudadas pelo meio técnico. Devido às formas minerais de sílica envolvidas, essa reação ocorre mais rapidamente. Dentre as formas minerais mais comuns, pode-se destacar a opala, a calcedônia, a cristobalita, entre outras. A reação álcali-silicato possui um desenvolvimento um pouco mais lento, e não é muito difundida. Essa reação tem o mesmo princípio da RAS, com a diferença que os minerais reativos estão mais presentes no núcleo do agregado, o que torna o processo mais lento. Os minerais envolvidos nesta reação são os expansivos do grupo dos filossilicatos, como a vermiculita, a ilita e a montmorilonita. A RAC possui uma interação química que envolve os álcalis do cimento e as dolomitas presentes no calcário, gerando a formação da brucita, em um processo conhecido como desdolomitização, que suscita o aparecimento de fissuras e o enfraquecimento da zona de transição (HASPARYK, 2005).

A RAS é o tipo de reação álcali-agregado mais comum no Brasil, e considerada como uma das principais responsáveis pela deterioração da maioria das estruturas. Ela pode ser dividida em duas fases. Na primeira fase, o agregado contendo sílica amorfa sofre um ataque de íons hidroxila gerando o rompimento das ligações de siloxano ( $\mathrm{Si}-\mathrm{O}-\mathrm{Si}$ ) (Figura 2.2a), o que produz silicato alcalino (de sódio ou potássio) e ácido silícico. 0 ácido reage imediatamente com íons hidroxila, levando à formação do gel sílico-alcalino (Figura 2.2b). Na segunda fase, o gel sílico-alcalino higroscópico absorve água e expande causando fissuração da pasta de cimento (Figura 2.2c) (GLASSER \& KATAOKA, 1981; HASPARYK, 2011).

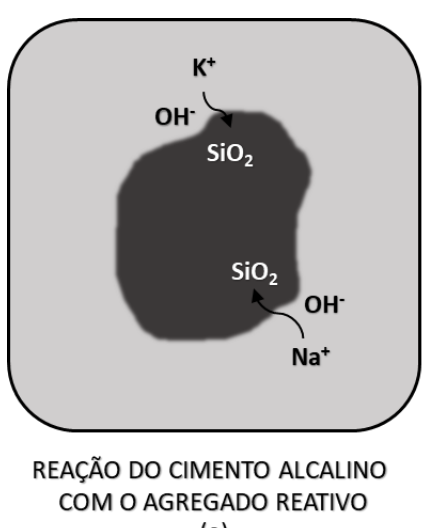

(a)

Figura 2.2 - Mecanismo da reação álcali-sílica.

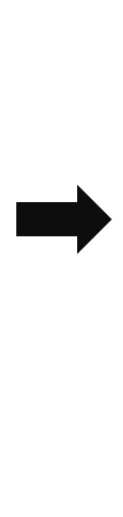

(b)

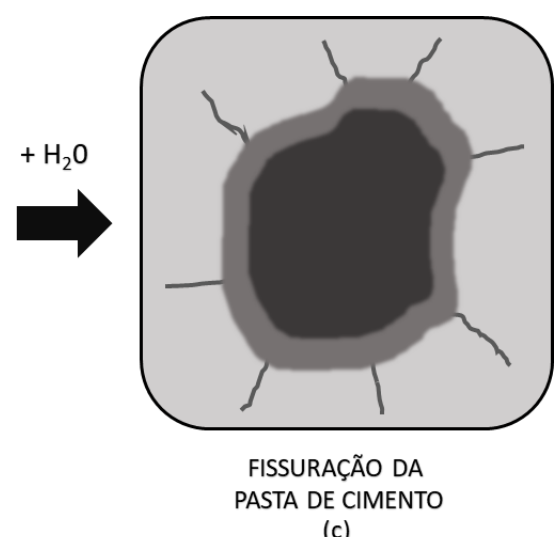

(c)

Fonte: Deschenes (2009).

Saouma et al. (2015) detalham a RAS em estágios com base em interpretações petrográficas da evolução da reação, como mostra a Figura 2.3. Para o estágio I, a reação começa ao redor do agregado sem causar expansão. No estágio II ocorre a formação do gel nos poros do agregado reativo dando início à expansão. 0 gel confinado nos poros do 
agregado exerce pressão, ocasionando a fissuração do agregado. No estágio III, o processo de deterioração se torna mais perceptível já que as fissuras do agregado reativo começam a se propagar para a pasta de cimento. Essas fissuras vão aumentando em tamanho e quantidade e o gel começa a migrar através delas para os vazios distantes do agregado reativo. Para o estágio IV, ocorre dano severo na estrutura, incluindo falhas como possível ruptura da armadura, distorção e perda de integridade estrutural.

Figura 2.3 - Interpretação petrográfica da evolução da RAS.

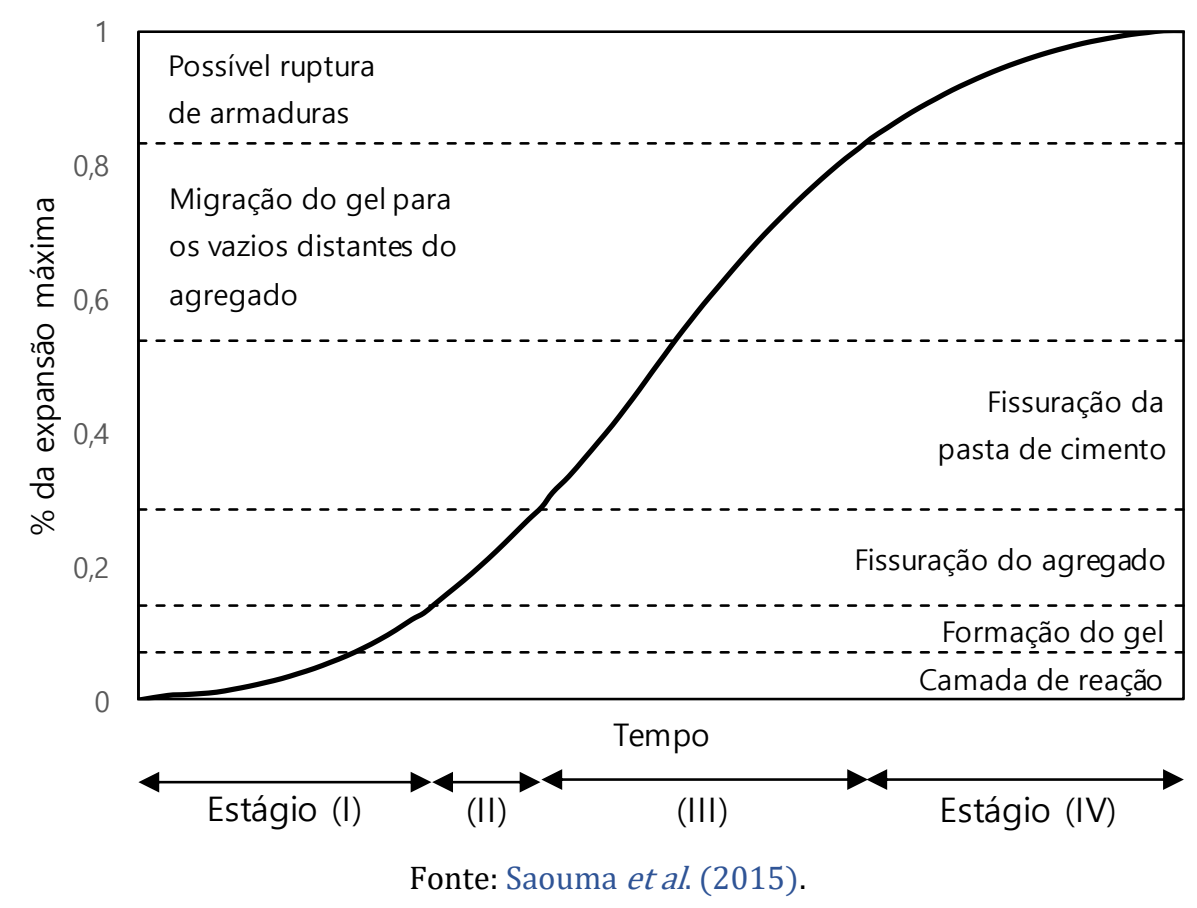

\subsection{FATORES QUE INTERFEREM NA RAA}

Para melhor compreender o fenômeno da RAA, é importante frisar quais são os fatores que interferem na reação. Além dos agregados reativos, dos álcalis presentes na pasta de cimento e da umidade, pode-se destacar também a temperatura, a porosidade e as tensões confinantes como fatores que influenciam a expansão por RAA.

\subsubsection{Agregado Reativo}

A taxa na qual as rochas contendo formas potencialmente reativas de sílica reagem é variável. Em consequência de resultados obtidos pelos ensaios laboratoriais, bem como pelo desempenho em campo, os agregados podem ser classificados quanto à reatividade alcalina como reativos "rápidos" a "normais" (5 a 20 anos), reativos "lentos" (mais de 15 a 20 anos) e 
"não-reativo" (LINDGÅRD et al., 2010). A reatividade do agregado está relacionada diretamente à velocidade em que as reações ocorrem, bem como com o tipo de reação que há de acontecer. 0 aumento da permeabilidade de agregados com maior porosidade pode aumentar a reatividade dos álcalis, devido ao acesso mais fácil aos fluidos de poros de concreto. Para a RAA, uma maior disponibilidade de água de cristalização propiciará um maior grau de reatividade (ST JOHN, POOLE \& SIMS, 1998; ZHANG et al., 1999; BROEKMANS, 2002).

A influência da classificação de agregados na RAA tem sido estudada desde Stanton (1940), que concluiu que os agregados (calcário de magnésio silicoso contendo opala e calcedônia) na faixa de 180-600 $\mu$ m produziram maior expansão que tamanhos diferentes destes, conforme mostra a Figura 2.4. Multon et al. (2010) afirmaram que o tamanho do agregado que causa a maior expansão por RAA depende da natureza e da composição do agregado. Para agregados reativos rápidos, verificou-se que a quantidade de sílica solúvel era semelhante para diferentes tamanhos de partículas de um determinado agregado, em que a expansão variou para frações de tamanhos diferentes, sendo maior para partículas mais grossas (MULTON et al., 2008).

Figura 2.4 - Efeito do tamanho e proporção do agregado na expansão por RAA.

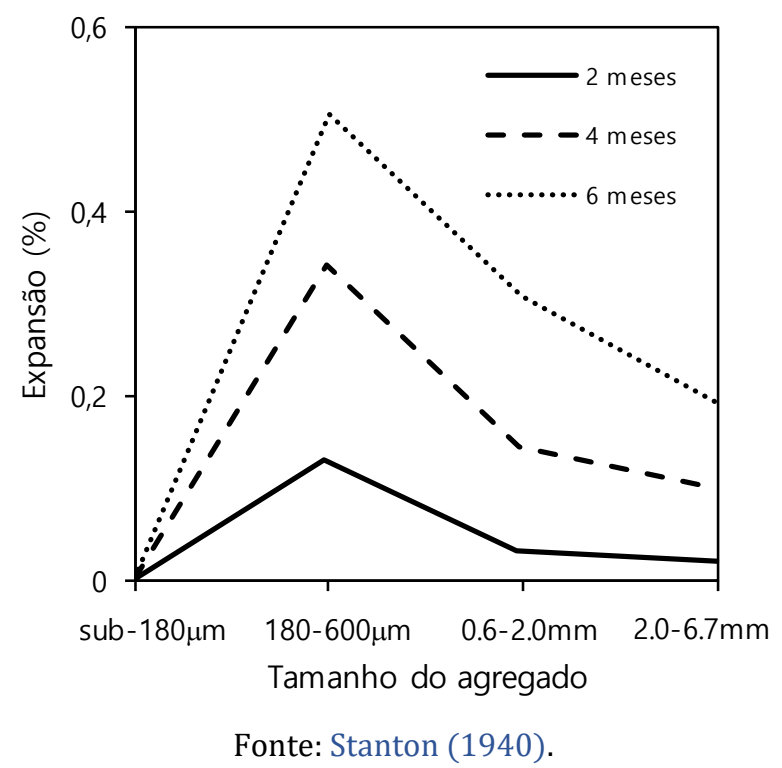

Em um achado aparentemente contraditório, Zhang et al. (1999) concluíram que, para agregados silicosos, quando o tamanho do agregado está dentro da faixa de 0,15 a $10 \mathrm{~mm}$, quanto menor o tamanho de partícula, maior a expansão por RAA. Eles também afirmaram que a classificação do agregado pode afetar a RAA quando há agregados maiores na amostra, em que a expansão é menor em idades iniciais, mas aumentará continuamente em idades 
posteriores. Deste modo, para testar de forma confiável o desempenho dos agregados quanto à RAA, incluindo efeitos de tamanho, é desejável que as frações usadas em estruturas sejam usadas nos testes de laboratório. Também, deve-se ter em mente que fracionar certos tipos de agregados para testes de laboratório, pode alterar algumas de suas características (LINDGÅRD et al., 2012).

Testes de laboratório realizados com diferentes tipos de agregados mostraram que nem sempre há uma relação linear entre a quantidade de constituintes potencialmente reativos e as expansões por RAS. Um nível máximo de expansão pode ocorrer em um determinado conteúdo do constituinte reativo conhecido como pessimum. Níveis decrescentes de expansão se desenvolverão para os conteúdos dos constituintes reativos acima ou abaixo do pessimum (GILLOTT, 1975; HOBBS, 1988; RILEM, 2003; LINDGÅRD et al., 2012). Há uma relação com a quantidade de álcalis disponíveis para a formação do gel expansivo, de modo que o pessimum pode diferir para diferentes constituintes potencialmente reativos. Para agregados reativos rápidos, como aqueles contendo opala, ocorre expansão máxima para baixos teores de sílica reativa, geralmente abaixo de 10\%, enquanto que, para agregados lentamente reativos a porcentagem será muito maior, até 100\%, ou seja, eles não mostram um efeito de pessimum (SHAYAN, 1992; BEKTAS et al., 2004).

Tiecher (2006) avaliou 40 amostras de agregados brasileiros, 30 delas eram rochas (granitos, riolitos, basaltos, calcário e gnaisse) e as outras 10 eram areias. Por meio de uma análise petrográfica a autora verificou que todos os agregados avaliados, sem exceção, apresentaram constituições mineralógicas potencialmente reativas. Os agregados estudados, de modo geral, possuíam em sua matriz minerais silicáticos deformados, potencializando a ocorrência da reação álcali-sílica. E, em parte das amostras, verificou-se a existência de minerais carbonáticos, o que favorece a ocorrência da reação álcali-carbonato.

\subsection{2 Álcalis}

O teor de álcalis proporciona o aumento da concentração de íons $\mathrm{OH}^{-}$na solução dos poros de concreto. Sabendo que são os íons hidroxila que causam o ataque à sílica presente nos agregados reativos, de modo a levar à formação do gel da RAS e consequente expansão do concreto, considera-se os álcalis como fatores condicionantes para a reação (HASPARYK, 2011). Tendo como análise o concreto, pode-se dizer que o cimento Portland é a principal fonte de álcalis no concreto, de modo que, quanto maior for o teor de álcalis no cimento ou o 
consumo de cimento no concreto, maiores serão as expansões. Oberholster (1983) propôs algumas diretrizes em termos do teor de cimento do concreto e o teor de álcali ativo do cimento para avaliar o potencial em que um concreto sofreria expansão devido à RAS. Os limites propostos nessas diretrizes podem ser observados na Figura 2.5. Posteriormente, com o intuito de evitar a ocorrência da reação álcali-agregado, foi estabelecido um limite no teor de álcalis de $0,6 \%$ do $\mathrm{Na}_{2} \mathrm{O}$ equivalente $\left(\mathrm{Na}_{2} \mathrm{O}+0,658 \mathrm{~K}_{2} \mathrm{O}\right)$ (COLLINS \& BAREHAM, 1987; ABNT NBR 15577-1:2008; MEHTA \& MONTEIRO, 2014).

Vale salientar que o teor de álcalis somente interferirá nas reações álcali-sílica e álcalisilicato, devido ao fato de os álcalis participarem da formação do gel expansivo como produto de reação com os agregados. Há ainda tipos de agregados que liberam álcalis na solução dos poros de concreto, permitindo a ocorrência da RAS mesmo em cimentos de baixa alcalinidade (BÉRUBÉ et al., 2002; CONSTANTINER \& DIAMOND, 2003).

Figura 2.5 - Potencialidade do concreto em desenvolver a RAS em função do teor de álcalis e quantidade de cimento no concreto.

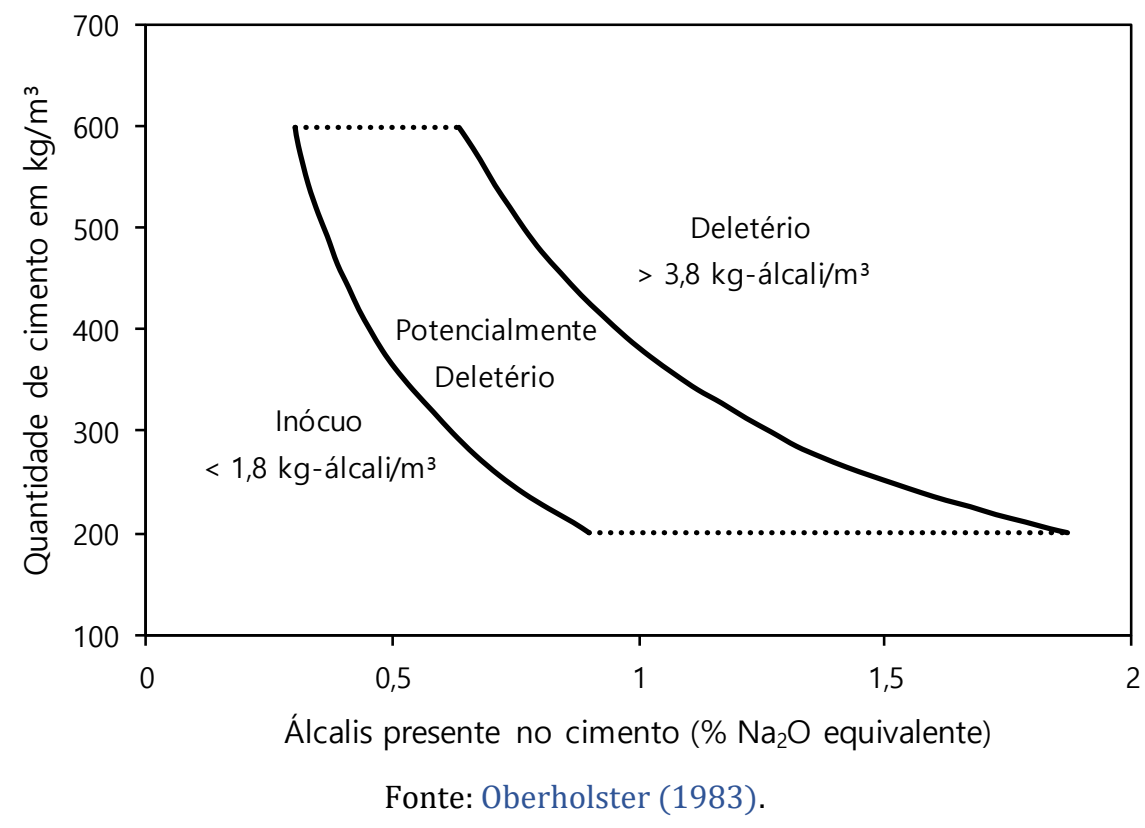

\subsection{3 Água}

A água presente no meio também pode ser considerada como um dos fatores condicionantes para o desenvolvimento da RAA, pois a expansão causada pela RAS é consequência da absorção de água pelo gel, assim, a extensão da expansão é dependente da quantidade de água disponível no concreto. A água age, então, no transporte dos álcalis no concreto, na dissolução da sílica e no mecanismo de expansão do gel sílico-alcalino (MEHTA \& MONTEIRO, 2014). 
Um estudo desenvolvido por Ólafsson (1986) trouxe a influência da umidade relativa na expansão por RAS, conforme indicado pela Figura 2.6, em que se observa que sob uma temperatura constante o aumento de umidade relativa resultou no aumento da expansão. De acordo com Bažant e Steffens (2000), para que ocorra a RAS, é necessária uma umidade relativa de 85\%. Já para Léger, Côté \& Tinawi (1996), para a ocorrência da reação, uma umidade de $75 \%$ já seria suficiente.

Figura 2.6 - Influência da umidade relativa na expansão por RAS.

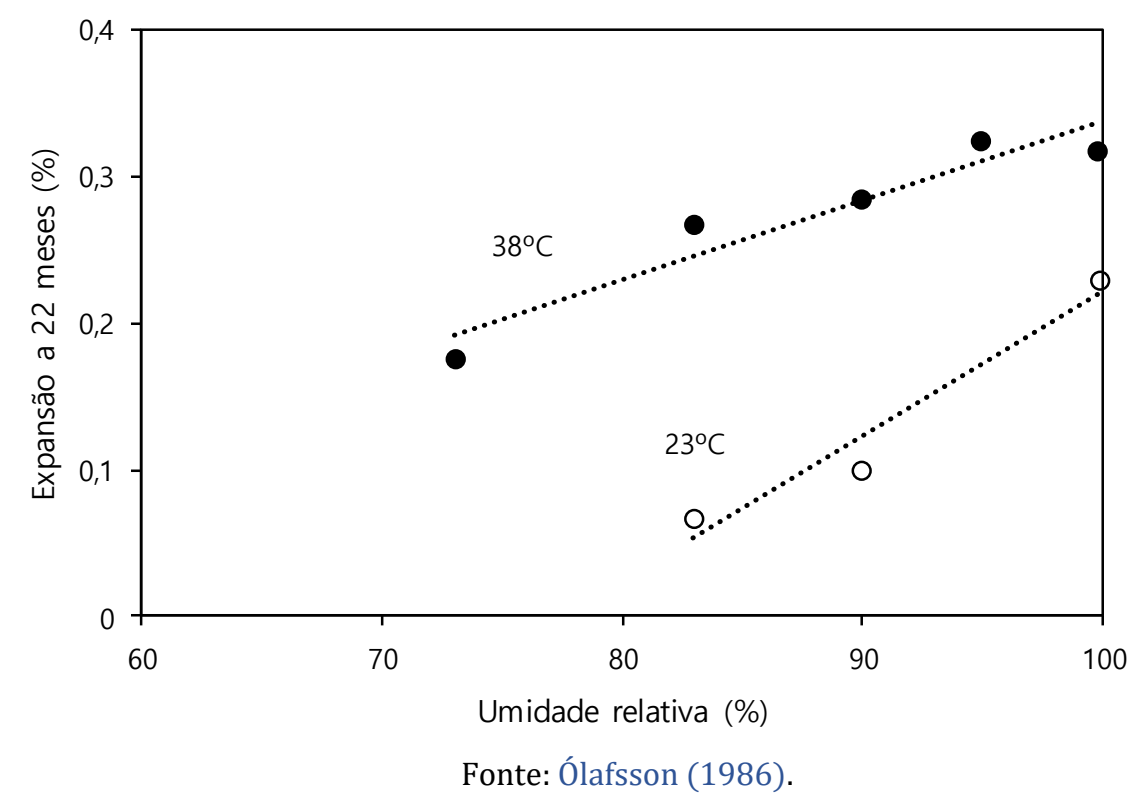

No processo de endurecimento e cura do concreto, a água é um fator imprescindível, em que são utilizadas relações de água/cimento variando de 0,35 a 0,60 para concretos convencionais. Desta maneira, a umidade resultante da água de amassamento presente nos poros de concreto endurecido é suficiente para reagir e, assim, contribuir para o desenvolvimento da RAA (PIGNATELLI, 2012; MEHTA \& MONTEIRO, 2014).

\subsubsection{Temperatura}

Ao aumentar a temperatura, há um aumento de solubilidade da sílica e uma diminuição de solubilidade do hidróxido de cálcio. Ao tornar a sílica mais propensa à reação, e ao reduzir a capacidade do hidróxido de cálcio de se combinar com o gel, de modo a diminuir suas capacidades expansivas, ocorre o aumento da velocidade de expansão por RAA (COLLINS \& BAREHAM, 1987; NEVILLE, 1997).

Entretanto, a expansão do concreto causada pela RAS apresenta picos em temperaturas de aproximadamente $40^{\circ} \mathrm{C}$, acima e abaixo da qual a expansão entra em 
declínio, conforme indicado pela Figura 2.7. Tal acontecimento pode estar relacionado a menor viscosidade do gel decorrente da RAS em temperaturas elevadas, o que resultaria na diminuição da expansão pelo aumento da facilidade da penetração do gel nos poros da matriz de cimento (GUDMUNDSSON \& ÁSGEIRSSON, 1975; DYER, 2015).

Figura 2.7 - Influência da temperatura na expansão por RAS.

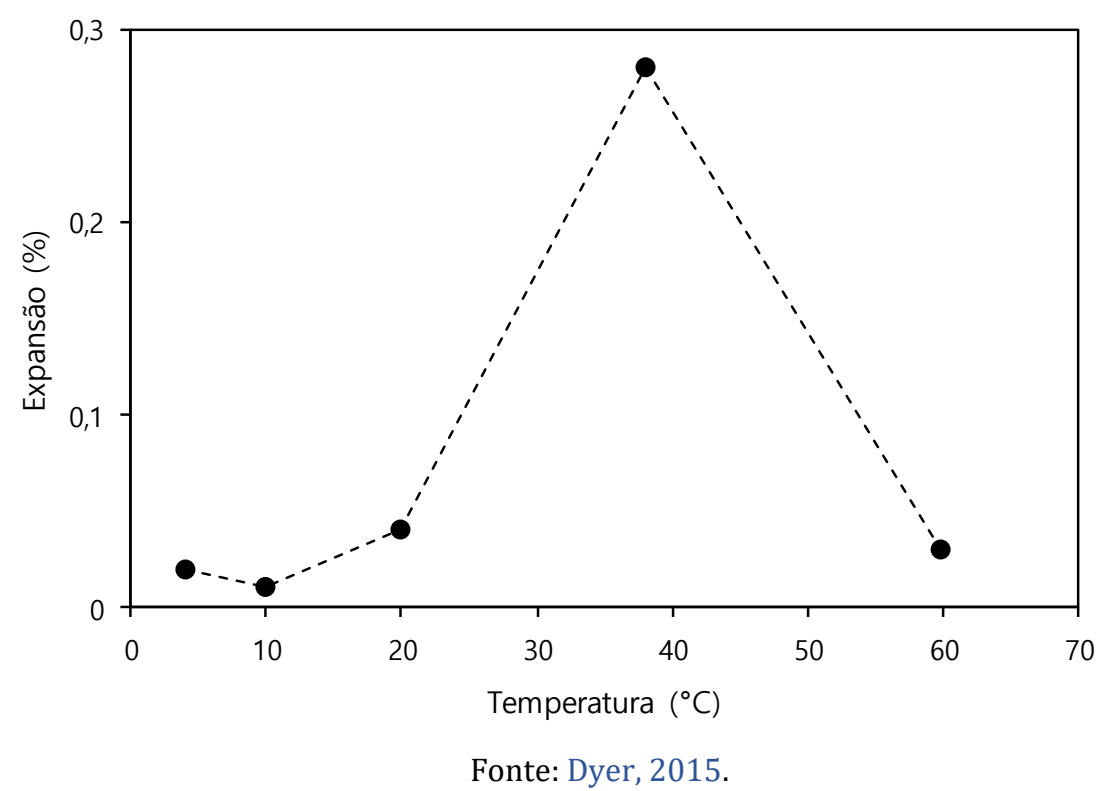

\subsubsection{Porosidade}

A porosidade pode influenciar na reação álcali-agregado de duas maneiras antagônicas. Por um lado, uma porosidade maior no concreto retém maior quantidade de água em seu interior, o que é indispensável para a ocorrência da RAA. Por outro lado, uma maior porosidade também significaria que o gel tem mais espaço para se expandir antes de dar início a pressão e fissuração no concreto (MADUREIRA, 2007).

A baixa porosidade em concretos resulta na limitação da mobilidade da água e do gel no seu interior, ocasionando a redução da expansão do gel e até mesmo impedindo a sua formação. Outra forma de redução da expansão máxima se dá pela incorporação de ar à mistura. Para uma inserção de ar de 4\%, há uma redução em torno de $40 \%$ na expansão final. (JENSEN et al., 1984).

\subsubsection{Tensões Confinantes}

As tensões confinantes são consideradas como um dos elementos mais importantes que influencia a expansão devido à reação álcali-agregado, pois elas têm a tendência de limitar 
a livre expansão do concreto, podendo até mesmo suprimi-la. Uma força de compressão causa a redução da expansão na direção da aplicação, do mesmo modo que uma força de tração auxilia na expansão na mesma direção (CARRAZEDO, 2004). As restrições na penetração das partículas de água na estrutura cristalina do gel podem ser consideradas como um possível mecanismo para a neutralização da expansão por RAA pelas tensões confinantes (SILVEIRA, 1997).

Quando uma força de compressão é aplicada em uma das direções, a direção ortogonal à força terá não somente a parcela de expansão que sofreria, mas também uma parcela referente à expansão da direção restringida, conforme exemplificado pela Figura 2.8, em que a carga é aplicada na direção 1 . A curva de expansão livre foi calculada pela soma das expansões nas direções 1 e 2 quando não haviam tensões aplicadas (CAPRA \& BOURNAZEL, 1998).

Figura 2.8 - Evolução da expansão, uniaxial, no tempo.

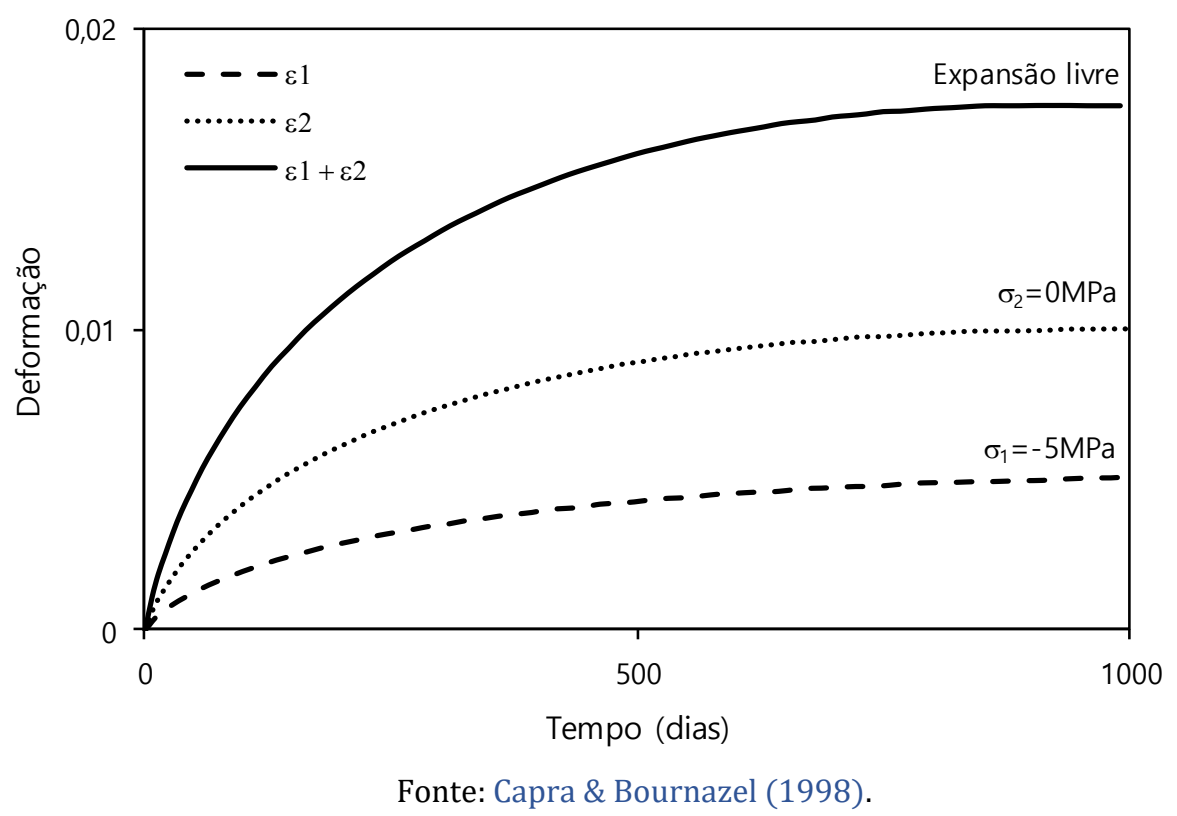

\subsection{MODELAGEM DA RAA}

Modelos numéricos que sejam aplicados à descrição da RAA vêm sendo desenvolvidos desde a década de 1980. Entretanto, o Brasil ainda é principiante no que diz respeito à produção de modelos para RAA (CARASEK, CASCUDO \& CAETANO, 2016).

A dificuldade em compreender os mecanismos da reação álcali-agregado e sua dependência de diversos fatores internos (composição química do concreto) e externos (condições ambientais), tornam a modelagem da RAA em estruturas de concreto 
consideravelmente complicadas (PIGNATELLI, 2012). Diante disso, para melhor discernimento do funcionamento dos modelos numéricos existentes, classificam-se os modelos quanto à vocação, natureza e escala (CHARLES-GIBERGUES e HORNAIN, 2008), conforme apresenta a Figura 2.9.

Figura 2.9 - Modelos numéricos para simulação da RAA.

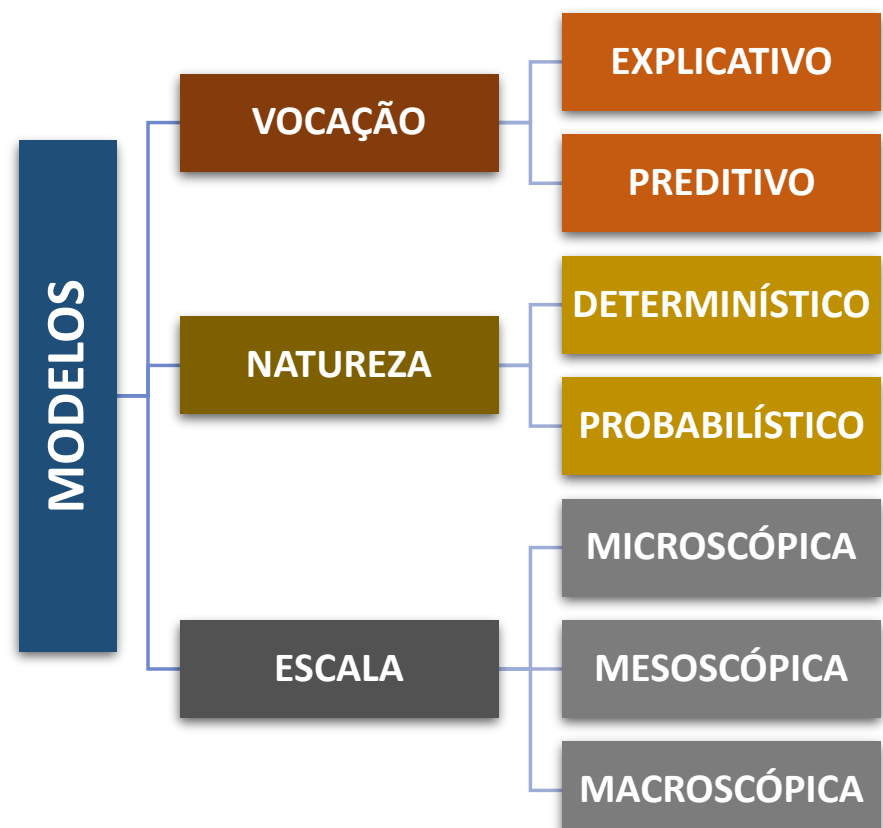

Fonte: Adaptado de Charles-Gibergues \& Hornain (2008).

Um modelo preditivo é usado para estimar um valor desconhecido de interesse: o alvo. A formulação deste modelo pode ser matemática, ou uma declaração lógica, como uma regra, podendo ainda ser um híbrido dos dois. Este valor poderia ser algo no futuro (no uso comum, verdadeira previsão), mas também poderia ser algo no presente ou no passado. De fato, uma vez que a mineração de dados geralmente trata de dados históricos, os modelos são construídos e testados com frequência usando eventos do passado. Isso contrasta com o modelo explicativo, em que o propósito primário do modelo não é estimar um valor, mas sim obter uma visão do fenômeno ou processo subjacente. Um modelo descritivo deve ser julgado em parte por sua inteligibilidade, e um modelo menos preciso pode ser preferido se for mais fácil de entender. Um modelo preditivo pode ser julgado apenas em seu desempenho preditivo. A diferença entre esses tipos de modelos não é tão rigorosa quanto isso pode implicar; algumas técnicas podem ser usadas para ambos, e geralmente um modelo pode servir a ambos os propósitos. Às vezes, grande parte do valor de um modelo preditivo está no entendimento adquirido por intermédio dele e não nas previsões que ele faz (PROVOST \& FAWCETT, 2013). 
Os modelos determinísticos são considerados o método mais usual de predição de desempenho em engenharia. As vantagens desses modelos residem em sua relativa facilidade de utilização e no fato de que sua produção é clara e facilmente compreendida pelos engenheiros. Os modelos de predição de desempenho determinísticos definem a deterioração ou alteração da condição de desempenho usando uma correlação funcional entre os atributos de condições estruturais e uma ou mais variáveis descritivas, em que ao menos uma possui um parâmetro dependente do tempo, por exemplo, a idade, o carregamento variável, as condições ambientais, entre outros. 0 desenvolvimento desses modelos se dá, basicamente, pela aplicação da análise das variáveis descritivas, de modo que, as informações obtidas em pesquisas e medições podem colaborar para a determinação de uma correlação entre as variáveis de saída e as variáveis descritivas. A forma mais simples da análise estatística é a linear com uma única variável descritiva dependente do tempo. A abordagem pode ser mais complexa por meio do uso de outras funções e com mais de uma variável, e, para essas funções, é necessário adaptá-las às pré-condições e configurações locais (STRAUSS et al., 2016).

Os modelos probabilísticos são considerados mais complexos do que os modelos determinísticos. Um vetor inicial define a distribuição de probabilidade da condição estrutural atual. A predição de desempenho é realizada modificando os componentes do vetor ao longo do tempo por meio do uso das probabilidades de transição. 0 processo de predição pode ser definido matematicamente, por exemplo, por um processo estocástico conhecido como cadeia de Markov. 0 processo começa em um dos estados e se move de um estado para outro. Se a cadeia estiver atualmente no estado $m_{i}$ e, então, ela se mover para o estado $m_{j}$ no próximo passo, a probabilidade de mudança de estados é denotada por $P\left(m_{i j}\right)$. Essa probabilidade depende apenas do estado atual (propriedade de Markov); nenhuma informação adicional é dada pelos estados precedentes. As mudanças de estados são chamadas transições, e as probabilidades $P\left(m_{i j}\right)$ são chamadas probabilidades de transição. 0 sistema pode permanecer no mesmo estado, o que é indicado por $m_{i i}$. As probabilidades ao longo do tempo são as mesmas para qualquer $t$ (STRAUSS et al., 2016).

No que condiz a classificação por escala, o concreto é um material heterogêneo extremamente complexo de estrutura microscópica aleatória, com diferentes escalas de comprimento. Na escala macroscópica, o concreto é tratado como material homogêneo. Já na escala mesoscópica há a inclusão da matriz de ligação, dos agregados e dos poros com distribuições de amplo tamanho, bem como das zonas de transição entre os agregados e matriz da pasta de cimento. E, por fim, a escala microscópica é a escala estrutural mais fina, 
representada pela microestrutura da pasta de cimento endurecido, composta pelos produtos de hidratação, clínquer residual não-hidratado e microporos (NGUYEN, STROEVEN \& SLUYS, 2012; WU, TEMIZER \& WRIGGERS, 2014), conforme ilustrado na Figura 2.10.

Figura 2.10 - Representação das escalas macroscópica, mesoscópica e microscópica.

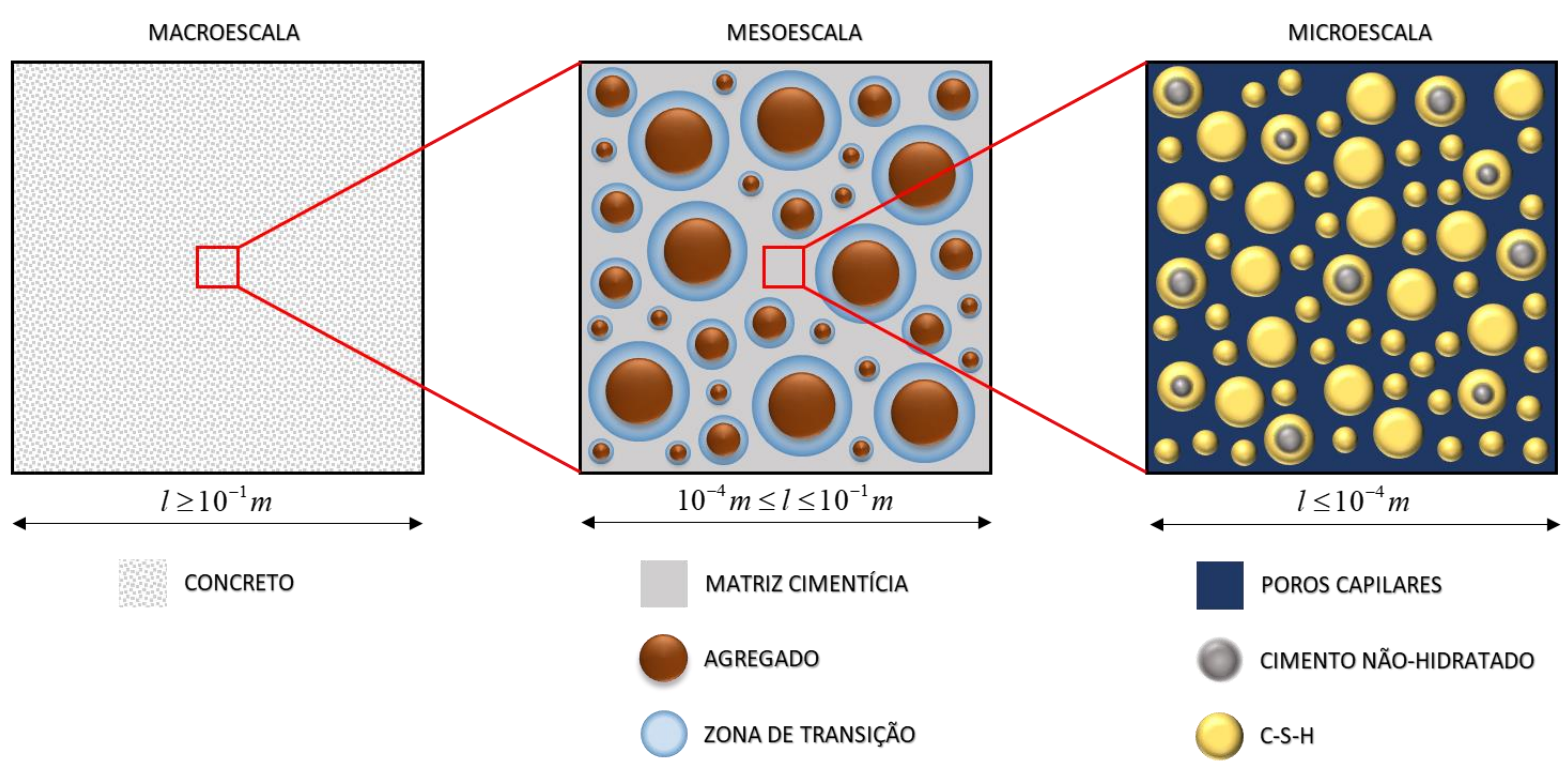

Fonte: Adaptado de Dunant \& Scrivener (2010) e Nguyen, Stroeven \& Sluys (2012).

Neste trabalho foi empregado o modelo explicativo determinístico em macroescala proposto por Carrazedo \& Lacerda (2008), que se baseou nos modelos paramétricos de Léger, Côté \& Tinawi (1996) e Pappalardo Jr, Pauletti \& Pimenta (2000), e na equação constitutiva apresentada por Pietruszczak (1996). Deste modo, são apresentados a seguir os modelos antecessores ao usado neste trabalho, para posterior explicação do modelo de Carrazedo \& Lacerda (2008).

\subsubsection{Pietruszczak (1996)}

Pietruszczak (1996) propôs um modelo macroscópico, determinístico, preditivo, simples, para a descrição das manifestações mecânicas da RAA. A abordagem invoca a suposição de que a formação de fases expansivas resulta em uma degradação progressiva das propriedades mecânicas do material. 0 material é considerado elastoplástico e, na fase elástica, a relação constitutiva se dá pelas equações (2.1) e (2.2). Na equação (2.1), $\mathbb{C}^{e}$ é a matriz elástica do material, $\delta$ é o delta de Kronecker, $\sigma$ é o tensor de tensões e $\varepsilon_{\mathrm{A}}$ é a expansão volumétrica causada pela formação do gel de álcali-sílica.

$$
\boldsymbol{\varepsilon}^{e}=\left[\mathbb{C}^{e}\right] \boldsymbol{\sigma}+\frac{1}{3} \varepsilon_{A} \boldsymbol{\delta}
$$




$$
\varepsilon_{\mathrm{A}}=g\left(\boldsymbol{\delta}^{T} \boldsymbol{\sigma}, t\right)
$$

A taxa de expansão depende em grande parte da composição química do material, em particular do teor de álcalis e do tipo de agregado. Em geral, a concentração de álcalis pode aumentar com o tempo devido, por exemplo, à migração de água para o interior do concreto. Para uma dada composição química e uma fração constante de álcalis, pode-se presumir que a função $g$ depende do tempo $t$ e da pressão hidrostática $\boldsymbol{\delta}^{T} \boldsymbol{\sigma}$. Multiplicando a equação (2.1) pela rigidez elástica $\mathbb{R}^{e}$, obtém-se:

$$
\sigma=\left[\mathbb{R}^{e}\right]\left(\varepsilon^{e}-\frac{1}{3} \varepsilon_{A} \delta\right)
$$

A formulação proposta foi obtida assumindo uma relação linear incremental demonstrada na equação (2.4):

$$
\dot{\varepsilon}_{A}=g_{1}\left(\boldsymbol{\delta}^{T} \boldsymbol{\sigma}\right) g_{2}(t)
$$

A expansão de volume causada pela RAA é governada pela forma funcional, dada pelas equações (2.5) e (2.6), em que $A_{1}$ e $A_{2}$ são constantes do material, $\varepsilon$ é a expansão livre devido à RAA e $f_{c 0}$ é a resistência à compressão uniaxial do concreto.

$$
\begin{array}{ll}
g_{1}\left(\boldsymbol{\delta}^{T} \boldsymbol{\sigma}\right)=\exp \left(-A_{1} \boldsymbol{\delta}^{T} \boldsymbol{\sigma} / f_{c 0}\right) ; & 0 \leq \mathrm{g}_{1}<1 \\
g_{2}(t)=\varepsilon t /\left(A_{2}+t\right) ; & \mathrm{g}_{2} \rightarrow \varepsilon \text { para } t \rightarrow \infty
\end{array}
$$

Considerando o trecho elástico, supôs-se que o único parâmetro degradante foi o módulo de elasticidade. Na equação (2.7), $A_{3}$ representa uma constante do material e $E_{0}$ representa o módulo de elasticidade inicial do concreto, antes do início da degradação pela RAA, e $E$ é o módulo de elasticidade reduzido em um instante de tempo $t$.

$$
E=E_{0}\left[1-\left(1-A_{3}\right) \frac{g_{2}}{\varepsilon}\right], \quad \text { se } g_{2} \rightarrow \varepsilon, \text { então } E \rightarrow A_{3} E_{0}
$$

As propriedades do material na faixa elastoplástica são descritas pela relação constitutiva proposta por Pietruszczak, Jiang, \& Mirza (1988), em que a superfície de falha $F=0$ é definida por:

$$
\begin{aligned}
& F=\bar{\sigma}-k(\theta) \bar{\sigma}_{c}=0 \\
& \bar{\sigma}_{c}=\frac{-a_{1}+\sqrt{\left(a_{1}^{2}+4 a_{2}\left(a_{3}+I / f_{c}\right)\right)}}{2 a_{2}} f_{c}
\end{aligned}
$$

Na equação (2.8) $a_{1}, a_{2}$ e $a_{3}$ são constantes adimensionais do material, $f_{c}$ é a resistência à compressão uniaxial do concreto e $I, \bar{\sigma}, \theta$ e $J_{3}$ são os invariantes do tensor de tensões, dados por: 


$$
\begin{aligned}
& I=-\sigma_{i i} \\
& \bar{\sigma}=\left(1 / 2 s_{i j} s_{i j}\right)^{1 / 2} \\
& \theta=1 / 3 \sin ^{-1}\left(3 \sqrt{3} J_{3} / 2 \bar{\sigma}^{3}\right) \\
& J_{3}=1 / 3 s_{i j} s_{j k} s_{k i}
\end{aligned}
$$

A superfície de falha é dada pelas equações (2.10):

$$
\begin{aligned}
& f=\bar{\sigma}-\beta(\xi) k(\theta) \bar{\sigma}_{c}=0 \\
& \beta=\xi /(A+B \xi) \\
& \xi=\left(\dot{e}_{i j}^{p} \dot{e}_{i j}^{p}\right)^{1 / 2} / \bar{\Phi}
\end{aligned}
$$

em que $\xi$ é uma função dependente de $e_{i j}$, sendo este último o tensor desviador de deformação, $\bar{\Phi}=\Phi(I, \theta)$ e $A$ e $B$ são constantes do material.

Considerando que o progresso da RAA resulte na degradação da resistência à compressão uniaxial $f_{c}$, tem-se que:

$$
f_{c}=f_{c 0}\left[1-\left(1-A_{4}\right)^{g_{2} / \varepsilon}\right], \quad \text { se } g_{2} \rightarrow \varepsilon, \text { então } f_{c} \rightarrow A_{4} f_{c 0}
$$

em que $A_{4}$ é uma constante de material e $f_{c 0}$ designa a resistência à compressão inicial. Notase que a degradação $f_{c}$ é acompanhada por uma redução proporcional da resistência à tração uniaxial, que é assegurada pela forma funcional das equações (2.8). Assim, considerando as equações (2.8) e (2.10), e ainda que $f_{c}=f_{c}(t)$, tem-se que:

$$
\frac{\partial f}{\partial t}=\frac{\partial f}{\partial \bar{\sigma}_{c}} \frac{\partial \bar{\sigma}_{c}}{\partial f_{c}} \frac{\partial f_{c}}{\partial g_{2}} \frac{d g_{2}}{d t}=-\beta(\xi) k(\theta) \frac{f_{c 0} A_{2}\left(1-A_{4}\right)}{\left(A_{2}+t\right)^{2}}\left(\frac{\bar{\sigma}_{c}}{f_{c}}-\frac{I}{2 a_{2} \bar{\sigma}_{c}+a_{1} f_{c}}\right)
$$

\subsubsection{Léger, Côté \& Tinawi (1996)}

Léger, Côté \& Tinawi (1996) apresentaram um modelo macroscópico, determinístico, preditivo para análise estrutural, por meio de elementos finitos, de barragens de concreto sujeitas à RAA, em que foram avaliados os principais mecanismos e fatores que interferem no processo evolutivo da RAA, bem como os efeitos da RAA sobre as propriedades mecânicas do concreto.

Com o intuito de racionalizar a modelagem numérica do processo de expansão do concreto devido à RAA, os autores propuseram uma metodologia para distribuir a expansão do concreto de modo que fosse proporcional ao estado de tensão, à umidade, à temperatura e à reatividade dos constituintes do concreto. 0 método tem como início o cálculo dos fatores de expansão normalizados $F_{C}, F_{T}, F_{M}$ e $F_{R}$ para diferentes zonas da barragem, em que se 
considera o confinamento ( $C$ ), a temperatura $(T)$, a umidade $(M)$ e a reatividade $(R)$ em um determinado intervalo de tempo. Combinam-se, então, esses fatores de expansão normalizados, com o auxílio de uma "regra de CTMR" para determinar a distribuição espacial consequente da expansão do concreto causada pela RAA em diferentes zonas da estrutura, a um determinado momento. Esta regra simula a taxa de crescimento não-uniforme anisotrópica e, consequentemente, a distribuição espacial da RAA em uma estrutura. Considerando uma zona particular $m$, de $n$ elementos finitos em que se espera características de expansão semelhantes, a deformação induzida pela RAA pode ser dada, então, por:

$$
\varepsilon_{\text {aar }}^{(m)}(t)=\beta^{(m)}(t) \cdot\left[F_{C}(\sigma, t) \cdot F_{T}(t) \cdot F_{M}(t) \cdot F_{R}(t)\right]^{(m)}=\beta^{(m)}(t) \cdot C T M R^{(m)}
$$

em que $C T M R^{(m)}$ é a tensão induzida pela RAA normalizada, $\beta^{(m)}$ é um fator de calibração para ajustar os deslocamentos calculados com base nos observados.

O fator de expansão considerando a umidade $F_{M}$, indicado na equação (2.13), pode ser analisado com base na Figura 2.11a, em que para o início de uma expansão significativa, é necessário aproximadamente $75 \%$ de umidade relativa (RH) no interior do concreto, de modo que, assume-se variar linearmente entre uma umidade relativa mínima de aproximadamente $75 \%\left(\mathrm{RH}_{\min }\right)$ e uma máxima de $100 \%\left(\mathrm{RH}_{\max }\right)$. Na falta de uma avaliação rigorosa do transporte de água e umidade, os autores adotam em sua avaliação uma distribuição homogênea impondo $F_{M}=1$.

Devido à variabilidade dos agregados usados no concreto de uma determinada estrutura, a circulação da água e migração de álcalis adotam caminhos preferenciais dentro da estrutura. A Figura 2.11b indica o fator de expansão, que representa a distribuição espacial relativa à expansão causada pela reatividade dos constituintes, variando entre 0 e 1 em diferentes regiões da estrutura. Entretanto, na prática é difícil quantificar a magnitude in loco e a distribuição espacial do material reativo. Assim, os autores sugerem considerar que o teor alcalino, a quantidade de material reativo, o tipo e o tamanho dos agregados sejam homogêneos dentro da estrutura, de modo que seja adotado $F_{R}=1$ em toda a estrutura.

A temperatura é um parâmetro importante na simulação da expansão por RAA, pois a taxa de reação pode aumentar sob temperaturas elevadas ou diminuir quando abaixo de um valor limite. Ao simular a expansão por RAA, os dados relativos à temperatura devem ser estimados caso a caso, para verificar a temperatura limite $\left(T_{L}\right)$ abaixo da qual a expansão será mínima (Figura 2.11c) e, a partir dela, haverá crescimento linear do fator relacionado à temperatura. Além disso, a temperatura tem uma influência indireta na expansão por RAA 
através das tensões compressivas decorrentes da resposta termomecânica da estrutura que podem restringir a expansão do concreto, e das fissurações e tensões térmicas de tração que alteram as propriedades mecânicas do material.

A influência das tensões confinantes é indicada na Figura 2.11d, em que $F_{C}$ é o fator de expansão de confinamento normalizado dado pela equação (2.14). Percebe-se que, até um determinado valor $\sigma_{L}$, a tensão será pequena a ponto de se considerar expansão livre, e partir de um valor limite $\sigma_{\text {maxx }}, F_{C}$ será igual a zero, de modo que, não haverá a ocorrência da RAA.

$$
F_{C}(\sigma, t)=\left[1-k_{1} \log \left(\sigma_{i}^{(m)} / \sigma_{L}\right)\right]
$$

Figura 2.11 - Fatores que influenciam a expansão do concreto por RAA.

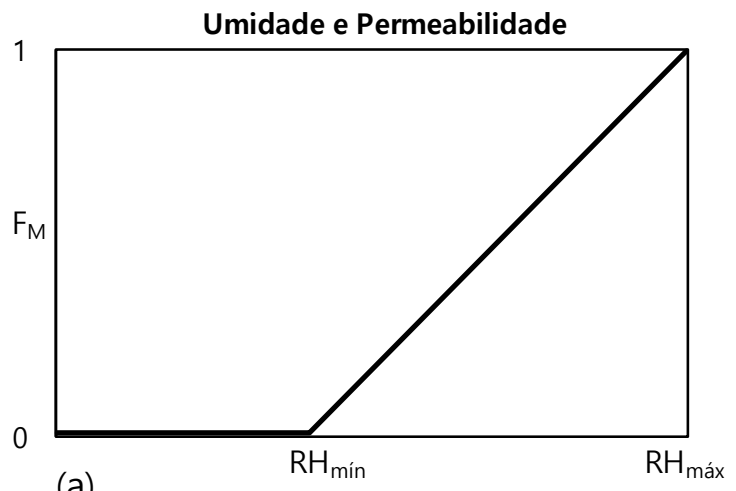

(a)

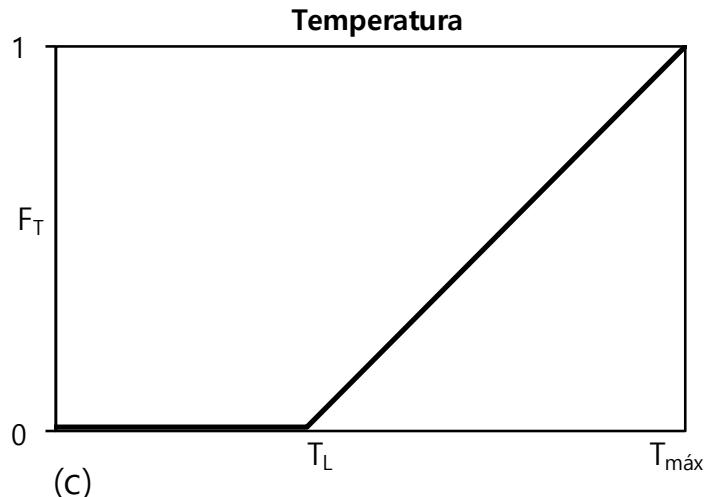

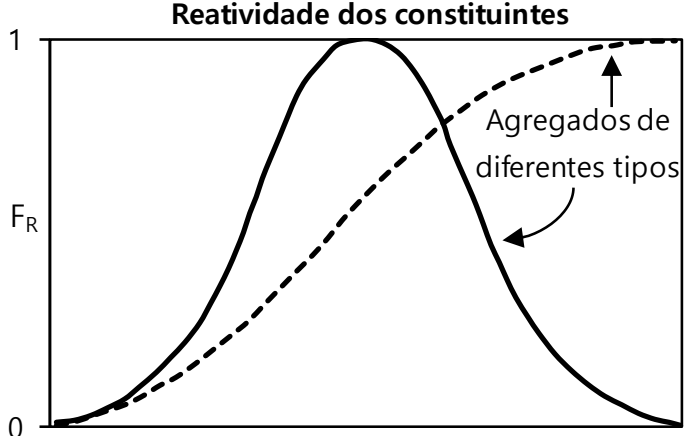

(b)

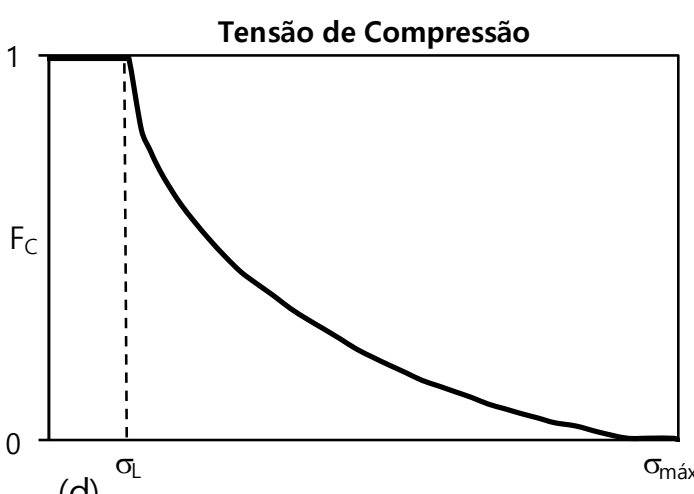

(d)

Fonte: Léger, Côté \& Tinawi (1996).

A expansão e os danos causados pela RAA são intensamente influenciados por tensões compressivas aplicadas ou compressão induzida pela restrição às forças expansivas. Os autores consideraram o modelo de Charlwood (1994), em que a expansão do concreto $\varepsilon_{g}$ está relacionada à tensão de compressão $\sigma_{i}$ dada pela equação (2.15). As expressões são aplicáveis nas três direções, assumindo uma suposição simplificadora de que as direções principais são independentes umas das outras, em que $\varepsilon_{u}$ é a livre expansão, $\varepsilon_{g}$ é a taxa de expansão restringida do concreto, $\sigma_{L}$ é a tensão abaixo da qual $\varepsilon_{g}$ é igual à taxa de expansão 
livre, $\sigma_{\max }$ é a tensão acima da qual $\varepsilon_{g}$ do concreto é zero e $K$ é a inclinação da linha que define a taxa de expansão do concreto em função do logaritmo das tensões.

$$
\begin{array}{ll}
\varepsilon_{g}=\varepsilon_{u}, & \text { para } 0 \leq \sigma_{i} \leq \sigma_{L} \\
\varepsilon_{g}=\varepsilon_{u}-K \log _{10}\left(\sigma_{i} / \sigma_{L}\right), & \text { para } \sigma_{L} \leq \sigma_{i} \leq \sigma_{\max }
\end{array}
$$

Uma vez compreendido os termos envolvidos na equação (2.13), pode-se partir para o cálculo do tensor de tensões, a começar pela equação de equilíbrio formulada da seguinte maneira:

$$
[K(t)]\{U(t)\}=\{R(t)\}
$$

em que $[K(t)]$ é a matriz de rigidez da estrutura, $\{U(t)\}$ e $\{R(t)\}$ são, respectivamente, os vetores de deslocamento e carregamento. A contribuição da expansão por RAA ao vetor de carregamento é dada pela seguinte equação:

$$
\{R(t)\}=\sum\{\beta(t)\}^{(m)} \cdot\{R(t)\}^{(m)}
$$

em que a soma é calculada considerando todas as zonas $m$ nas quais as estruturas foram subdivididas. A contribuição para cada uma dessas zonas é escrita como:

$$
\{R(t)\}^{(m)}=\beta^{(m)}(t) \cdot \sum \int\left[B_{i}\right]^{T}\left[E_{i}(t)\right]\left\{C T M R^{(M)}(t)\right\} d V
$$

em que $\left[B_{i}\right]$ representa a matriz de transformação deformação-deslocamento para o elemento $i, V$ é o volume do elemento. A soma é contabilizada sobre todos os elementos finitos na zona $m .\left[E_{i}(t)\right]$ é a matriz das propriedades efetivas do material, calculada em função de vários parâmetros, por exemplo, o coeficiente de Poisson, a resistência à tração, o módulo de elasticidade, a fluência, a expansão por RAA e a deformação.

A matriz de rigidez das estruturas é obtida, então, pela seguinte equação:

$$
[K(t)]=\sum \int\left[B_{i}\right]^{T}\left[E_{i}(t)\right]\left[B_{i}\right] d V
$$

em que a soma é feita sobre todos os elementos da estrutura. Após a solução para os deslocamentos $\{U(t)\}$, o tensor de tensões pode ser finalmente calculado pela equação:

$$
\left\{\sigma(t)_{i}\right\}=\left[E(t)_{i}\right] \cdot\left(\left[B_{i}\right]\{U(t)\}-\left\{\varepsilon_{\text {aar }}(t)\right\}\right)
$$

\subsubsection{Pappalardo Jr, Pauletti \& Pimenta (2000)}

Pappalardo Jr, Pauletti \& Pimenta (2000) apresentaram uma abordagem macroscópica, determinística, preditiva, baseada no uso de equações constitutivas para representar os fenômenos da fluência e expansão por RAA. Para isso, foi considerado um 
grupo reduzido de fatores de influência da RAA, sendo eles a temperatura, a reatividade dos constituintes, a umidade, a porosidade e o confinamento estrutural.

A metodologia proposta assume um campo escalar de taxa de deformação por RAA, representada pela seguinte equação constitutiva:

$$
\dot{\varepsilon}^{r a a}=\frac{\varepsilon_{v o l}^{\max } \cdot\left(A_{2} g_{T}\right)}{\left[\left(A_{2} g_{T}\right)+\left(t-t_{P} g_{P}\right)\right]^{2}} \cdot \sqrt{g_{U} g_{C}}
$$

em que $\varepsilon_{v o l}^{\operatorname{máx}}$ está ligado à quantidade total de reagentes presentes no concreto, $A_{2}$ representa o tempo de estabilização do processo de expansão, $g_{T}, g_{U}, g_{P}$ e $g_{C}$ são, respectivamente, os fatores de influência relacionados à temperatura, à umidade, à porosidade e ao confinamento. $t_{P} g_{P}$ é o tempo necessário para o completo preenchimento dos poros do concreto, dando, então, início ao processo expansivo. E, por fim, $\left(t-t_{P} g_{P}\right)$ representa o tempo de análise decorrido contado a partir do início do processo de expansão.

Figura 2.12 - Fatores de influência e coeficientes de calibração.
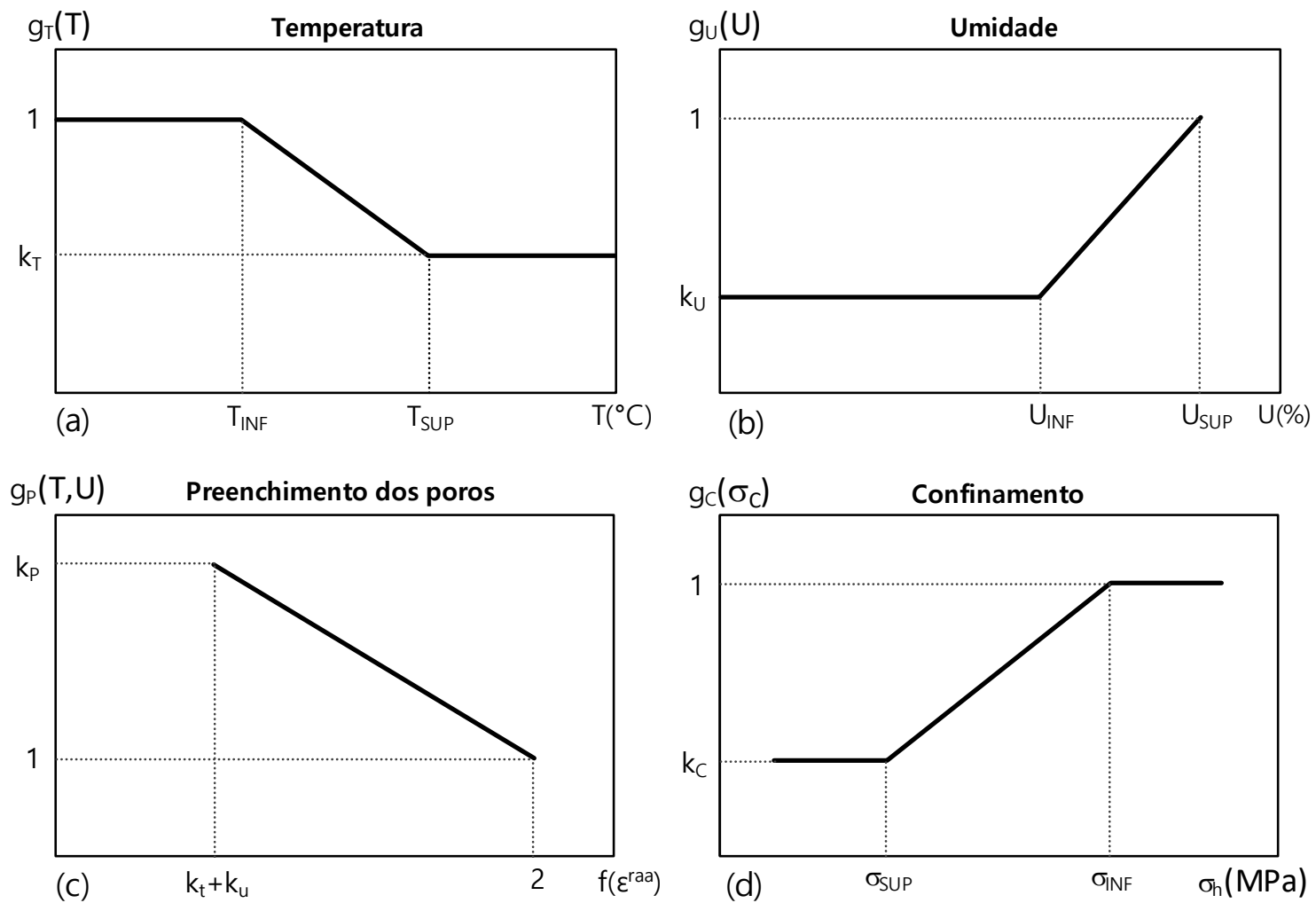

Fonte: Pappalardo, Pauletti \& Pimenta (2000).

Para a conversão dos campos de temperatura, umidade, porosidade e confinamento estrutural com seus respectivos fatores de influência, os autores adotaram leis de correlação lineares, que foram baseadas no trabalho de Léger, Côté \& Tinawi (1996), representadas na 
Figura 2.12. Os fatores de influência são ponderados pelos coeficientes de calibração de temperatura, umidade, porosidade e confinamento representados, respectivamente, por $k_{T}$, $k_{U}, k_{P}$ e $k_{C}$.

Os autores utilizaram o modelo sólido-padrão, representado pela associação em série de uma mola a um elemento de Kelvin (Figura 2.13a), para representar o comportamento viscoelástico do concreto. De acordo com este modelo, a deformação é proporcional à tensão $\sigma_{0}$, variando da deformação instantânea $\sigma_{0} / E_{0}$ em $t=0$, até a deformação assintótica $\sigma_{0} / E_{\infty}$ em $t=\infty$ (Figura 2.13b).

Figura 2.13 - (a) Modelo sólido-padrão (b) Relação deformação vs tempo.

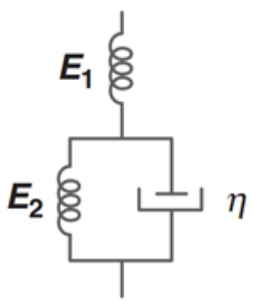

(a)

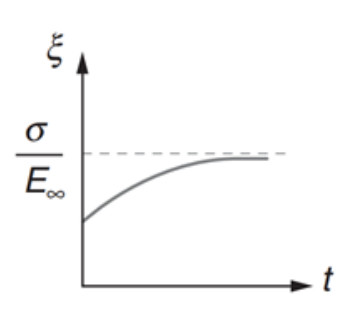

(b)

Fonte: Mehta \& Monteiro (2014).

Para o concreto inerte, o módulo de elasticidade assintótico é usualmente representado pela equação (2.22), em que $\phi$ é o coeficiente de fluência variando normalmente entre 1,0 e 1,5. Entretanto, considerando que a RAA intensifica a fluência no concreto, os autores assumiram $\phi=2,5$ para as regiões da estrutura onde a RAA é intensa; onde a RAA é inócua, foi considerado $\phi=1,0$.

$$
E_{\infty}=\frac{E_{0}}{(1+\phi)}
$$

\subsubsection{Carrazedo \& Lacerda (2008)}

Carrazedo \& Lacerda (2008) apresentaram um modelo em que a taxa de deformação volumétrica causada pela RAA é obtida através da combinação dos fatores que influenciam a reação por meio de uma lei constitutiva. Dentre os fatores considerados estão a reatividade dos materiais, a umidade, a porosidade, a temperatura e o estado de tensão.

Devido à singularidade causada pelo denominador da equação (2.21), os autores propuseram a inclusão de uma função Heaviside sobre $t$ e $t_{p}$. Enquanto o tempo $t$ for menor do que o tempo $t_{p} F_{p}$, a função Heaviside valerá zero, de modo a não evidenciar a expansão 
para o primeiro estágio da reação, em que ocorre a formação do gel dentro dos poros do concreto. Assim, a representação da expansão por RAA passa a ter a seguinte forma:

$$
\dot{\varepsilon}_{R A A}=H\left(t-t_{p} F_{p}\right) \frac{\varepsilon_{v o l}^{\max } A_{2} F_{t}}{\left(A_{2} F_{T}+t-t_{p} F_{p}\right)^{2}} \sqrt{F_{c} F_{m}}
$$

Partindo da curva de expansão observada na Figura 2.14, os autores verificaram que uma equação exponencial na forma da equação (2.24) era capaz de representar as principais características da expansão.

$$
f(t)=H\left(t-t^{p}\right)\left[a_{0}-a_{1} \exp \left(-a_{2}\left(t-t_{p}\right)\right)\right]
$$

Figura 2.14 - Curva de expansão de uma amostra de concreto sujeita à expansão livre.

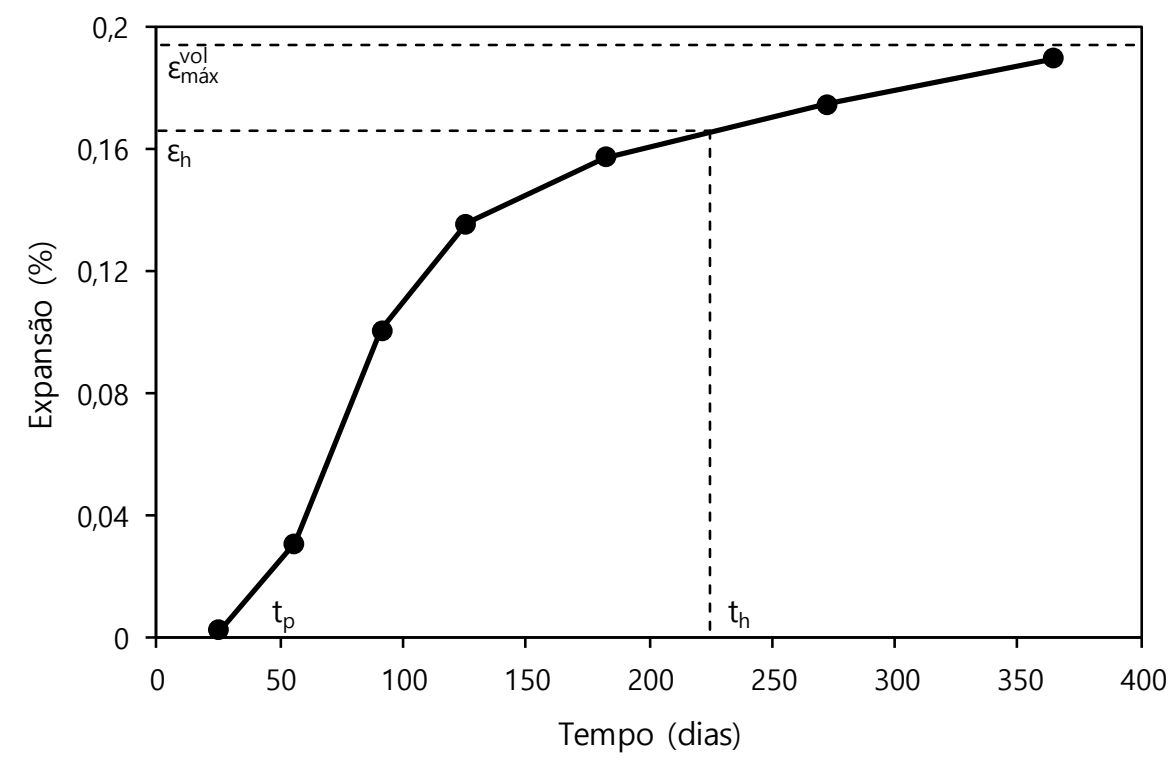

Fonte: Boddy, Hooton \& Thomas (2000).

Considerando $f(t)$ como a expansão volumétrica devido à RAA $\left(\varepsilon_{R A A}\right), t_{h}$ como um tempo qualquer e $\varepsilon_{h}$ a sua expansão correspondente, é possível verificar as seguintes constatações:

$$
\begin{aligned}
& \varepsilon_{R A A}=0, \text { enquanto } t \leq t_{p} \\
& \varepsilon_{R A A}=\varepsilon_{h}, \text { quando } t=t_{h} \\
& \varepsilon_{R A A}=\varepsilon_{v o l}^{\max }, \text { quando } t \rightarrow \infty
\end{aligned}
$$

Com isso é possível determinar pela equação (2.26) os coeficientes $a_{0}$, $a_{1}$ e $a_{2}$. Substituindo na equação (2.24) os coeficientes calculados, é possível verificar que o coeficiente $a_{2}$ tem ação inversa ao coeficiente $A_{2}$ apresentado nas equações (2.21) e (2.23). Este coeficiente está relacionado ao índice de reatividade dos constituintes do concreto, que modifica a velocidade com que a expansão atinge o seu máximo. 


$$
\begin{aligned}
& a_{0}=a_{1}=\varepsilon_{v o l}^{\max } \\
& a_{2}=\frac{\ln \left(\frac{\varepsilon_{v o l}^{\max }-\varepsilon^{h}}{\varepsilon_{v o l}^{\max }}\right)}{t_{h}-t_{p}}
\end{aligned}
$$

Devido à anisotropia da expansão em função das tensões aplicadas ou induzidas, é necessário incluir os fatores de influência normalizados da temperatura, da umidade, da porosidade e do estado de tensões para representar a equação constitutiva de expansão por RAA. Deste modo, a equação assume a seguinte forma:

$$
\varepsilon_{R A A}=H\left(t-t_{p} F_{p}\right) \varepsilon_{v o l}^{\max }\left[1-\exp \left\{\frac{-\left(t-t_{p} F_{p}\right)}{A_{2} F_{t}}\right\}\right] \sqrt{F_{m} F_{c}}
$$

em que $A_{2}=1 / a_{2}$. Para obter a taxa de expansão causada por RAA, diferencia-se a equação anterior em relação ao tempo, obtendo a seguinte equação:

$$
\dot{\varepsilon}_{R A A}=H\left(t-t_{p} F_{p}\right) \varepsilon_{v o l}^{\max }\left[\exp \left\{\frac{-\left(t-t_{p} F_{p}\right)}{A_{2} F_{t}}\right\} / A_{2} F_{t}\right] \sqrt{F_{m} F_{c}}
$$

É importante observar que devido ao uso da função Heaviside não ocorrerão expansões antes de $t_{p}$. Consequentemente, dependendo do passo de tempo adotado, poderá existir um erro na análise, que pode ser minimizado com o refinamento da discretização temporal. Os autores adotaram como alternativa uma lei de conversão do tipo "escada" para $F_{p}$, conforme mostrado na Figura 2.15, e adotaram um passo de tempo de tal modo que $t_{p}$ seja múltiplo desse valor. Desta forma, $t_{p}$ estará sempre no começo de um passo de tempo. Para um intervalo de análise, o número de divisões da lei de normalização é dado por:

$$
N_{d i v}=\frac{t^{p} F_{p}}{\Delta t}-\frac{t^{p}}{\Delta t}+1
$$

Figura 2.15 - Fatores de influência e coeficiente de calibração com relação a porosidade.

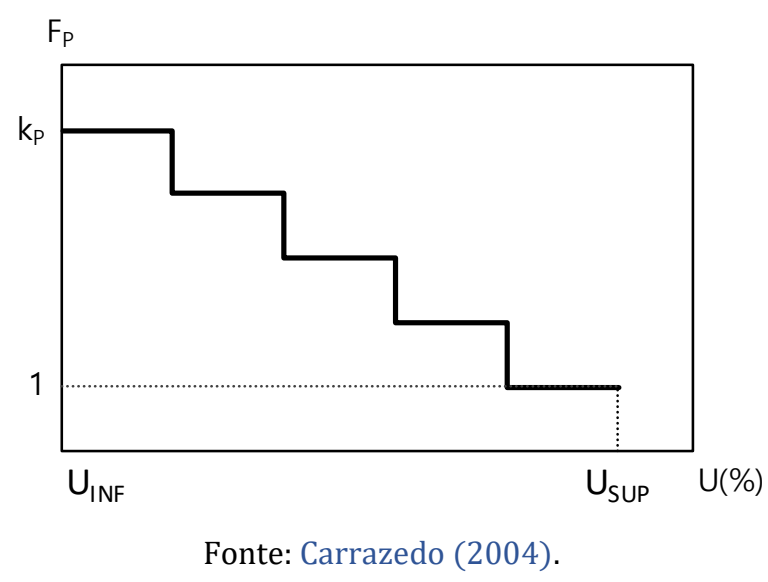


Maiores informações quanto ao modelo utilizado podem ser encontradas também no trabalho de Carrazedo (2004). Evoluções recentes destes modelos são tratados nos trabalhos de Posterlli (2017) na análise de elementos armados, Salomão (2017) na análise de problemas de percolação e Oliveira (2013) no tratamento da expansão ortotrópica. Este trabalho apresenta uma nova abordagem ao associar este modelo aos efeitos de retração e fluência, em que estes últimos fenômenos são apresentados no próximo capítulo. 


\section{CAPÍTULO 3}

\section{RETRAÇÃO E FLUÊNCIA DO CONCRETO}

Neste capítulo é apresentada uma breve fundamentação teórica dos conceitos de retração e fluência, bem como os fatores que influenciam a ocorrência de ambos os fenômenos. Esse entendimento é necessário para melhor compreensão dos modelos numéricos que são apresentados em seguida, utilizados para a modelagem das deformações causadas tanto pela fluência quanto pela retração, bem como dos parâmetros utilizados por cada modelo. Para a fundamentação teórica, foi utilizada como base os livros-textos de Neville \& Brooks (2013), Mehta \& Monteiro (2014) e Dyer (2015).

\subsection{CONCEITOS GERAIS}

Os fenômenos de retração e fluência podem ser discutidos em conjunto, uma vez que ambos têm a mesma origem, a pasta de cimento hidratado. As curvas de deformação-tempo para ambos também são muito semelhantes. Os fatores que influenciam a retração normalmente influenciam também a fluência. Diante disso, este capítulo abordará os dois fenômenos.

\subsubsection{Retração Plástica}

Pode-se descrever o acontecimento de dois processos simultâneos na superfície de um elemento de concreto (Figura 3.1a). Primeiro, os constituintes sólidos têm a tendência de se assentar (Figura 3.1b), o que leva à formação de uma camada de água na superfície do elemento. Segundo, a água livre da superfície evapora. A retração plástica ocorre, então, quando em determinado instante, após a taxa de evaporação ter superado a taxa de transpiração, as partículas de cimento na superfície do elemento deixam de estar cobertas pela água, induzindo tensões de tração na camada superficial devido à restrição desta camada pelo concreto interno, e como consequência há a formação de meniscos de água entre as partículas (Figura 3.1c). Com a progressiva evaporação da água, os raios dos meniscos 
diminuem, e em determinado momento os raios de parte dos meniscos serão tão pequenos que não preencherão o espaço entre partículas de cimento, de modo que a superfície de água precisará se rearranjar em um ponto abaixo da superfície inicial, tendo como resultado a penetração do ar (Figura 3.1d). Quanto maior for a velocidade de evaporação, que depende de fatores como temperatura e umidade, maior será a retração plástica.

Figura 3.1 - Fissuração por retração plástica.

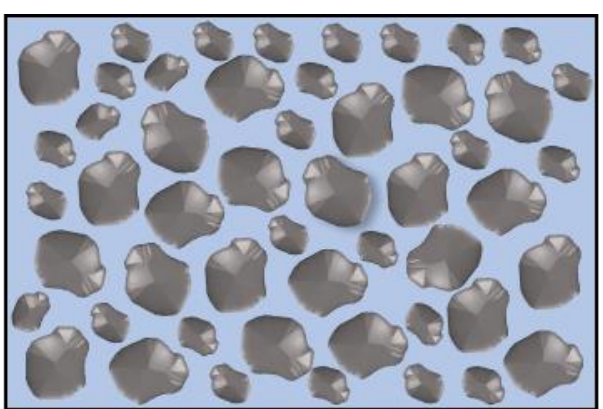

(a)

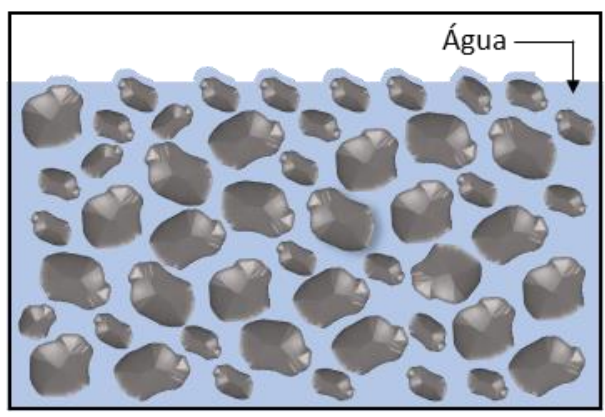

(c)

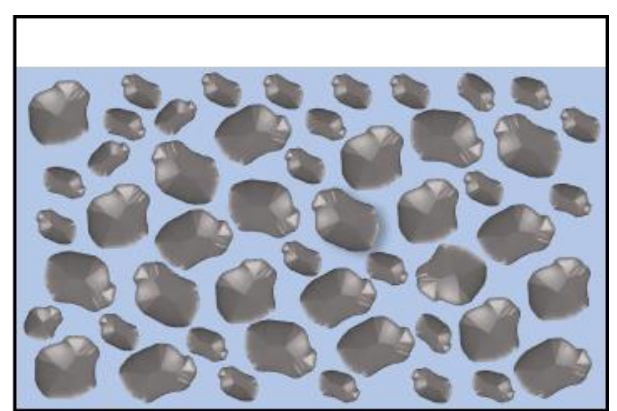

(b)

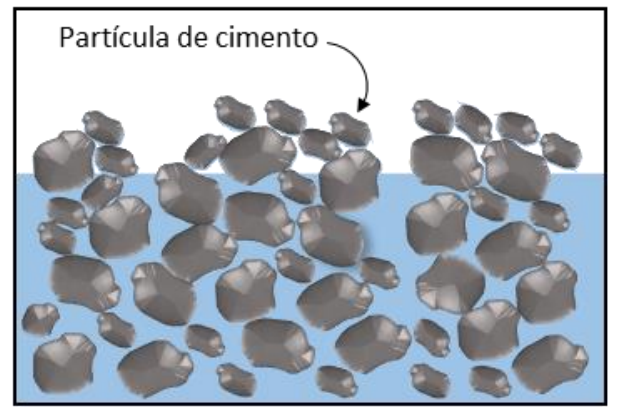

(d)

Fonte: Adaptado de Dyer (2015).

\subsubsection{Retração por Secagem}

A retração ocorre no concreto endurecido devido à perda de água fisicamente adsorvida do silicato de cálcio hidratado (CSH). O CSH é o produto de reação formado durante a fixação e o endurecimento do cimento, representa cerca de 50 a 60\% do volume de sólidos em uma pasta de cimento inteiramente hidratada, fornecendo a maior parte da resistência e durabilidade a longo prazo. A pasta de cimento saturada, quando exposta a umidades do ambiente que estiverem abaixo da saturação, não se manterá dimensionalmente estável, resultando na deformação por retração. A retração por secagem pode ser classificada como reversível e irreversível. A primeira é devido à movimentação de umidade, em que parte da retração total pode ser reproduzida por ciclos de molhagem-secagem. Na segunda não há recuperação da retração por secagem, mesmo após um longo período de armazenamento de 
água (molhagem). A Figura 3.2 ilustra a reversibilidade da retração por secagem ao longo do tempo.

Figura 3.2 - Reversibilidade da retração por secagem.

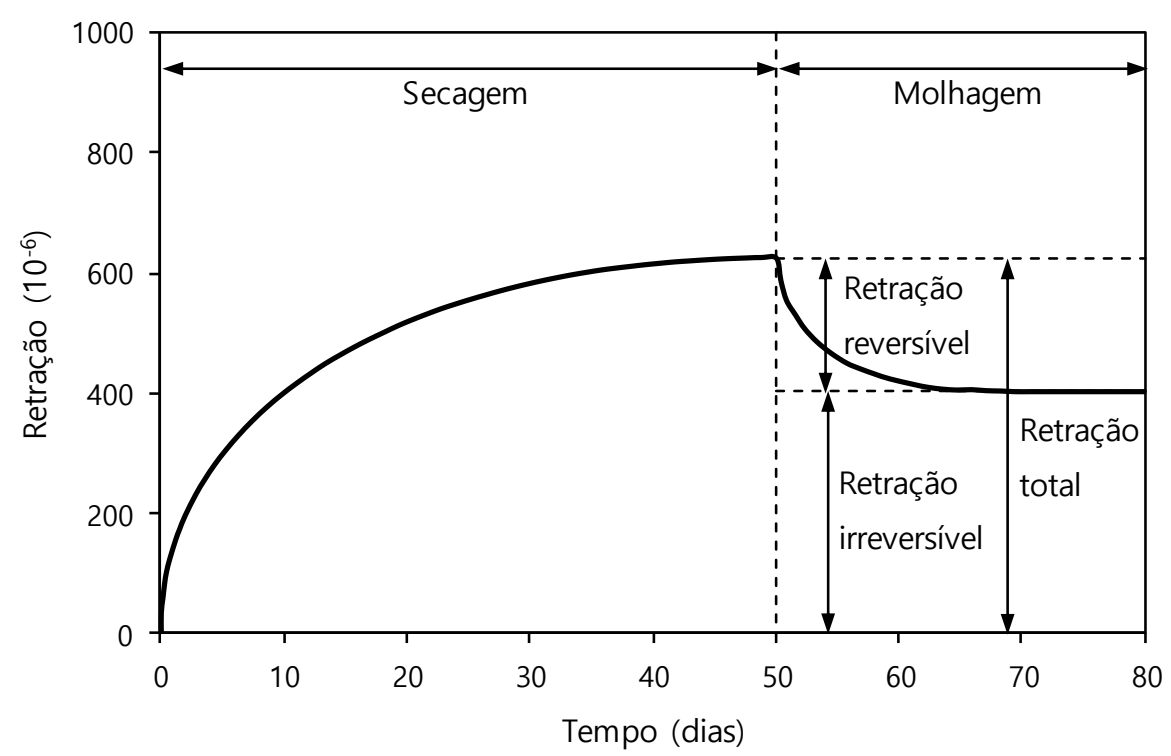

Fonte: Mehta \& Monteiro (2014).

A reversibilidade da retração é dependente da duração dos ciclos de molhagemsecagem, em que a secagem ocorre de modo consideravelmente mais lento que a molhagem. Assim, um curto período de chuvas pode ser suficiente para reverter as consequências da secagem. Associa-se a parte irreversível da retração à formação de ligações químicas e físicas adicionais no gel de cimento quando a água absorvida é removida. Na secagem do concreto, inicialmente ocorre a perda de água livre, induzindo gradientes internos de umidade relativa no interior da pasta de cimento, de maneira que as moléculas de água, com o tempo, são transferidas da grande área superficial do CSH para os vazios capilares, e então, para fora do concreto, causando a contração da pasta de cimento.

\subsubsection{Retração Autógena}

A retração no concreto ainda pode acontecer mesmo quando não há movimento de água para ou do concreto, justamente porque a evaporação não é o único meio pelo qual a água pode ser removida dos poros do concreto. Conforme as reações de hidratação acontecem no cimento, a água livre é convertida em água quimicamente combinada, de modo que essa perda de água utilizada na hidratação pode levar a retração, neste caso chamada de retração autógena. Essa retração consiste, então, na redução macroscópica do volume de materiais cimentícios que ocorre quando o cimento hidrata após a pega inicial, já seco. 
A retração autógena ocorre nos mais diversos tipos de concreto, é consideravelmente pequena em concretos de resistência convencional, entretanto, não pode ser ignorada em concretos de alta resistência por ser muito alta. A retração autógena não compreende alterações de volume devido à perda ou ao ingresso de substâncias, variação de temperatura, ou aplicação de uma resistência externa e restrição.

\subsubsection{Deformação Elástica}

Um material é considerado perfeitamente elástico quando as deformações aparecem e desaparecem de maneira imediata após a aplicação e remoção de um carregamento. É importante observar que um material elástico não implica em relação linear para o gráfico de tensão x deformação. As características elásticas de um determinado material são uma medida de sua rigidez. Rüsch (1981) ressalta que a velocidade com que a carga é aplicada também influencia na deformação instantânea registrada. A deformação que acontece imediatamente ou concomitantemente à aplicação de uma carga é considerada elástica, e o aumento posterior a essa deformação causada pelo carregamento constante é tratado como deformação lenta, também conhecido como fluência.

\subsubsection{Fluência}

A fluência pode ser entendida como o aumento da deformação sob uma tensão constante ao longo do tempo após a consideração de outras deformações dependentes do tempo não associadas à tensão, por exemplo, a retração. Considerando a deformação como constante, a fluência ocorre pela redução da tensão com o tempo, fenômeno conhecido como relaxação. A fluência no concreto pode ser entendida como a perda de água do CSH fisicamente adsorvida devido a uma tensão constante, em que essa perda depende da intensidade e duração da tensão aplicada.

Quando a retração por secagem pode ser desprezada, a fluência básica pode ser vista como o aumento de deformação ao longo do tempo, com aplicação de uma tensão constante, sob condições de umidade relativa de 100\%, não ocorrendo a transferência de água entre o concreto e o meio ambiente.

A fluência por secagem é uma forma de fluência adicional que ocorre quando o corpo está sob a ação de um carregamento e é simultaneamente exposto a um ambiente de baixa umidade relativa. Assim, a fluência total se dá pela soma da fluência básica e da fluência por 
secagem, e a deformação total será a soma da deformação elástica, deformação por retração livre, deformação por fluência básica e deformação devido à fluência por secagem (Figura 3.3).

Figura 3.3 - Deformação do concreto submetido à carga constante.

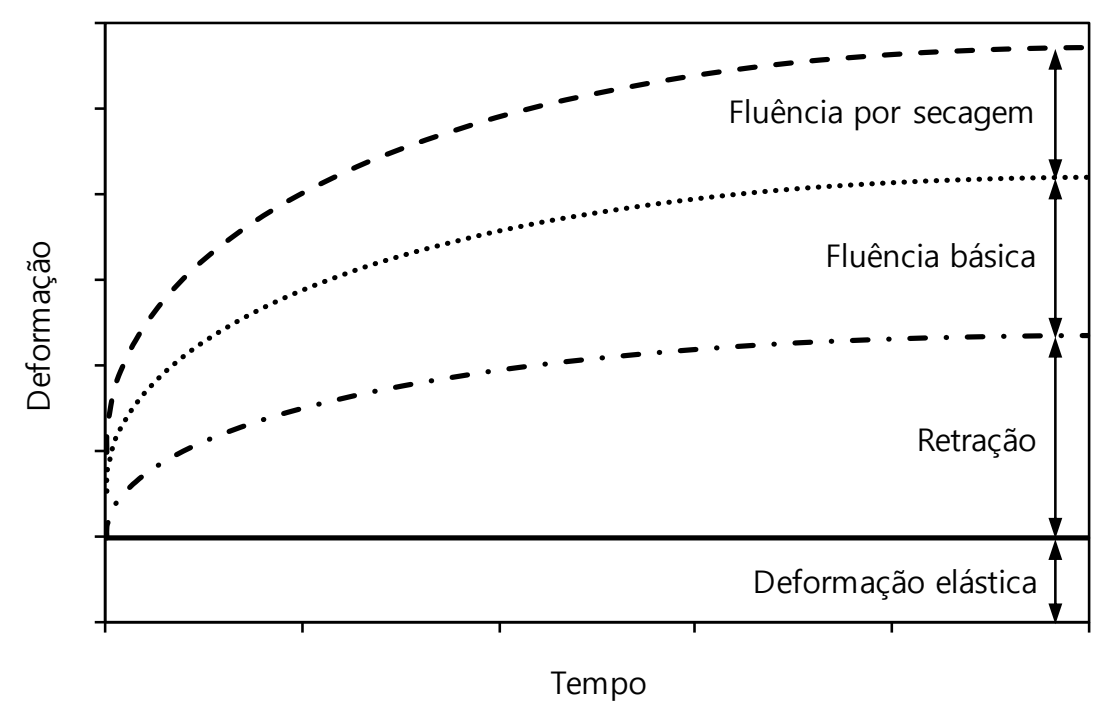

Um concreto com consumo de cimento de $350 \mathrm{~kg} / \mathrm{m}^{3}$, carregado aos sete dias com uma carga de aproximadamente $10 \mathrm{MPa}$ sob umidade relativa igual a 50\%, apresentou em apenas quatro dias deformação total quase três vezes maior que a deformação elástica, e, ao fim de três anos, essa diferença foi superior a seis vezes (KUPERMAN, 2007).

Figura 3.4 - Deformação total do concreto ao longo do tempo.

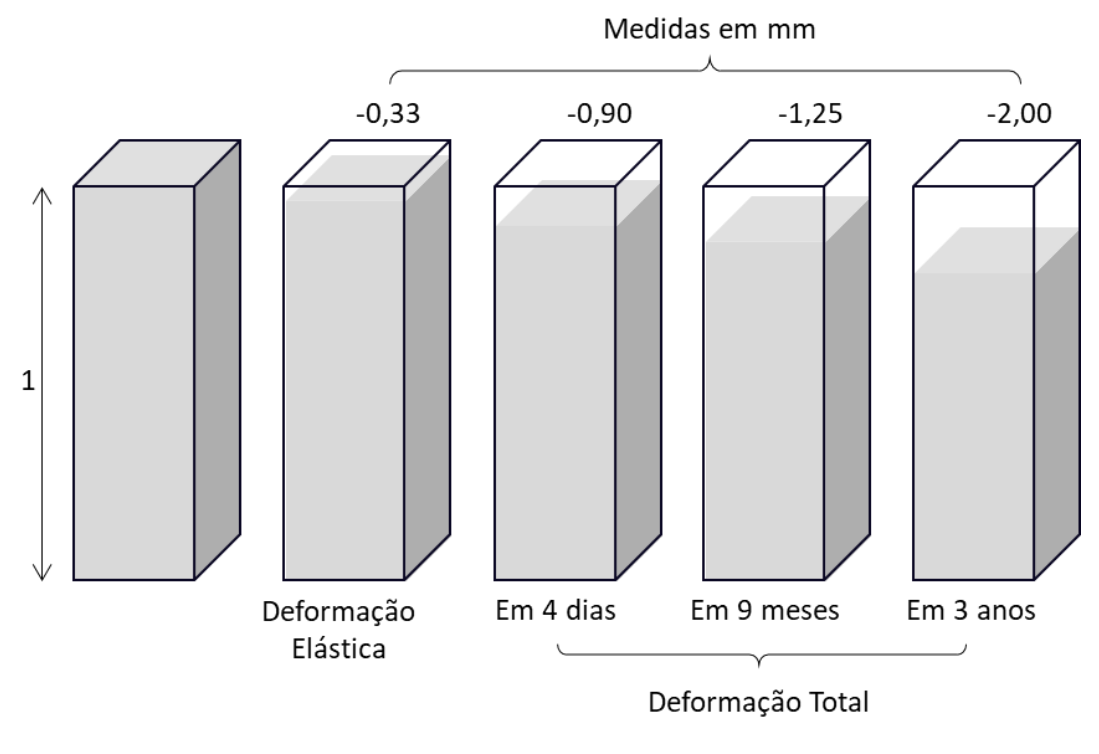

Fonte: Kuperman (2007).

Nas estruturas de concreto, a fluência reduz as tensões internas decorrentes da retração não uniforme ou restringida. Por outro lado, considerando o concreto massa, a 
fluência sozinha pode causar a fissuração quando o concreto restringido sofre um ciclo de mudança de temperatura causado pelo desenvolvimento do calor de hidratação e resfriamento que o sucede.

Figura 3.5 - Reversibilidade da fluência.

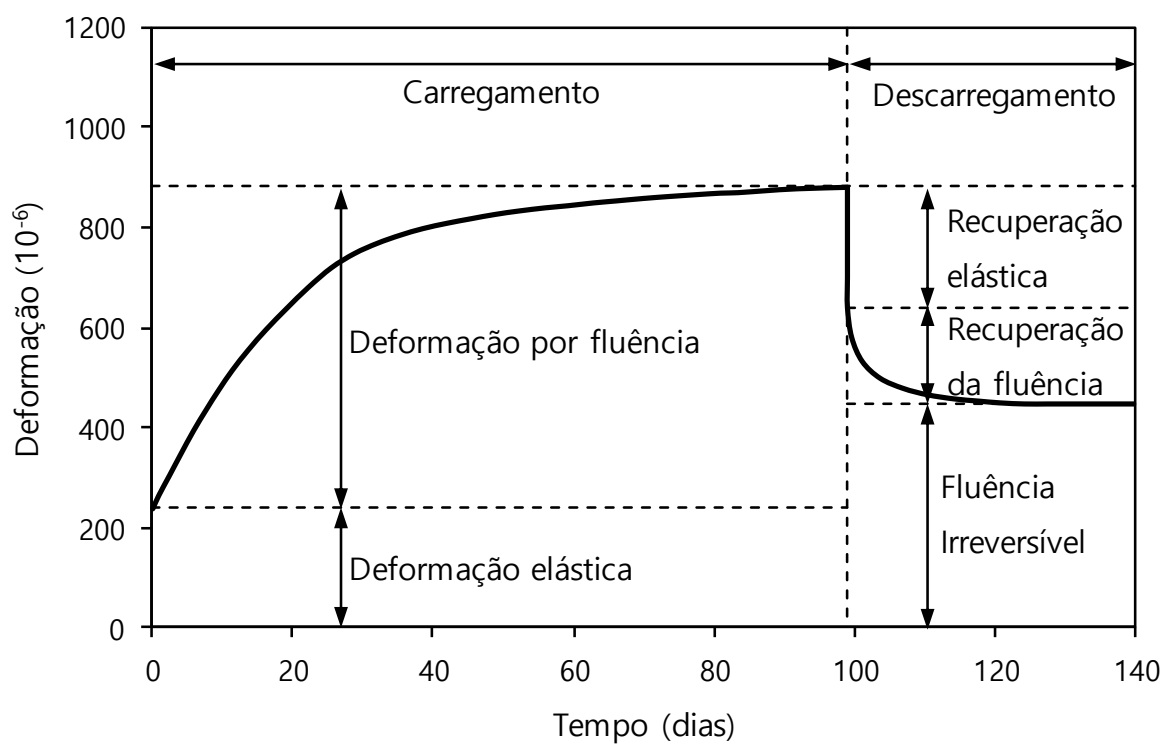

Fonte: Mehta \& Monteiro (2014).

Na Figura 3.5 o concreto mostra uma deformação elástica instantânea. As deformações aumentam com a continuidade de aplicação do carregamento ao longo do tempo. Quando ocorre o descarregamento, a recuperação elástica é aproximadamente de mesma ordem da deformação elástica resultante da primeira aplicação do carregamento. Ocorre uma redução gradual da deformação, conhecida como recuperação da fluência, que acompanha a recuperação instantânea. Por mais que a recuperação da fluência venha a ocorrer de maneira mais rápida que a fluência, não é total a reversão da deformação por fluência. De modo análogo à retração por secagem, essa propriedade é definida pelos conceitos de fluência reversível e irreversível.

\subsection{FATORES QUE INTERFEREM NA FLUÊNCIA E RETRAÇÃO}

Para melhor compreender os fenômenos da fluência e da retração, é importante frisar quais são os fatores que interferem em ambos, destacando-se os materiais empregados no concreto, umidade, temperatura, adições, aditivos, geometria da peça estrutural, intensidade do carregamento e idade do carregamento. 


\subsubsection{Relação água/cimento}

Outro fator de grande importância é a relação água/cimento devido a sua grande influência na porosidade e, deste modo, na resistência do concreto, de modo que quanto menor a relação a/c, maior será a resistência do concreto. Considerando um teor de pasta de cimento constante, um aumento da relação a/c resultará no aumento da deformação por fluência (Figura 3.6), pois há decréscimo da resistência, do módulo de elasticidade e acréscimo de permeabilidade.

Figura 3.6 - Influência da relação água/cimento sobre a fluência.

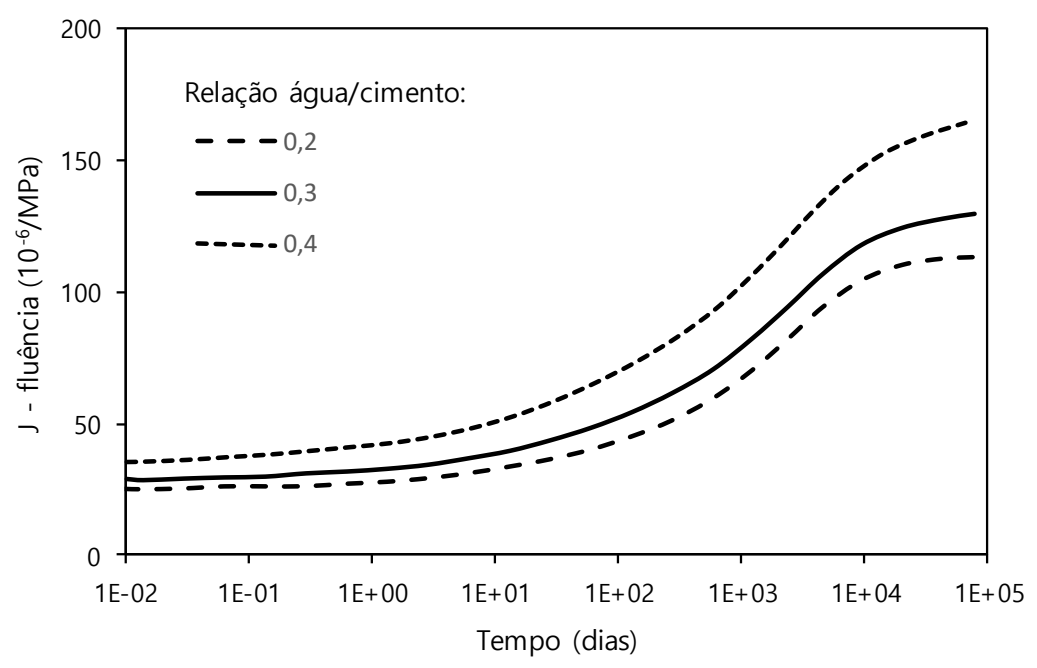

Fonte: Wendner, Hubler \& Bažant (2015).

Figura 3.7 - Influência da relação água/cimento e teor de agregados sobre a retração.

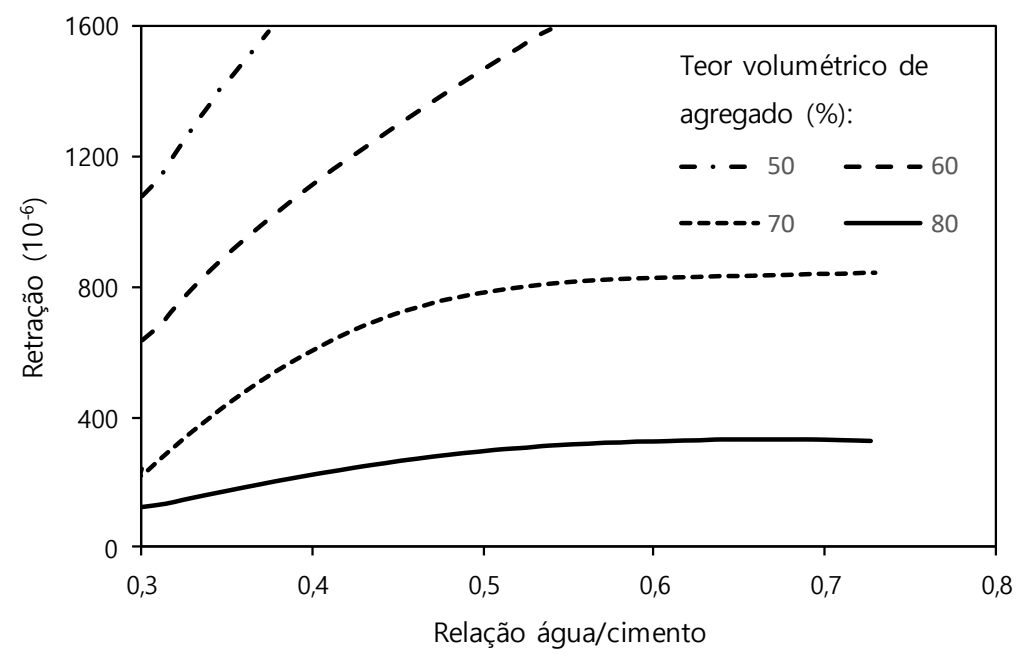

Fonte: Neville \& Brooks (2013).

A relação a/c interfere na qualidade da pasta de cimento de modo a influenciar, também, na intensidade da retração. Pode-se dizer que quanto maior a relação a/c, maior a 
retração, assim, considerando um determinado teor de agregados, a retração do concreto é função da relação a/c (Figura 3.7).

\subsubsection{Cimento}

O tipo de cimento é o principal fator interveniente, uma vez que é ele que determina a hidratação da matriz da pasta de cimento. 0 tipo de cimento afeta a fluência na medida em que altera a resistência do concreto no momento de aplicação da carga. 0 concreto que utiliza cimento Portland comum, ao ser carregado nas primeiras idades, apresenta uma fluência maior do que um concreto correspondente que utiliza cimento de alta resistência inicial. Deste modo, para análise da fluência, é necessário levar em conta os efeitos do tipo de cimento sobre a resistência às primeiras idades do concreto.

O consumo de cimento afeta também, de forma direta, a retração uma vez que a perda de água da pasta de cimento é a responsável pelo fenômeno. Assim, quanto maior o consumo de cimento, mais intensa a retração. Além disso, quanto mais fino for o cimento, maior é o risco de fissuração, uma vez que as reações de hidratação serão mais lentas, levando a uma taxa reduzida da evolução da força de tensão, retardando o processo de endurecimento.

\subsubsection{Agregado}

É possível notar pela Figura 3.7 a influência de outro fator na análise da retração: verifica-se que a intensidade foi menor quanto maior foi o teor de agregados. A granulometria, dimensão máxima, forma e textura do agregado são fatores que interferem tanto na fluência quanto na retração por secagem.

A dimensão máxima, per si, não interfere na intensidade da retração do concreto. Contudo, agregados maiores permitem o uso de misturas mais magras - sob relação a/c constante - resultando assim em menor retração. Entende-se que dentre as características do agregado, o módulo de elasticidade é o fator mais preponderante pois trabalha no controle das deformações, uma vez que tanto a fluência quanto a retração por secagem podem aumentar em cerca de 2,5 vezes quando há substituição de um agregado de alto módulo de elasticidade por um de baixo módulo. As demais características podem influenciar de maneira indireta, e.g., na capacidade de adensamento da mistura de concreto. 


\subsubsection{Adições e Aditivos}

Os aditivos redutores de água e retardadores de pega, que causam uma melhor dispersão das partículas de cimento anidro na água, levam a um refinamento de poros no produto de hidratação. Deste modo, espera-se que esses aditivos aumentem a retração por secagem e fluência. 0 efeito principal acaba sendo indireto, pois o uso de aditivos modifica o teor da água e/ou cimento, influenciado, assim, na retração. Os aditivos redutores de água e retardadores podem, ainda, aumentar a fluência básica. Brooks (1989) ressalta que é importante ter cuidado ao avaliar a interferência dos aditivos, pois quando o uso desses componentes é feito simultaneamente, com alterações do traço original, a comparação entre duas misturas torna-se incorreta. Para obter uma avaliação mais confiável, seria necessário fazer o uso de aditivos apenas para melhorar a trabalhabilidade da mistura.

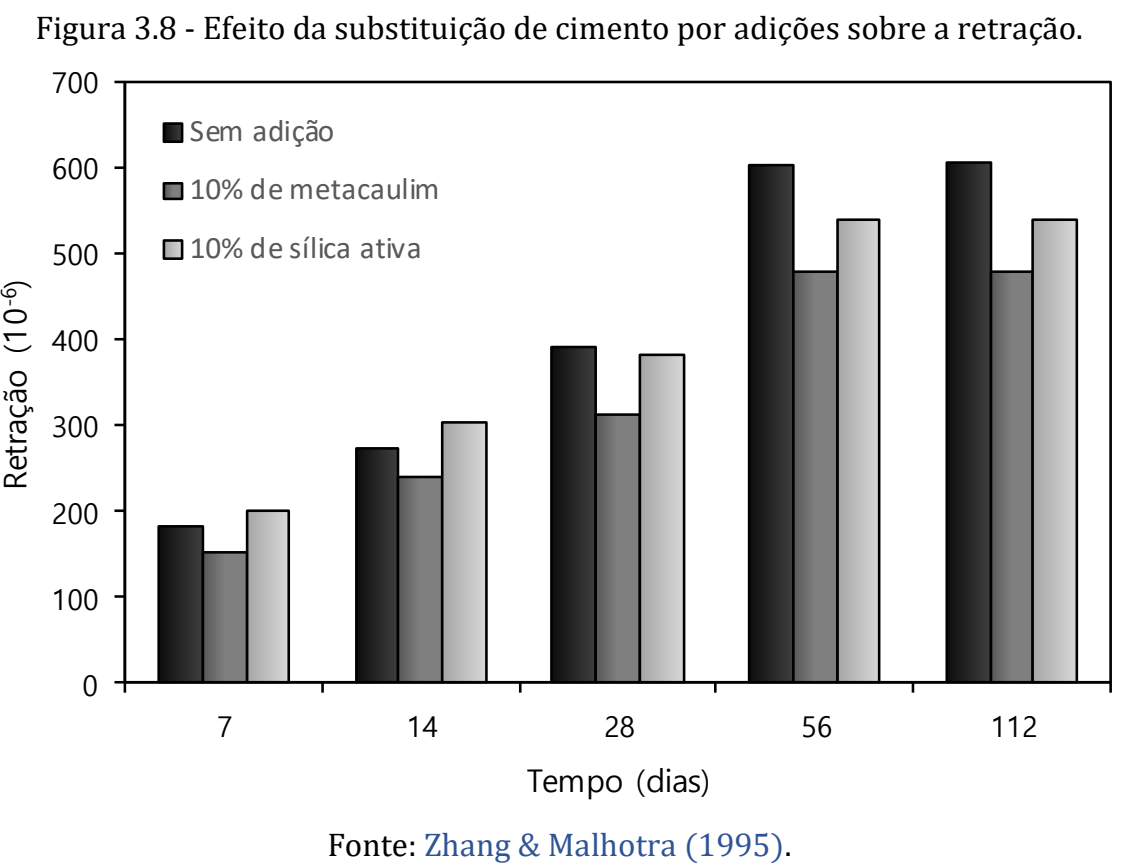

A adição de misturas minerais reduz o tamanho dos poros com o aumento da distribuição do tamanho dos poros, o que, por sua vez, reduz a porosidade, a permeabilidade, a retração e a fluência. A redução do diâmetro médio dos poros é altamente e inversamente dependente do volume de cimento substituído e da idade do concreto ou da pasta; isto é, com a idade e o volume crescente de substituição de cimento, o diâmetro médio dos poros e a porosidade total diminuem. A retração e a fluência aumentam com o aumento da idade e do volume de substituição de cimento, e a taxa de aumento dessas amostras é menor nos concretos pozolânicos do que nos concretos simples (AYUB, KHAN \& MEMON, 2014). Zhang \& Malhotra (1995), por meio de um estudo experimental, mostraram que a adição de, por 
exemplo, metacaulim ou sílica ativa reduz a porosidade e permeabilidade do concreto e consequentemente reduz a retração por secagem (Figura 3.8). Mazloom, Ramezanianpour \& Brooks (2004) verificaram que com o aumento do nível de substituição de sílica ativa, ocorre uma taxa equivalente de diminuição na fluência total e básica do concreto (Figura 3.9).

Figura 3.9 - Efeito da substituição de cimento por sílica ativa sobre a fluência.

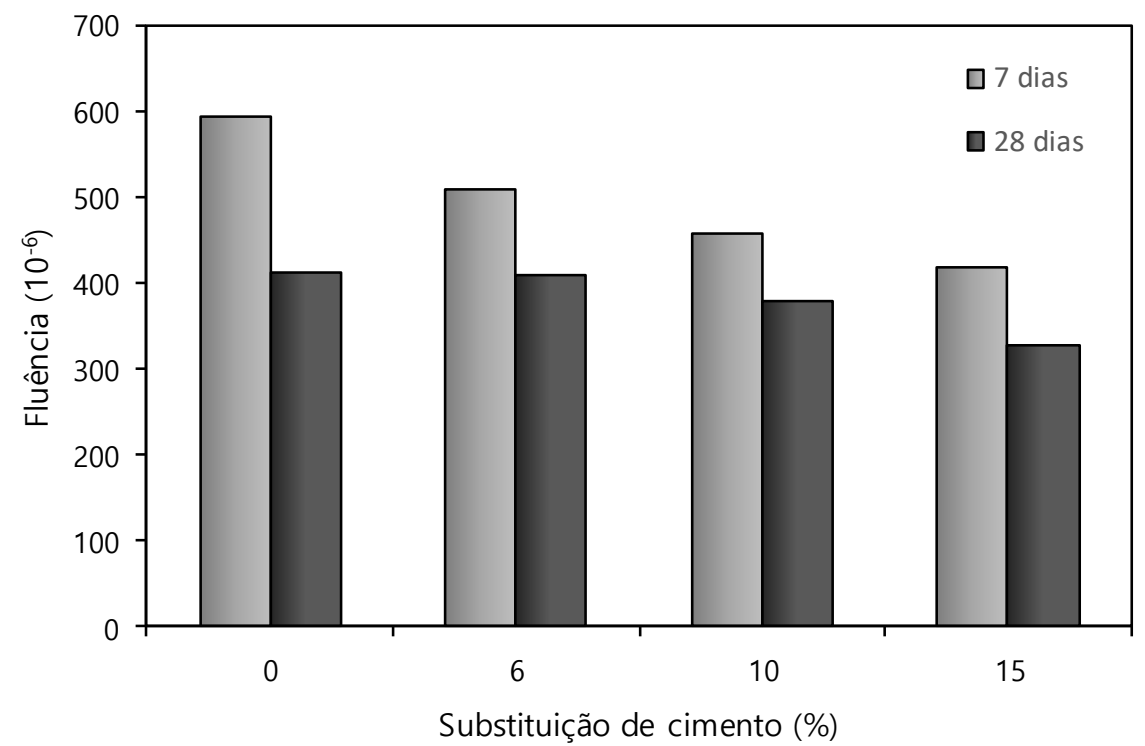

Fonte: Mazloom, Ramezanianpour \& Brooks (2004).

\subsubsection{Umidade do Ar e Temperatura}

Joshaghani, Balapour \& Ramezanianpour (2018) mostraram em seu estudo o potencial de retração com o tempo decorrido sob diferentes condições ambientes. Essas mudanças de volume induzidas pela umidade são uma característica da argamassa. Como a retração por secagem está relacionada à perda de umidade da argamassa, ela é influenciada por fatores externos que afetam a secagem, como a temperatura e a umidade relativa do ambiente. Conforme exibido na Figura 3.10, níveis mais altos de umidade relativa podem impedir a perda de umidade e mitigar os efeitos adversos da retração, de modo que os espécimes apresentaram menores tendências de retração nos maiores níveis de umidade (90\%). Temperaturas mais baixas $\left(25^{\circ} \mathrm{C}\right)$ produziram geralmente uma diminuição na retração por secagem devido à evaporação mais lenta. Todavia, a água tem alta energia térmica disponível para conduzir a evaporação em temperatura mais alta $\left(65^{\circ} \mathrm{C}\right)$. É interessante observar o desempenho contraditório ao aumentar a temperatura. 0 efeito direto de um aumento na temperatura é o aumento da taxa de evaporação da água e um aumento nos valores de deformação por retração. No entanto, um aumento na temperatura 
acelera o processo de hidratação, em que o desenvolvimento da hidratação não só pode evitar a evaporação da água livre, como também pode aumentar a resistência à compressão e o módulo de elasticidade em idades precoces, o que pode reduzir indiretamente os valores das deformações por retração. Em geral, para os autores, um aumento na temperatura é mais poderoso em afetar a taxa de evaporação da água do que o processo de hidratação.

Figura 3.10 - Influência das condições do ambiente sobre a retração.

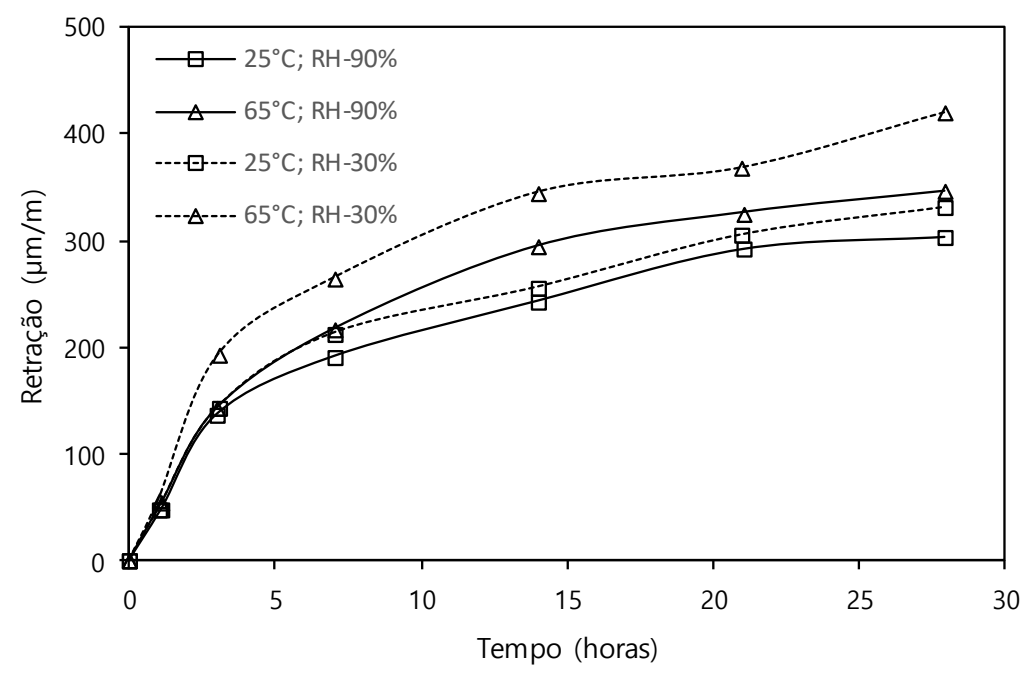

Fonte: Joshaghani, Balapour \& Ramezanianpour (2018).

Sabendo que a fluência é, para uma grande variedade de misturas, inversamente proporcional à resistência do concreto, é necessário verificar o modo como as condições do ambiente afetam a resistência do concreto, e consequentemente, a fluência. Em seu estudo, Joshaghani, Balapour \& Ramezanianpour (2018) constataram que para uma umidade relativa constante, a temperatura ambiente mais alta causa um aumento na resistência à compressão das amostras em idades iniciais (Figura 3.11). Entretanto, os corpos de prova com 28 dias de idade, que foram curados sob uma temperatura mais alta $\left(65^{\circ} \mathrm{C}\right)$, apresentaram valores de resistência à compressão mais baixos em comparação aos corpos de prova curados sob uma temperatura mais baixa. Este acontecimento pode estar relacionado à aceleração da produção de gel CSH nas idades iniciais, o que ajuda a desenvolver resistência à compressão.

O concreto é mais resistente em níveis mais baixos de umidade relativa e menos resistente em graus mais altos de saturação. No baixo grau de saturação (30\%), a tensão de compressão aumenta devido ao efeito de sucção capilar, pois a adsorção física é o resultado das forças de atração e das moléculas no sólido (JOSHAGHANI, BALAPOUR \& RAMEZANIANPOUR, 2018). 
Figura 3.11 - Influência das condições do ambiente sobre a resistência à compressão.

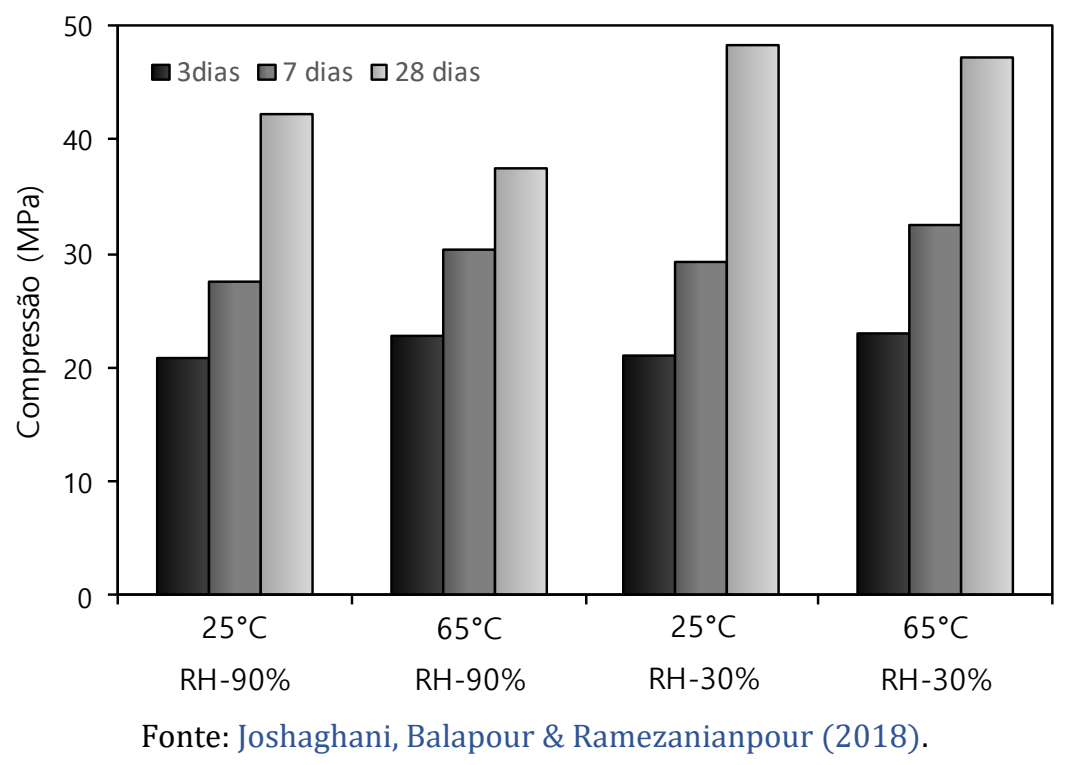

\subsubsection{Intensidade e Idade do Carregamento}

Ao considerar um determinado tipo de cimento, conforme aumenta-se a idade de aplicação do carregamento, poderá haver diminuição na fluência, em que isso decorre do aumento da resistência com a idade, a fluência é, então, para uma grande variedade de misturas, inversamente proporcional à resistência do concreto na idade de aplicação do carregamento.

Há uma proporcionalidade direta entre a magnitude da tensão constante e a fluência do concreto. Troxell, Raphael \& Davis (1958) mostraram que para corpos de prova com 90 dias de idade, o valor da fluência final dobrou quando a tensão de carga cresceu de 4 MPa para $8 \mathrm{MPa}$. Em virtude do efeito da resistência à compressão sobre a fluência, os autores mostraram que, para um dado nível de tensão, foram obtidos valores menores de fluência para o concreto carregado aos 3 meses quando comparado ao concreto carregado aos 28 dias, uma vez que para o primeiro caso houve maior tempo de cura.

\subsubsection{Geometria da Peça}

A taxa de perda de água é controlada pelo comprimento do caminho a ser vencido pela água expelida durante a fluência e/ou retração, devido à resistência ao transporte de água do interior da peça de concreto para a atmosfera. Deste modo, a dimensão e forma de um elemento de concreto, sob umidade relativa constante, determinam a intensidade da retração 
e fluência. É possível expressar os fatores de dimensão e forma por um único valor, denominado espessura teórica ou efetiva, sendo igual à razão entre a área da seção e o semiperímetro em contato com a atmosfera. Verifica-se pela Figura 3.12a, a relação entre o coeficiente de fluência e a espessura teórica da peça, considerando diferentes condições de umidade e, pela Figura 3.12b, o comportamento da retração ao longo do tempo, considerando diferentes espessuras teóricas.

Figura 3.12 - Influência da espessura teórica na fluência e retração.

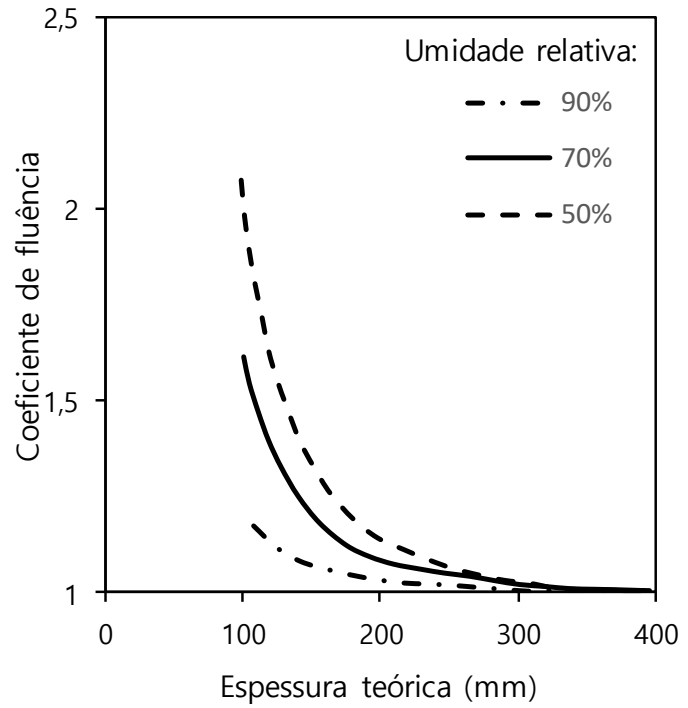

(a)

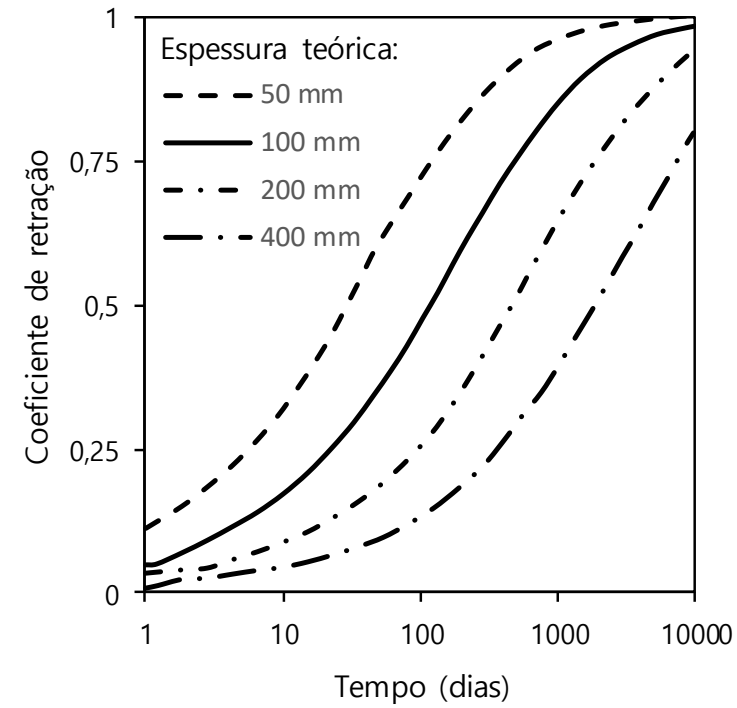

(b)

Fonte: Mehta \& Monteiro (2014).

\subsubsection{Idade do Concreto}

A retração pode ocorrer por um longo período, todavia, a taxa de retração diminui rapidamente com o tempo. Considerando a retração aos 20 anos, estima-se, de modo geral, que 14 a 34\% da retração ocorre em duas semanas, 40 a $80 \%$ em três meses e 66 a 85\% em um ano. Assim como a retração, a fluência também apresenta pequeno aumento após um carregamento de 20 anos, em que se assume que cerca de $25 \%$ da fluência ocorre nas duas primeiras semanas, $50 \%$ em até 3 meses e $75 \%$ em até um ano.

\subsection{MODELAGEM DA RETRAÇÃO E FLUÊNCIA}

Na prática da engenharia civil, o comportamento médio dependente do tempo do concreto, relacionado aos fenômenos físicos de fluência e retração, é usualmente previsto utilizando modelos recomendados por códigos de projeto como o Model Code 2010 (FIB, 
2012), ACI 209 (ACI 209, 2008) e JSCE (JSCE, 2010), ou modelos acadêmicos, por exemplo, B3 (BAŽANT \& BAWEJA, 2000), B4 (BAŽANT \& RILEM, 2015) e GL2000 (GARDNER, 2004).

\subsubsection{B3, 2000}

O modelo B3 de Bažant e Baweja (2000) é resultado de uma série de métodos de previsão de retração e de fluência desenvolvidos por Bažant e seus colaboradores na Universidade de Northwestern, baseado na descrição matemática de dez fenômenos físicos que afetam a fluência e retração. De acordo com os autores, o modelo B3 é mais simples e é teoricamente mais justificado que os modelos que o precedem. 0 efeito da composição do concreto e a solicitação de projeto nos parâmetros do modelo é a principal fonte de erro do modelo. Este modelo foi previsto para ser útil àqueles que trabalham tanto com estruturas simples, quanto complexas. Para o modelo foram utilizadas funções de conformidade a fim de reduzir o risco dos erros causados por valores imprecisos do módulo elástico. 0 modelo ainda separa claramente a fluência básica e a de secagem. 0 modelo considera como fatores a idade do concreto, idade do concreto considerando o carregamento, quantidade de agregados, quantidade de cimento, tipo de cimento, resistência à compressão, condições de cura, umidade relativa, geometria do elemento estrutural, relação entre volume e superfície e relação a/c. A deformação média de retração $\varepsilon_{s h}\left(t, t_{c}\right)$ para a idade do concreto em $t$ (dias), medida a partir do início da secagem em $t_{c}$ (dias), é calculada pela equação (3.1).

$$
\varepsilon_{\text {sh }}\left(t, t_{c}\right)=-\varepsilon_{\text {shoo }} k_{h} S\left(t-t_{c}\right)
$$

em que $k_{h}$ é um coeficiente dependente da umidade, $\varepsilon_{\text {sh }}$ e $S\left(t-t_{c}\right)$ são dados respectivamente pelas equações a seguir:

$$
\begin{aligned}
& \varepsilon_{\text {sh } \infty}=\alpha_{1} \alpha_{2}\left[0,019 w^{2,1} f_{c m 28}^{-0,28}+270\right] E_{c m 28}\left(\frac{t}{4+0,85 t}\right)^{0,5} \times 10^{-6} \\
& S\left(t-t_{c}\right)=\tanh \sqrt{\frac{\left(t-t_{c}\right)}{0,085 t_{c}^{-0,08} f_{c m 28}^{-0,25}\left[2 k_{s}(V / S)\right]^{2}}}
\end{aligned}
$$

em que $w$ é o teor de água presente no concreto, $f_{c m 28}$ e $E_{c m 28}$ são respectivamente a resistência à compressão e módulo de elasticidade do concreto aos 28 dias, $\alpha_{1}$ e $\alpha_{2}$ são constantes relacionadas ao tipo de cimento e às condições de cura, $k_{s}$ é o fator de correção da forma da seção transversal e $V / S$ é a relação volume-superfície. 0 cálculo da função de conformidade que leva em consideração a fluência no concreto é dado pela equação (3.4). 


$$
J\left(t, t_{0}\right)=q_{1}+C_{0}\left(t, t_{0}\right)+C_{d}\left(t, t_{0}, t_{c}\right)
$$

em que $q_{1}$ é a deformação instantânea devido à tensão unitária, $C_{0}\left(t, t_{0}\right)$ é a função de conformidade para a fluência básica, dada pela equação (3.5), e $C_{d}\left(t, t_{0}, t_{c}\right)$ é a função de conformidade adicional para a fluência por secagem, dada pela equação (3.7). $t, t_{0}$ e $t_{c}$ são, respectivamente, a idade do concreto, a idade a partir do início da secagem ou do fim da cura, e a idade do carregamento.

$$
C_{0}\left(t, t_{0}\right)=q_{2} Q\left(t, t_{0}\right)+q_{3} \ln \left[1+\left(t-t_{0}\right)^{n}\right]+q_{4} \ln \left(t / t_{0}\right)
$$

em que $q_{2}$ é um parâmetro relacionado à quantidade de cimento e a resistência à compressão aos 28 dias, $q_{3}$ é o parâmetro de conformidade viscoelástico, $q_{4}$ é o parâmetro de conformidade do fluxo de envelhecimento, e $Q\left(t, t_{0}\right)$ é dada pela equação a seguir:

$$
Q\left(t, t_{0}\right)=\left[0,086 t_{0}^{2 / 9}+1,21 t_{0}^{4 / 9}\right]^{-1}\left[1+\left(\frac{\left[0,086 t_{0}^{2 / 9}+1,21 t_{0}^{4 / 9}\right]^{-1}}{t_{0}^{-0,5} \ln \left[1+\left(t-t_{0}\right)^{0,1}\right]}\right)^{1,7 t_{0}^{0.12}+8}\right]^{-1 / 1,1 t_{0}^{0.12}+8}
$$

A equação (3.7) mostra o cálculo da função de conformidade adicional para a fluência por secagem:

$$
C_{d}\left(t, t_{0}, t_{c}\right)=q_{5}\left[\exp \{-8 H(t)\}-\exp \left\{8 H\left(t_{0}\right)\right\}\right]^{1 / 2}
$$

em que $q_{5}$ é o parâmetro de conformidade da fluência por secagem, $H(t)$ e $H\left(t_{0}\right)$ são calculados da seguinte forma:

$$
\begin{aligned}
& H(t)=1-(1-h) \tanh \left[\left(\frac{t-t_{c}}{\tau_{s h}}\right)^{1 / 2}\right] \\
& H\left(t_{0}\right)=1-(1-h) \tanh \left[\left(\frac{t_{0}-t_{c}}{\tau_{s h}}\right)^{1 / 2}\right]
\end{aligned}
$$

em que $h$ é a umidade relativa e $\tau_{s h}$ é função dependente da espessura teórica e da resistência à compressão. Todos os parâmetros aqui mencionados podem ser obtidos a partir das equações completas e tabelas disponíveis no trabalho dos autores.

\subsubsection{GL2000, 2004}

O modelo GL2000 foi desenvolvido por Gardner \& Lockman (2001), com pequenas modificações introduzidas por Gardner (2004). 0 modelo foi feito para se adequar às diretrizes do modelo ACI 209. Apresenta uma metodologia para o cálculo da retração e da 
fluência de concretos de resistência normal. 0 método pode ser usado independentemente dos aditivos químicos ou adições minerais presentes no concreto, da temperatura ou do regime de cura. Os valores previstos podem ser aprimorados pela simples medição do desenvolvimento da resistência do concreto com o tempo e o módulo de elasticidade. Este modelo inclui um termo para secagem antes do carregamento, que se aplica tanto à fluência básica quanto à fluência por secagem.

Os parâmetros necessários para este modelo são a idade do concreto quando a secagem começa, idade do concreto considerando o carregamento, resistência à compressão média do concreto aos 28 dias, resistência à compressão média do concreto considerando o carregamento, módulo de elasticidade do concreto aos 28 dias, módulo de elasticidade do concreto na carga, umidade relativa e relação volume-superfície. A deformação por retração é dada pela equação (3.9).

$$
\varepsilon_{s h}=\left(t, t_{c}\right)=900 k\left(\frac{30}{f_{c m 28}}\right)^{1 / 2}\left(1-1,18 h^{4}\right) \beta\left(t-t_{c}\right) \times 10^{-6}
$$

em que $k$ é a constante de retração que depende do tipo de cimento, $t$ e $t_{c}$ representam a idade do concreto e a idade em que começa a secagem ou o fim da cura, $h$ é a umidade relativa, e $\beta\left(t-t_{c}\right)$ é dada pela equação a seguir:

$$
\beta\left(t-t_{c}\right)=\left[\frac{\left(t-t_{c}\right)}{\left(t-t_{c}\right)+77(V / S)^{2}}\right]^{1 / 2}
$$

em que $V / S$ representa a relação volume-superfície. 0 cálculo da função de conformidade que leva em consideração a fluência no concreto é dado pela equação (3.11).

$$
J\left(t, t_{0}\right)=\frac{1}{E_{c m t 0}}+\frac{\phi_{28}\left(t, t_{0}\right)}{E_{c m 28}}
$$

em que $E_{c m t 0}$ é o módulo de elasticidade na idade de carregamento, $E_{c m 28}$ é o módulo de elasticidade aos 28 dias e $\phi_{28}\left(t, t_{0}\right)$ é dado por:

$$
\phi_{28}\left(t, t_{0}\right)=\Phi\left(t_{c}\right)\left[\begin{array}{l}
2 \frac{\left(t-t_{0}\right)^{0,3}}{\left(t-t_{0}\right)^{0,3}+14}+\left(\frac{7}{t_{0}}\right)^{0,5}\left(\frac{\left(t-t_{0}\right)}{\left(t-t_{0}\right)+7}\right)^{0,5}+ \\
2,5\left(1-1,086 h^{2}\right)\left(\frac{\left(t-t_{0}\right)}{\left(t-t_{0}\right)+0,12(V / S)^{2}}\right)^{0,5}
\end{array}\right]
$$

em que $\Phi\left(t_{c}\right)$ é dado pela equação (3.13).

Todos os parâmetros aqui mencionados podem ser obtidos a partir das equações completas e tabelas disponíveis nos trabalhos dos autores. 


$$
\Phi\left(t_{c}\right)=\left[1-\left(\frac{\left(t-t_{0}\right)}{\left(t-t_{0}\right)+0,12(V / S)^{2}}\right)^{0,5}\right]^{0,5}
$$

\subsubsection{ACI, 2008}

O modelo ACI 209 (2008) foi desenvolvido inicialmente por Branson e Christiason em 1971, com modificações posteriores introduzidas no ACI 209R-82 (ACI Committee 209, 1982), e incorporado em 1992 ao ACI 209R-92. Os modelos preditivos das tensões de fluência e retração em função do tempo têm o mesmo princípio: uma curva hiperbólica que tende a um valor assintótico chamado de valor final. A configuração destas equações é pensada para ser apropriada para finalidades de projeto, em que o conceito do valor final (no tempo) é modificado pela relação de tempo (desenvolvimento tempo-dependente) para alcançar o resultado desejado. A forma da curva e o valor final dependem de vários fatores, tais como condições de cura, idade na aplicação da carga, proporção da mistura, temperatura ambiente, umidade, entre outros.

A deformação por retração é dada pela equação (3.14):

$$
\varepsilon_{s h}\left(t, t_{c}\right)=\frac{\left(t-t_{c}\right)^{\alpha}}{f+\left(t-t_{c}\right)^{\alpha}} 780\left(\gamma_{s h, t c} \gamma_{s h, R H} \gamma_{s h, v s} \gamma_{s h, s} \gamma_{s h, \psi} \gamma_{s h, c} \gamma_{s h, \alpha}\right) \times 10^{-6}
$$

em que $\left(t-t_{c}\right)$ é o tempo de início de secagem, $f$ e $\alpha$ são constantes para uma determinada forma e tamanho do elemento estrutural, $\gamma_{s h, t c}, \gamma_{s h, R H}, \gamma_{s h, v s}, \gamma_{s h, s}, \gamma_{s h, \psi}, \gamma_{s h, c}$ e $\gamma_{s h, \alpha}$ são parâmetros que representam, respectivamente, a cura inicial, umidade relativa ambiente, tamanho do elemento estrutural em termos da relação volume-superfície, abatimento, agregados finos, quantidade de cimento e percentual de vazios. 0 cálculo da função de conformidade que leva em consideração a fluência no concreto é dado pela equação (3.15).

$$
J\left(t, t_{0}\right)=\frac{1+\phi\left(t, t_{0}\right)}{E_{\text {cmto }}}
$$

em que $E_{c m t o}$ é o módulo de elasticidade no momento do carregamento e $\phi\left(t, t_{0}\right)$ é o coeficiente de fluência dado por:

$$
\phi\left(t, t_{0}\right)=\frac{\left(t-t_{0}\right)^{\psi}}{d+\left(t-t_{0}\right)^{\psi}} 2,35\left(\gamma_{c, t o} \gamma_{c, R H} \gamma_{c, v s} \gamma_{c, s} \gamma_{c, \psi} \gamma_{s h, \alpha}\right)
$$

em que $\left(t-t_{0}\right)$ é o tempo desde a aplicação da carga, $d$ e $\psi$ são constantes para uma determinada forma e tamanho do elemento estrutural, $\gamma_{c, t o}, \gamma_{c, R H}, \gamma_{c, v s}, \gamma_{c, s}, \gamma_{c, \psi}$ e $\gamma_{s h, \alpha}$ são 
parâmetros que representam, respectivamente, a idade do fator de carregamento, umidade relativa ambiente, tamanho do elemento estrutural, abatimento, agregados finos, quantidade de cimento e percentual de vazios. Todos os parâmetros aqui mencionados podem ser obtidos a partir das equações completas e tabelas disponíveis nos trabalhos dos autores.

\subsubsection{JSCE, 2010}

O modelo JSCE (2010) foi obtido a partir das especificações disposta no livro Standard specifications for concrete structures criadas pela Sociedade de Engenheiros Civis do Japão, que buscam refletir as tecnologias de ponta no campo do concreto estrutural, e fornecem normas relacionadas aos aspectos técnicos das estruturas de concreto em uma série de etapas, desde o planejamento até a manutenção.

A JSCE (2010) recomenda que as deformações por retração e fluência utilizadas para efeitos de verificação devem ser determinadas com base nos valores obtidos a partir dos ensaios de deformação ou de dados anteriores. Caso não haja dados disponíveis, o valor das deformações pode ser calculados a partir das equações (3.17) e (3.22). A retração e a fluência do concreto são afetadas pelas propriedades do agregado e do cimento, compactação do concreto e condições de cura, bem como temperatura e umidade em torno das estruturas, forma e dimensão das seções transversais dos elementos, e proporção dos materiais presentes no concreto. A retração pode ser calculada pela equação a seguir:

$$
\varepsilon_{c s}\left(t, t_{0}\right)=\left[1-\exp \left\{-0,108\left(t-t_{0}\right)^{0,56}\right\}\right] \varepsilon_{s h}
$$

em que $\varepsilon_{s h}$ é o valor final da retração, dado por:

$$
\varepsilon_{\text {sh }}=-50+78[1-\exp \{(R H / 100)\}]+38 \ln W-5[\ln (V / S / 10)]^{2}
$$

em que $R H$ é a umidade relativa, $W$ é a quantidade de água presente no concreto e $V / S$ representa a relação volume-superfície. Nos casos de concreto de alta resistência, o modelo leva em consideração a retração autógena, de modo que a deformação por retração passa a ser dada pela equação (3.19).

$$
\varepsilon_{c s}\left(t, t_{0}\right)=\varepsilon_{d s}\left(t, t_{0}\right)+\varepsilon_{a s}\left(t, t_{0}\right)
$$

em que $\varepsilon_{d s}\left(t, t_{0}\right)$ é a deformação de retração por secagem e $\varepsilon_{a s}\left(t, t_{0}\right)$ é a deformação de retração autógena, dadas pelas seguintes equações:

$$
\varepsilon_{d s}\left(t, t_{0}\right)=\frac{\alpha(1-R H / 100) W}{1+150 \exp \left\{-500 / f_{c 28}\right\}} \frac{1}{1+\left(10^{-4}\left[15 \exp \left\{0,007 f_{c 28}\right\}+0,25 W\right]\right) t_{0}} \frac{\left(t-t_{0}\right)}{\beta+\left(t-t_{0}\right)}
$$




$$
\varepsilon_{a s}\left(t, t_{0}\right)=\gamma[3070 \exp \{-7,2(W / C)\}]\left\{\left[1-\exp \left\{-a\left(t-t_{s}\right)^{b}\right\}\right]-\left[1-\exp \left\{-a\left(t_{0}-t_{s}\right)^{b}\right\}\right]\right\}
$$

em que $\alpha$ é um coeficiente relacionado ao tipo de cimento, $\beta$ representa a dependência temporal da retração por secagem, $\gamma$ é um coeficiente que representa a influência do tipo de cimento e aditivos, $W / C$ representa a relação água/cimento, $a$ e $b$ são coeficientes que representam a característica do progresso da retração autógena, e $t_{s}$ representa o início considerado da retração autógena. 0 modelo fornece também a deformação causada pela fluência por unidade de tensão dada pela equação (3.22).

$$
\varepsilon_{c c}\left(t, t^{\prime}, t_{0}\right) / \sigma_{c p}=\left[1-\exp \left\{-0,09\left(t-t^{\prime}\right)^{0,06}\right\}\right]\left(\varepsilon_{b c}+\varepsilon_{d c}\right)
$$

em que $t_{0}, t^{\prime}$ e $t$ representam, respectivamente, o início da secagem, o início do carregamento, duração do carregamento, $\varepsilon_{b c}$ e $\varepsilon_{d c}$ representam os valores finais das deformações devido à fluência básica e fluência por secagem, calculadas pelas equações a seguir:

$$
\begin{aligned}
& \varepsilon_{b c}=15(C+W)^{2,0}(W / C)^{2,4}\left(\ln t^{\prime}\right)^{-0,67} \\
& \varepsilon_{d c}=4500(C+W)^{1,4}(W / C)^{4,2}[\ln (V / S / 10)]^{-2,2}(1-R H / 100)^{0,36} t_{0}^{-0,30}
\end{aligned}
$$

em que $C$ é a quantidade de cimento presente no concreto. Quando a relação a/c é reduzida para aumentar a resistência à compressão, caso dos concretos de alta resistência, a equação (3.22) passa ter a seguinte forma:

$$
\varepsilon_{c c}\left(t, t^{\prime}, t_{0}\right) / \sigma_{c p}=\frac{4 W(1-R H / 100)+350}{12+f_{c}\left(t^{\prime}\right)} \ln \left(t-t^{\prime}+1\right)
$$

em que $f_{c}$ representa a resistência à compressão do concreto no tempo $t^{\prime}$.

Todos os parâmetros aqui mencionados podem ser obtidos a partir das equações completas e tabelas disponíveis nos trabalhos dos autores.

\subsubsection{FIB, 2012}

O Model Code 2010 foi desenvolvido pela Federação Internacional de Concreto Estrutural - FIB. O modelo considera não somente as demandas tradicionais como a segurança e serviço, mas também os critérios de projeto de durabilidade e sustentabilidade (FIB, 2012).

As equações para calcular a deformação por fluência são empíricas e foram calibradas com base em ensaios laboratoriais em concretos estruturais. A fluência total é dividida em fluência básica e fluência por secagem, refletindo os diferentes mecanismos físicos associados. 
Neste modelo são tomados como parâmetros aqueles que são normalmente conhecidos pelo projetista, ou seja, a resistência característica à compressão do concreto, as dimensões do elemento, a umidade relativa, a idade do carregamento, a duração do carregamento e o tipo de cimento. Enfatiza-se que neste modelo a fluência não depende da resistência à compressão ou da idade considerando a carga, mas da composição e grau de hidratação.

A fluência do concreto diminui com a redução da relação a/c, diminuição do teor de pasta de cimento, aumento da rigidez dos agregados e aumento do grau de hidratação. A retração do concreto, assim como a fluência, não depende da resistência à compressão do material. A retração por secagem diminui com a redução da relação a/c e diminuição do teor de cimento, enquanto que a retração autógena aumenta com a diminuição da relação a/c e diminui com a redução do teor de cimento. A resistência à compressão serve como um parâmetro de substituição conveniente, sempre conhecido na fase de concepção.

A deformação por fluência, neste modelo, é dada por:

$$
\varepsilon_{c c}\left(t, t_{0}\right)=\frac{\sigma_{c}\left(t_{0}\right)}{E_{c i}} \varphi\left(t, t_{0}\right)
$$

em que $\sigma_{c}\left(t_{0}\right)$ é a tensão de compressão, $E_{c i}$ é o módulo de elasticidade aos 28 dias, e o coeficiente de fluência $\varphi\left(t, t_{0}\right)$ é dado por:

$$
\varphi\left(t, t_{0}\right)=\varphi_{b c}\left(t, t_{0}\right)+\varphi_{d c}\left(t, t_{0}\right)
$$

em que $\varphi_{b c}\left(t, t_{0}\right)$ é a fluência básica, e $\varphi_{d c}\left(t, t_{0}\right)$ é a fluência por secagem, dadas por:

$$
\begin{aligned}
& \varphi_{b c}\left(t, t_{0}\right)=\beta_{b c}\left(f_{c m}\right) \ln \left(\left(\frac{30}{t_{0, a d j}}+0,035\right)^{2}\left(t-t_{0}\right)+1\right) \\
& \varphi_{d c}\left(t, t_{0}\right)=\beta_{d c}\left(f_{c m}\right) \beta(R H)\left(\frac{1}{0,1+t_{0, a d j}^{0,2}}\right) \ln \left(\left(\frac{30}{t_{0, a d j}}+0,035\right)^{2}\left(t-t_{0}\right)+1\right)
\end{aligned}
$$

em que $\beta_{b c}\left(f_{c m}\right)$ e $\beta_{d c}\left(f_{c m}\right)$ são os parâmetros relacionados à resistência à compressão média do concreto aos 28 dias, $\beta(R H)$ é o parâmetro relacionado à umidade relativa, $t$ é a idade do concreto, $t_{0}$ é a idade do concreto com o carregamento e $t_{0, a d j}$ é o ajuste na idade do concreto relativa ao tipo de cimento.

A deformação devido à retração é dada por:

$$
\varepsilon_{c s}\left(t, t_{s}\right)=\varepsilon_{c a s}(t)+\varepsilon_{c d s}\left(t, t_{s}\right)
$$

em que $\varepsilon_{c a s}(t)$ representa a retração autógena e $\varepsilon_{c d s}\left(t, t_{s}\right)$ representa a retração por secagem, expressa pelas seguintes equações: 


$$
\begin{aligned}
& \varepsilon_{c a s}(t)=-\alpha_{a s}\left(\frac{f_{c m} / 10}{6+f_{c m} / 10}\right)^{2,5}(1-\exp \{-0,2 \sqrt{t}\}) \times 10^{-6} \\
& \varepsilon_{c d s}\left(t, t_{s}\right)=\left[\left(220+110 \alpha_{d s 1}\right) \exp \left\{-\alpha_{d s 2} f_{c m}\right\}\right]\left(\frac{\left(t-t_{s}\right)}{0,035 h^{2}+\left(t-t_{\sigma}\right)}\right)^{0,5} \beta(R H) \times 10^{-6}
\end{aligned}
$$

em que $\alpha_{a s}, \alpha_{d s 1}$ e $\alpha_{d s 2}$ são coeficientes relacionado ao tipo de cimento, $t_{s}$ é a idade do concreto no início da secagem e $h$ é um coeficiente relacionado a geometria do elemento estrutural. Todos os parâmetros aqui mencionados podem ser obtidos a partir das equações completas e tabelas disponíveis nos trabalhos dos autores.

\subsubsection{B4, 2015}

O modelo B4 representa uma melhoria em relação ao modelo B3, calibrado com base em uma série de dados, desenvolvido pela Universidade de Northwestern. As fórmulas relacionadas aos parâmetros de fluência e retração sobre a resistência do concreto, proporção dos materiais presentes no concreto, tipos de cimento e agregados e métodos de cura foram completamente revisadas e calibradas por meio da otimização estatística de uma nova e extensa base de dados de testes laboratoriais. Uma das principais mudanças foi que a expansão da base de dados também possibilitou incluir no modelo a retração autógena, e ainda considerar outras influências como o tipo de agregado (mineralogia), e estender a aplicabilidade aos concretos modernos (BAŽANT \& RILEM, 2015).

A deformação por retração passa a ter, então, a seguinte forma:

$$
\varepsilon_{\text {sh,total }}\left(t, t_{0}\right)=\varepsilon_{s h}\left(t, t_{0}\right)+\varepsilon_{\text {au }}\left(t, t_{0}\right)
$$

em que $\varepsilon_{a u}\left(t, t_{0}\right)$ é a deformação devido à retração autógena, dada pela fórmula (3.35), e a deformação devido à retração por secagem $\varepsilon_{s h}\left(t, t_{0}\right)$ continua sendo dada pela equação (3.1), com mudança no termo $\varepsilon_{\text {shoo }}\left(t_{0}\right)$, assumindo a seguinte configuração:

$$
\varepsilon_{s h \infty}\left(t_{0}\right)=-\varepsilon_{0} k_{\varepsilon a} \frac{E\left(7 \beta_{T h}+600 \beta_{T s}\right)}{E\left(t_{0}+\tau_{s h} \beta_{T s}\right)}
$$

em que $k_{\varepsilon a}$ é um fator relacionado ao tipo de agregado presente no concreto, $\tau_{s h}$ é o intervalo de retração, $\beta_{T h}$ e $\beta_{T s}$ são parâmetros relacionados à umidade e à temperatura, e $\varepsilon_{0}$ é um parâmetro relacionado à proporção dos materiais presentes no concreto.

$$
\varepsilon_{a u}\left(t, t_{0}\right)=\varepsilon_{a u \infty}\left[1+\left(\frac{\tau_{a u}}{t+t_{0}}\right)^{\alpha}\right]^{r_{t}}, \quad \alpha=r_{a}\left(\frac{w / c}{0,38}\right)
$$


em que $w / c$ é a relação água/cimento, $\varepsilon_{a u \infty}$ e $\tau_{a u}$ são dadas pelas fórmulas a seguir:

$$
\begin{aligned}
\varepsilon_{a u \infty} & =-\varepsilon_{a u, c e m}\left(\frac{a / c}{6}\right)^{r_{s a}}\left(\frac{w / c}{0,38}\right)^{r_{c w}} \\
\tau_{a u} & =\tau_{a u, c e m}\left(\frac{w / c}{0,38}\right)^{r_{\tau w}}
\end{aligned}
$$

em que $a / c$ é a relação agregado/cimento, $r_{t}, r_{a}, r_{\varepsilon a}, r_{\varepsilon w}, r_{\tau w}, \varepsilon_{a u, c e m}$ e $\tau_{a u, c e m}$ são parâmetros relacionados ao tipo de cimento.

As fórmulas (3.4), (3.5) e (3.6) relativas à fluência permanecem as mesmas para o modelo B4, havendo alteração no cálculo da função de conformidade para a fluência por secagem, passando a ter a seguinte forma:

$$
C_{d}\left(t, t_{0}, t_{c}\right)=q_{5}\left[\exp \left\{-p_{5 H} H\left(t, t_{c}\right)\right\}-\exp \left\{-p_{5 H} H_{c}\left(t_{0}, t_{c}\right)\right\}\right]^{1 / 2}
$$

em que $p_{5 H}$ é um parâmetro relacionado ao tipo de cimento.

Uma das principais diferenças entre os modelos B4 e B3 está nos parâmetros utilizados nas equações, que embora tendo o mesmo significado, quando há parâmetros comuns a ambos os modelos, o modelo B4 trabalha com esses após um refinamento, apresentados sob a forma de tabela e/ou equações.

Todos os parâmetros aqui mencionados podem ser obtidos a partir das equações completas e tabelas disponíveis nos trabalhos dos autores.

Neste trabalho optou-se pela implementação do modelo B4 (BAŽANT \& RILEM, 2015), por ser uma versão mais atualizada do modelo B3 (BAŽANT \& BAWEJA, 2000), possuindo maior refinamento quanto aos parâmetros utlizados. Além disso, implementou-se também os modelos JSCE (JSCE, 2010) e Model Code 2010 (FIB, 2012), devido à atualidade e reconhecimento destes modelos na literatura e meio técnico. Ainda, sabendo que este trabalho não tem como foco as estruturas de concreto de alta resistência, optou-se pela desconsideração da parcela referente à retração autógena de cada modelo adotado, uma vez que esta é consideravelmente pequena em concretos de resistência convencional. 


\section{CAPÍTULO 4}

\section{MODELAGEM DO CONCRETO POR MEIO DO MEFP}

Neste capítulo é abordada a modelagem do concreto por meio do Método dos Elementos Finitos Posicional (MEFP). A fundamentação teórica que antecede a implementação do método foi realizada com base nos livros de Timoshenko \& Goodier (1951), Novozhilov (1953), Ogden (1997), Villaça \& Garcia (1998), Holzapfel (2000) e Proença (2006). A dedução do MEFP proposto por Coda (2003) foi feita com base no trabalho do próprio autor, além dos auxílios dos trabalhos de Coda \& Greco (2004), Greco \& Coda (2006), Coda \& Paccola (2007), Pascon (2012), Sampaio (2014), Friedel (2016) e Kzam (2016).

A propriedade da elasticidade está presente, em certa medida, em todos os materiais estruturais. Isso significa que, se as forças externas ao produzirem uma deformação na estrutura não excederem um determinado limite, a deformação desaparecerá ao cessar das forças. Neste trabalho considera-se que a matéria de um corpo elástico é homogênea e continuamente distribuída sobre o seu volume, de modo que não foi considerado a microscopia do material. Assim, o menor elemento cortado do corpo possuirá as mesmas propriedades físicas específicas do corpo estrutural, sendo, portanto, uma abordagem macroscópica. É considerado ainda a isotropia do material, ou seja, as propriedades elásticas são as mesmas em todas as direções.

O concreto, a princípio, não satisfaz as suposições adotadas acima, não sendo homogêneo, pois há variação das propriedades elásticas do agregado para matriz cimentícia. Entretanto, as soluções da teoria da elasticidade baseadas nas suposições de homogeneidade e isotropia podem ser aplicadas às estruturas de concreto de forma simplificada. Essa aplicação decorre, primeiro, da consideração da aleatoriedade da distribuição dos agregados na matriz cimentícia, de maneira que as propriedades elásticas do concreto são resultantes das médias das propriedades dos agregados e da matriz cimentícia, sendo possível, portanto, tratar o concreto como material isotrópico. E, segundo, as dimensões geométricas que definem a forma de um elemento estrutural de concreto são grandes em comparação às 
dimensões de um único agregado, de modo que a suposição de homogeneidade pode ser usada com precisão para a abordagem em macroescala deste trabalho.

Adotando, então, o concreto como material contínuo, para elaboração de observações físicas de um determinado corpo de concreto é necessário estabelecer configurações específicas. Para fins de referência, é, portanto, conveniente identificar uma certa configuração fixa (mas arbitrariamente escolhida) do corpo de modo que as partículas do corpo possam então ser rotuladas durante o movimento nessa configuração. Na Figura 4.1 observam-se duas configurações para um determinado corpo sujeito a diferentes solicitações, em que há dois vetores infinitesimais $d x$ e $d y$ fixados nas configurações inicial e atual do corpo contínuo, respectivamente. 0 corpo $\Omega_{0}$ representa a configuração inicial indeformada, enquanto o corpo $\Omega$ representa a configuração atual deformada. 0 vetor $d y$ representa o vetor $d x$ após a deformação causada pelos carregamentos na configuração inicial. A configuração atual do corpo $\Omega$ é dada, então, por uma função mudança de configuração, em que a letra $x$ é usada para representar as coordenadas da configuração inicial e a letra $y$ para representar as coordenadas da configuração atual.

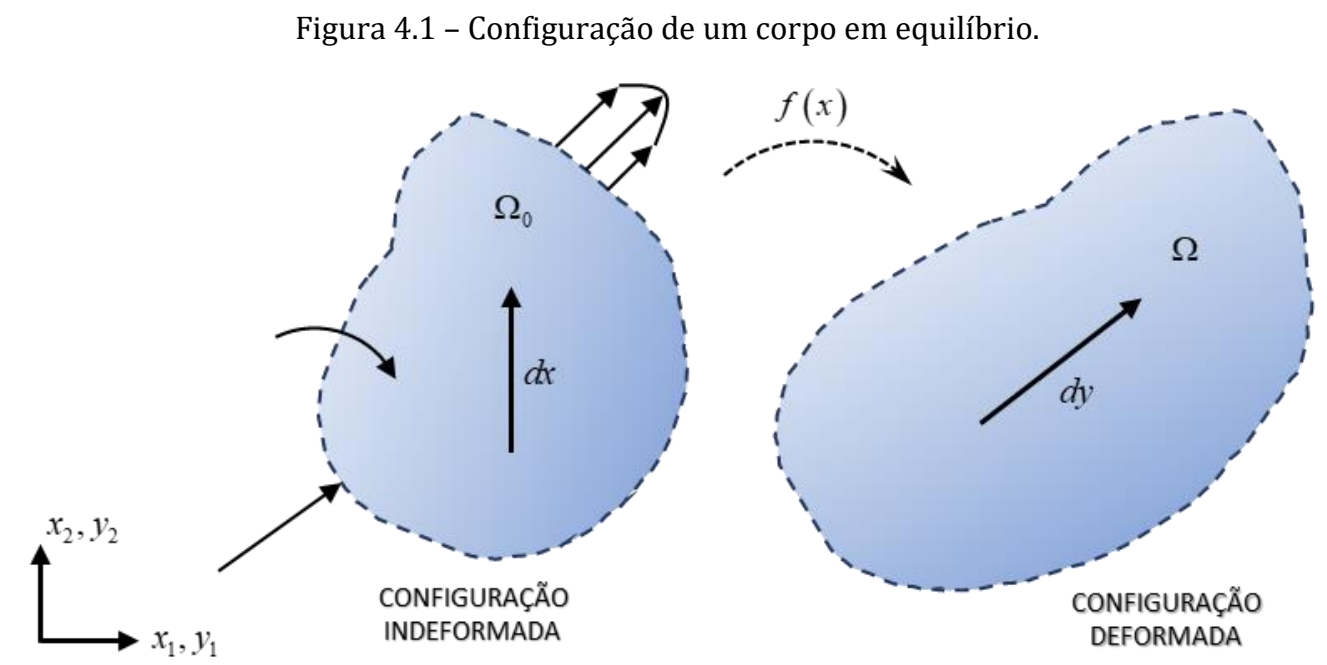

A manifestação de um movimento através da família de configurações depende da escolha do referencial. Neste aspecto destacam-se duas representações que são usualmente utilizadas na mecânica do contínuo para descrever o comportamento do material, sendo a descrição lagrangiana (material) e a descrição euleriana (espacial). A descrição lagrangiana é comumente utilizada na mecânica dos sólidos, em que faz uso de referenciais fixos para caracterizar o comportamento da estrutura, usualmente tendo como referencial a configuração inicial indeformada, representada pelo corpo $\Omega_{0}$. Na descrição material, a análise é direcionada a uma partícula, e observa-se o que acontece a ela enquanto se move no 
espaço. Já a descrição Euleriana, empregada principalmente na mecânica dos fluidos, utiliza referenciais móveis para caracterizar o comportamento do objeto em análise, tendo como referencial a configuração atual deformada, representada pelo corpo $\Omega$. Na descrição espacial, a análise é direcionada a um ponto (ou região) no espaço, e estuda-se o que acontece neste ponto ao longo do tempo.

Ao considerar um elemento infinitesimal do corpo, as deformações passam a ser os alongamentos e contrações longitudinais e transversais. Observa-se, então, que a translação e rotação de um elemento de volume não são características de sua deformação. Neste contexto, o conceito de pequenas deformações não está associado à pequenez dos deslocamentos e rotações. Mesmo que pequenos deslocamentos e rotações impliquem em pequenas deformações, o contrário é falso. É o caso da formulação de não linearidade geométrica (NLG), em que se admite a situação de grandes deslocamentos e pequenas deformações, permitindo que as posições atuais e finais sejam tratadas de maneira inteiramente distintas.

Neste contexto se considera o Método dos Elementos Finitos Posicional (MEFP) proposto por Coda (2003), pois neste método a função mudança de configuração é utilizada para a definição de grandezas não lineares de tensão e deformação. Deste modo, as posições nodais constituem valores atuais de cada nó de modo a considerar a não linearidade geométrica. 0 objetivo do MEFP não é alcançar um modelo melhor que os já existentes na literatura, mas oferecer uma maneira alternativa de realizar o procedimento numérico para análise não linear geométrica.

O MEFP é uma formulação simples, sendo alternativa ao método dos elementos finitos tradicional, pois é baseado na posição como variável incógnita do problema. A deformação é determinada diretamente pela variação da posição. O MEFP faz uso da função mudança de configuração para escrever a energia potencial total $\Pi$ em função das posições nodais, utilizando a energia específica de deformação $\mathbb{U}_{e}$ e o potencial das cargas externas $\mathbb{P}$.

$$
\Pi=\mathbb{U}_{e}+\mathbb{P}
$$

Sabe-se, que, para este trabalho, em que se empregará elementos de concreto em resistência convencional, a abordagem não linear geométrica é dispensável. Entretanto, o MEFP quando comparado às contrapartes clássicas, possui uma formulação simplificada, sendo justamente este aspecto seu principal atributo, além de ser possível utilizá-lo em aplicações práticas, apresentando boa convergência e precisão. Deste modo, mesmo não 
sendo escopo deste trabalho a análise não linear geométrica, a simplicidade do MEFP justifica sua utilização.

\subsection{MUDANÇA DE CONFIGURAÇÃO}

No MEFP, para a formulação de um determinado elemento finito, são necessárias três configurações, conforme demonstrado na Figura 4.2: a configuração adimensional de referência $\Omega_{1}$; a configuração inicial indeformada $\Omega_{0}$; e a configuração final deformada $\Omega$. A função mudança de configuração será aquela que determina o movimento de uma partícula de uma configuração a outra. Na Figura 4.2 também são apresentados seus respectivos gradientes $\boldsymbol{A}, \boldsymbol{A}_{0}$ e $\boldsymbol{A}_{1}$. Tratando-se de posição, é possível explicar a função mudança de configuração como uma função matemática que determina o deslocamento, rotação e deformação dos pontos de um elemento, de uma configuração a outra. Para definir o estado de deformação do elemento, utiliza-se o gradiente da função mudança de configuração.

Figura 4.2 - Formulação de um elemento finito posicional 2D.
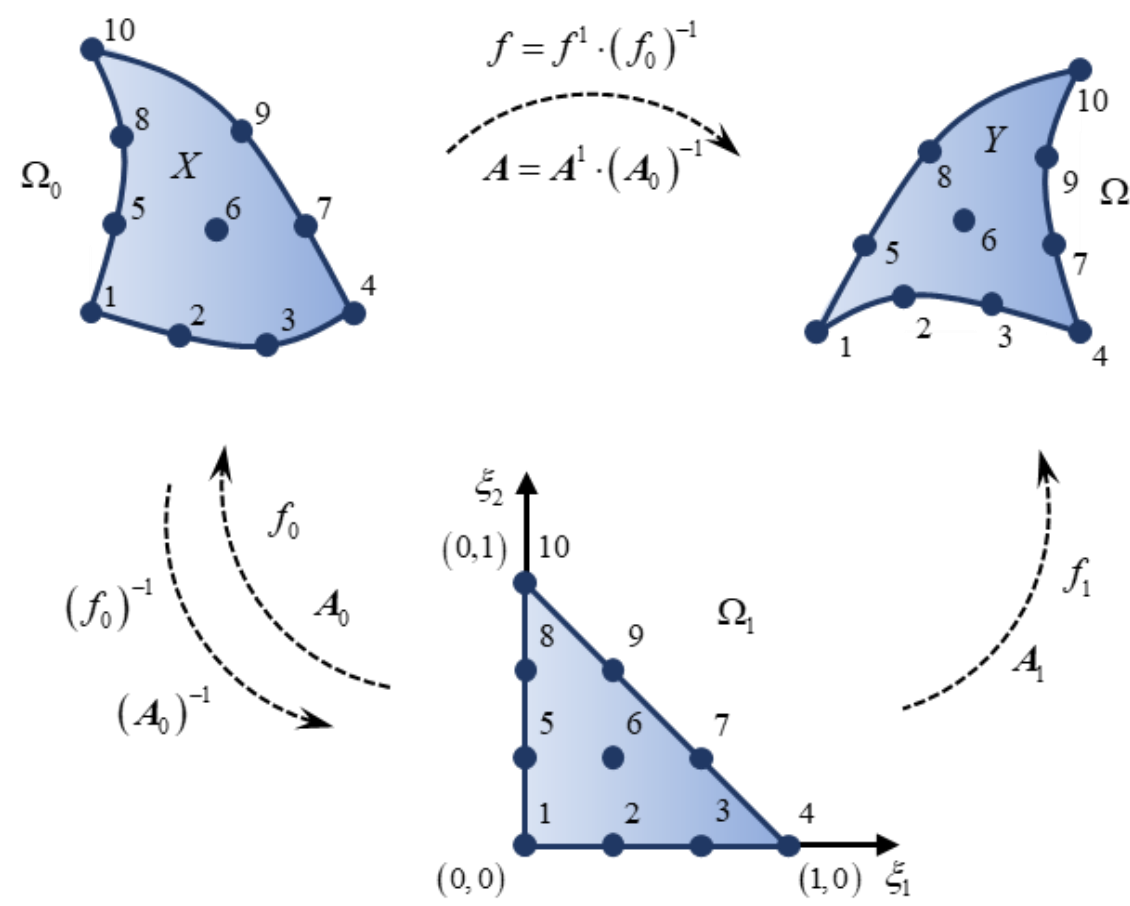

Pela Figura 4.2, a posição inicial e a final são representadas respectivamente pelos campos vetoriais $X$ e $Y$, podendo ser chamados de vetores posição inicial e final. Neste método, as operações diferenciais e integrais são realizadas em relação ao estado inicial do corpo, o que implica em descrição Lagrangiana. Os elementos utilizados neste trabalho são triangulares, de aproximação cúbica, de modo que cada elemento possuirá 10 nós. As funções 
mudança de configuração $f_{0}$ e $f_{1}$ são dadas com relação às coordenadas adimensionais $\xi_{1}$ e $\xi_{2}$. As posições são expressas matematicamente da seguinte maneira:

$$
f_{0}=(X)^{k} \varphi_{k}\left(\xi_{1}, \xi_{2}\right) \quad f_{1}=(Y)^{k} \varphi_{k}\left(\xi_{1}, \xi_{2}\right)
$$

em que $(X)^{k}$ e $(Y)^{k}$ representam, respectivamente, as coordenadas iniciais do nó $k$, $\varphi_{k}\left(\xi_{1}, \xi_{2}\right)$ representa a função de forma com relação ao nó $k$, escritas de maneira explícita a seguir:

$$
\begin{aligned}
& \varphi_{1}\left(\xi_{1}, \xi_{2}, \xi_{3}\right)=\frac{1}{2} \xi_{1}\left(3 \xi_{1}-1\right)\left(\xi_{1}-2\right) \\
& \varphi_{2}\left(\xi_{1}, \xi_{2}, \xi_{3}\right)=\frac{9}{2} \xi_{2} \xi_{1}\left(3 \xi_{1}-1\right) \\
& \varphi_{3}\left(\xi_{1}, \xi_{2}, \xi_{3}\right)=\frac{9}{2} \xi_{1} \xi_{2}\left(3 \xi_{2}-1\right) \\
& \varphi_{4}\left(\xi_{1}, \xi_{2}, \xi_{3}\right)=\frac{1}{2} \xi_{2}\left(3 \xi_{2}-1\right)\left(\xi_{2}-2\right) \\
& \varphi_{5}\left(\xi_{1}, \xi_{2}, \xi_{3}\right)=\frac{9}{2} \xi_{3} \xi_{1}\left(3 \xi_{1}-1\right) \\
& \varphi_{6}\left(\xi_{1}, \xi_{2}, \xi_{3}\right)=27 \xi_{1} \xi_{2} \xi_{3} \\
& \varphi_{7}\left(\xi_{1}, \xi_{2}, \xi_{3}\right)=\frac{9}{2} \xi_{3} \xi_{2}\left(3 \xi_{2}-1\right) \\
& \varphi_{8}\left(\xi_{1}, \xi_{2}, \xi_{3}\right)=\frac{9}{2} \xi_{1} \xi_{3}\left(3 \xi_{3}-1\right) \\
& \varphi_{9}\left(\xi_{1}, \xi_{2}, \xi_{3}\right)=\frac{9}{2} \xi_{2} \xi_{3}\left(3 \xi_{3}-1\right) \\
& \varphi_{10}\left(\xi_{1}, \xi_{2}, \xi_{3}\right)=\frac{1}{2} \xi_{3}\left(3 \xi_{3}-1\right)\left(\xi_{3}-2\right)
\end{aligned}
$$

em que $\xi_{3}=1-\xi_{1}-\xi_{2}$.

$\boldsymbol{A}_{0}$ e $\boldsymbol{A}_{1}$ são os gradientes da função mudança de configuração inicial e atual, respectivamente, sendo escritos da seguinte forma:

$$
\boldsymbol{A}_{0}=\frac{\partial \vec{f}_{0}}{\partial \vec{X}} \quad \boldsymbol{A}_{1}=\frac{\partial \vec{f}_{1}}{\partial \vec{Y}}
$$

Ao considerar as funções de forma, $\boldsymbol{A}_{0}$ e $\boldsymbol{A}_{1}$ adotam a seguinte forma:

$$
\boldsymbol{A}_{0}=\left(\begin{array}{ll}
\frac{\partial \varphi_{k}}{\partial \xi_{1}} X_{1}^{k} & \frac{\partial \varphi_{k}}{\partial \xi_{2}} X_{1}^{k} \\
\frac{\partial \varphi_{k}}{\partial \xi_{1}} X_{2}^{k} & \frac{\partial \varphi_{k}}{\partial \xi_{2}} X_{2}^{k}
\end{array}\right)
$$




$$
\boldsymbol{A}_{1}=\left(\begin{array}{ll}
\frac{\partial \varphi_{k}}{\partial \xi_{1}} Y_{1}^{k} & \frac{\partial \varphi_{k}}{\partial \xi_{2}} Y_{1}^{k} \\
\frac{\partial \varphi_{k}}{\partial \xi_{1}} Y_{2}^{k} & \frac{\partial \varphi_{k}}{\partial \xi_{2}} Y_{2}^{k}
\end{array}\right)
$$

O gradiente de transformação $\boldsymbol{A}$ é um tensor de segunda ordem, que fornece as informações quanto à variação da função $f$ com relação às coordenadas dos materiais, e representa a maneira como $\Omega_{0}$ se transforma em $\Omega$, após a deformação, sendo calculado da seguinte forma:

$$
\boldsymbol{A}=\boldsymbol{A}_{1} \cdot\left(\boldsymbol{A}_{0}\right)^{-1}
$$

A partir do gradiente da função mudança de configuração pode-se definir uma série de medidas de deformação. A adotada neste trabalho é a medida de deformação GreenLagrange.

\subsection{TENSOR DE DEFORMAÇÃO DE GREEN-LAGRANGE}

Antes de definir o tensor de Green-Lagrange, é necessário definir o tensor de deformação à direita de Cauchy-Green, que representa o estiramento quadrático de uma fibra do sólido na configuração atual, definido a seguir:

$$
\boldsymbol{C}=\boldsymbol{A}^{t} \cdot \boldsymbol{A}
$$

O tensor de Cauchy-Green a direita, como também é conhecido, é simétrico positivo e representa a medida Lagrangiana do alongamento de uma fibra do sólido. 0 tensor de deformações Green-Lagrange, medida não linear mais simples obtida do tensor de CauchyGreen, na maior parte dos problemas da mecânica dos sólidos deformáveis satisfaz as aplicações da engenharia estrutural. Esse tensor é calculado da seguinte maneira:

$$
\boldsymbol{E}=\frac{1}{2}(\boldsymbol{C}-\boldsymbol{I})
$$

em que $I$ é o tensor identidade de segunda ordem. Ao tensor de Green-Lagrange é subtraída a composição aditiva, equação (4.10), das deformações relacionadas à RAA, retração e fluência representadas pelos termos $\boldsymbol{\varepsilon}_{R A A}, \boldsymbol{\varepsilon}_{\text {fluência }}$ e $\boldsymbol{\varepsilon}_{\text {retração }}$, respectivamente. Essa adição é válida por se trabalhar no regime de pequenas deformações.

$$
\boldsymbol{\varepsilon}=\boldsymbol{\varepsilon}_{R A A}+\boldsymbol{\varepsilon}_{\text {fluência }}+\boldsymbol{\varepsilon}_{\text {retração }}
$$

Quando ocorre uma mudança de configuração no corpo que envolve pequenas deformações e grandes deslocamentos, o tensor $\boldsymbol{E}$ se mantém como medida válida, pois o 
tensor de deformação Green-Lagrange é invariante com relação aos sistemas de coordenadas e aos movimentos de corpo rígido.

O comportamento de um material pode ser descrito quando se tem o conjugado energético de tensão/deformação de Green-Lagrange. Contudo, essa medida não permite um significado físico se tratando de forças de superfície, de modo que é necessária uma lei constitutiva para então ser descrita a energia de deformação energicamente conjugada.

\subsection{LEI CONSTITUTIVA DE SAINT-VENANT-KIRCHHOFF}

Considerando o comportamento NLG das estruturas, e ainda, um modelo constitutivo para materiais elásticos e isotrópicos, em que a energia específica de deformação é em função da deformação de Green-Lagrange ou de parâmetros a ele relacionados, assim como seus invariantes, a energia de deformação pode ser calculada da seguinte forma:

$$
u_{e}=\frac{1}{2}(\boldsymbol{E}: \mathbb{C}: \boldsymbol{E})
$$

em que $\mathbb{C}$ é o tensor módulo de rigidez elástica, de quarta ordem, calculado do seguinte modo:

$$
\mathbb{C}=\frac{2 G v}{1-2 v} \boldsymbol{I} \otimes \boldsymbol{I}+G \mathbb{I}
$$

sendo $\mathbb{I}$ o tensor de identidade de ordem quatro, $v$ o coeficiente de Poisson, e $G$ o módulo de rigidez transversal, dado por:

$$
G=\frac{E}{2(1+v)}
$$

em que $E$ é o módulo de rigidez longitudinal.

\subsection{TENSOR DE TENSÃO DE PIOLA-KIRCHHOFF DE SEGUNDA ESPÉCIE}

O comportamento de um corpo pode ser descrito a partir de sua lei constitutiva, recorrendo-se ao conceito do conjugado energético das deformações. Assim, o conjugado energético tensão/tensor de deformações de Green-Lagrange, também conhecido como tensor de tensão de Piola-Kirchhoff de segunda espécie, pode ser descrito como:

$$
\frac{\partial u_{e}}{\partial \boldsymbol{E}}=\boldsymbol{S}=\mathbb{C}: \boldsymbol{E}
$$


Apesar de o tensor de Piola-Kirchhoff de segunda espécie não possuir significado físico se tratando de forças de superfície, ele é comumente usado na formulação da lei constitutiva de sólidos deformáveis e na mecânica computacional. No entanto, o tensor $\boldsymbol{S}$, matematicamente ponderado, relaciona-se à medida de tensão de Cauchy, também conhecida como medida de tensão verdadeira, através da equação a seguir:

$$
\boldsymbol{\sigma}=\frac{\boldsymbol{A} \cdot \boldsymbol{S} \cdot \boldsymbol{A}^{t}}{J}
$$

em que $J$ é o jacobiano dado pelo determinante do gradiente $\boldsymbol{A}$.

\subsection{PRINCÍPIO DA CONSERVAÇÃO DA ENERGIA MECÂNICA}

De acordo com o princípio da conservação da energia mecânica, para um corpo submetido à ação de forças conservativas, a energia mecânica total do sistema permanecerá constante. A energia mecânica pode ser expressa como a soma da energia cinética e energia potencial total do sistema. Considerando um regime quase estático de aplicação das forças, pode-se calcular a energia mecânica a partir da contribuição da energia potencial total, expressa pela soma da energia específica de deformação, a energia armazenada no corpo, e o potencial das cargas externas:

$$
\Pi=U_{e}+\mathbb{P}
$$

A energia específica de deformação pode ser expressa, em quantidades lagrangianas, sobre o volume inicial, dada pela seguinte equação:

$$
U_{e}=\int_{\Omega_{0}} u_{e} d V_{0}
$$

0 potencial das cargas externas pode ser expresso a partir do trabalho realizado pela resultante do carregamento na configuração atual, dado pela equação a seguir:

$$
\mathbb{P}=-\overrightarrow{F_{e x t}} \cdot \vec{Y}
$$

O carregamento externo é responsável pela diminuição da capacidade do corpo elástico em armazenar a energia potencial de deformação à medida que se eleva a magnitude das forças, o que resulta no sinal de subtração. Sabendo que a variação da energia potencial total é igual a zero, é necessário determinar o vetor $\vec{Y}$, conforme equação a seguir:

$$
\delta \Pi=\int_{\Omega_{0}} \frac{\partial u_{e}}{\partial \vec{Y}} d V_{0} \cdot \delta \vec{Y}-\overrightarrow{F_{e x t}} \cdot \delta \vec{Y}=0
$$

Isolando $\delta \vec{Y}$ e fazendo uso da equação (4.14), a equação (4.19) assume a seguinte forma: 


$$
\delta \Pi=\left(\int_{\Omega_{0}} \boldsymbol{S}: \frac{\partial \boldsymbol{E}}{\partial \vec{Y}} d V_{0}-\overrightarrow{F_{e x t}}\right) \delta \vec{Y}=0
$$

Deste modo, a equação (4.20) pode ser simplificada na equação (4.21), em que $\overrightarrow{F_{i n t}}$ é o vetor de forças internas.

$$
\int_{\Omega_{0}} S: \frac{\partial \boldsymbol{E}}{\partial \vec{Y}} d V_{0}-\overrightarrow{F_{e x t}}=\overrightarrow{F_{i n t}}-\overrightarrow{F_{e x t}}=0
$$

\subsection{MÉTODO DE NEWTON-RAPHSON}

O sistema de equações a ser resolvido pode ser resumido, então, do seguinte modo:

$$
F_{\text {ext }}-F_{\text {int }}=0
$$

Uma vez que o vetor de forças internas depende de forma não linear das posições, e ainda, a posição atual é arbitrária, utiliza-se o método iterativo de Newton-Raphson, portanto, cria-se um vetor de desbalanceamento g demonstrado na equação (4.23).

$$
F_{\text {ext }}-F_{\text {int }}\left(y_{i}\right)=\mathrm{g}\left(y_{i}\right)
$$

Para que seja possível equilibrar o sistema, faz-se necessário a criação de um novo vetor de forças internas pela imposição de uma correção $\mathrm{g}$, até que g alcance um valor suficientemente pequeno. Sabendo que o carregamento externo independe dos resíduos, g pode ser expandido por meio da série de Taylor:

$$
\mathrm{g}\left(y_{i}\right)=\mathrm{g}\left(y_{i-1}\right)+\left.\frac{\partial \mathrm{g}}{\partial y}\right|_{y_{i-1}}\left(y_{i}-y_{i-1}\right)
$$

Considerando que se deseja que o resíduo seja nulo, o acréscimo das posições pode ser calculado da seguinte forma:

$$
\left.\frac{\partial \mathrm{g}}{\partial y}\right|_{y_{i-1}} \Delta y_{i}=F_{e x t}-F_{i n t}\left(y_{i-1}\right)
$$

A variação do vetor de desbalanceamento, também conhecida como matriz Hessiana, é dada por:

$$
H_{\alpha \beta \gamma \eta}=\left.\frac{\partial \mathrm{g}}{\partial y}\right|_{y_{i-1}}=\frac{\partial^{2} U_{e}}{\partial Y_{\alpha}^{\beta} \partial Y_{\gamma}^{\eta}}
$$

Sabendo o valor de $\Delta y_{i}$, é necessário verificar se ele é pequeno o suficiente considerando uma determinada tolerância. Dessa maneira, pode-se utilizar como critério de 
convergência a equação (4.27), em que \| \| é a norma euclidiana, e tol é uma tolerância adotada para a norma.

$$
\text { erro }=\frac{\left\|\Delta y_{i}\right\|}{\left\|y_{0}\right\|} \leq \text { tol }
$$

\subsection{MATRIZ HESSIANA}

A matriz Hessiana do elemento é uma forma quadrática positivo-definida, calculada por meio da segunda variação da energia de deformação em relação às posições generalizadas, obtida na seguinte equação para o elemento finito triangular:

$$
H_{\alpha \beta \gamma \eta}=\frac{\partial^{2} U_{e}}{\partial Y_{\alpha}^{\beta} \partial Y_{\gamma}^{\eta}}=\int_{0}^{1} \int_{0}^{1-\xi_{1}} \frac{\partial^{2} u_{e}}{\partial Y_{\alpha}^{\beta} \partial Y_{\gamma}^{\eta}} J_{0}\left(\xi_{1}, \xi_{2}\right) d \xi_{1} d \xi_{2}
$$

em que o termo dentro da integral por ser calculado conforme a equação a seguir:

$$
\frac{\partial^{2} u_{e}}{\partial Y_{\alpha}^{\beta} \partial Y_{\gamma}^{\eta}}=\frac{1}{4} \frac{\partial^{2} u_{e}}{\partial \boldsymbol{E} \partial \boldsymbol{E}}: \frac{\partial \boldsymbol{C}}{\partial Y_{\gamma}^{\eta}}: \frac{\partial \boldsymbol{C}}{\partial Y_{\alpha}^{\beta}}+\frac{1}{2} \frac{\partial u_{e}}{\partial \boldsymbol{E}}: \frac{\partial^{2} \boldsymbol{C}}{\partial Y_{\gamma}^{\eta} \partial Y_{\alpha}^{\beta}}
$$

em que o último termo da equação anterior pode ser expresso por:

$$
\frac{\partial^{2} \boldsymbol{C}}{\partial Y_{\gamma}^{\eta} \partial Y_{\alpha}^{\beta}}=\left(\boldsymbol{A}_{0}\right)^{-T} \cdot \frac{\partial\left(\boldsymbol{A}_{1}\right)^{T}}{\partial Y_{\alpha}^{\beta}} \cdot \frac{\partial\left(\boldsymbol{A}_{1}\right)}{\partial Y_{\gamma}^{\eta}} \cdot\left(\boldsymbol{A}_{0}\right)^{-1}+\left(\boldsymbol{A}_{0}\right)^{-T} \cdot \frac{\partial\left(\boldsymbol{A}_{1}\right)^{T}}{\partial Y_{\gamma}^{\eta}} \cdot \frac{\partial\left(\boldsymbol{A}_{1}\right)}{\partial Y_{\alpha}^{\beta}} \cdot\left(\boldsymbol{A}_{0}\right)^{-1}
$$

O tensor hessiano do elemento triangular de 10 nós pode ser organizado na forma de uma matriz hessiana 20x20, assumindo a seguinte configuração:

$$
H_{\alpha \gamma}^{\beta \eta}=\left(\begin{array}{lllll}
h_{1111} & h_{1121} & h_{1112} & & \\
h_{2111} & h_{2121} & h_{2112} & & \\
h_{1211} & h_{1221} & h_{1212} & & \\
& & & \ddots & \\
& & & & h_{[2(\beta-1)+\alpha][2(\eta-1)+\gamma]}
\end{array}\right)
$$

em que $\beta$ e $\eta$ variam de 1 até 10 (número de nós), $\alpha$ e $\gamma$ variam de 1 a 2 (número de direções).

\subsection{FLUXOGRAMA}

A fim de sintetizar o que já foi visto até este ponto, apresenta-se na Figura 4.3 um fluxograma em que se esquematiza a rotina computacional desenvolvida. Antes da utilização do programa desenvolvido, é necessário a geração da malha discretizada em elementos triangulares de aproximação cúbica, para isso se fez uso do software AcadMesh2D. 
AcadMesh2D é um CAD simples acoplado a um gerador de malhas criado para gerar arquivos de saída de modelos de elementos finitos, contendo tanto informações do sólido modelado (material, espessura e malha), quanto das condições de contorno (forças, pressões e deslocamentos aplicados), desenvolvido por Piedade Neto, Fagá Jr. \& Paccola (2012). A malha gerada pelo programa é armazenada em um arquivo de texto.

O fluxograma tem como início, então, a leitura da malha gerada e dos dados de entrada necessários para o cálculo das deformações, como propriedades do concreto e fatores relacionados aos fenômenos de RAA, retração e fluência.

Em seguida é feita a atualização do vetor de forças externas. Após a atualização do vetor, calculam-se as deformações por RAA, retração e fluência. É possível, então, calcular as forças internas e a matriz hessiana, para em seguida aplicar as condições de contornos e calcular o vetor de desbalanceamento.

Após a obtenção do vetor de desbalanceamento, resolve-se o sistema não linear, para em seguida atualizar o vetor posição, verifica-se se este está abaixo de uma determinada tolerância, caso não esteja, calculam-se novamente as forças internas e matriz hessiana, e esse processo se repete até que a tolerância seja respeitada.

Estando o vetor posição abaixo da tolerância desejada, calculam-se, então, as tensões Cauchy a partir do tensor de tensões de Piola-Kirchhoff. Calculadas as tensões e os deslocamentos, verifica-se se o tempo de análise chegou ao fim, caso não tenha chegado, o programa retorna ao cálculo das forças externas e repete-se todo o roteiro.

Ao fim da análise temporal, é gerado, finalmente, o arquivo de saída em formato de arquivo de texto. No arquivo de saída do programa são gravados, para cada passo de tempo, os deslocamentos nas direções x e y, e as tensões em x, y e xy.

A visualização do arquivo de saída é feita pelo software AcadView, sendo este um programa para pós-processamento em elementos finitos 2D e 3D desenvolvido por Paccola \& Coda (2005). Pelo software é possível verificar a deformação da estrutura em cada passo de tempo, bem como o mapa de tensões e deslocamentos em todo o elemento analisado.

Os programas AcadMesh2D e AcadView foram desenvolvidos no Laboratório de Informática e Mecânica Computacional da EESC-USP. As análises dos resultados são realizadas por meio do software Excel para cada exemplo, sendo esta análise disposta no capítulo a seguir. 
Figura 4.3 - Fluxograma esquemático da rotina computacional desenvolvida.

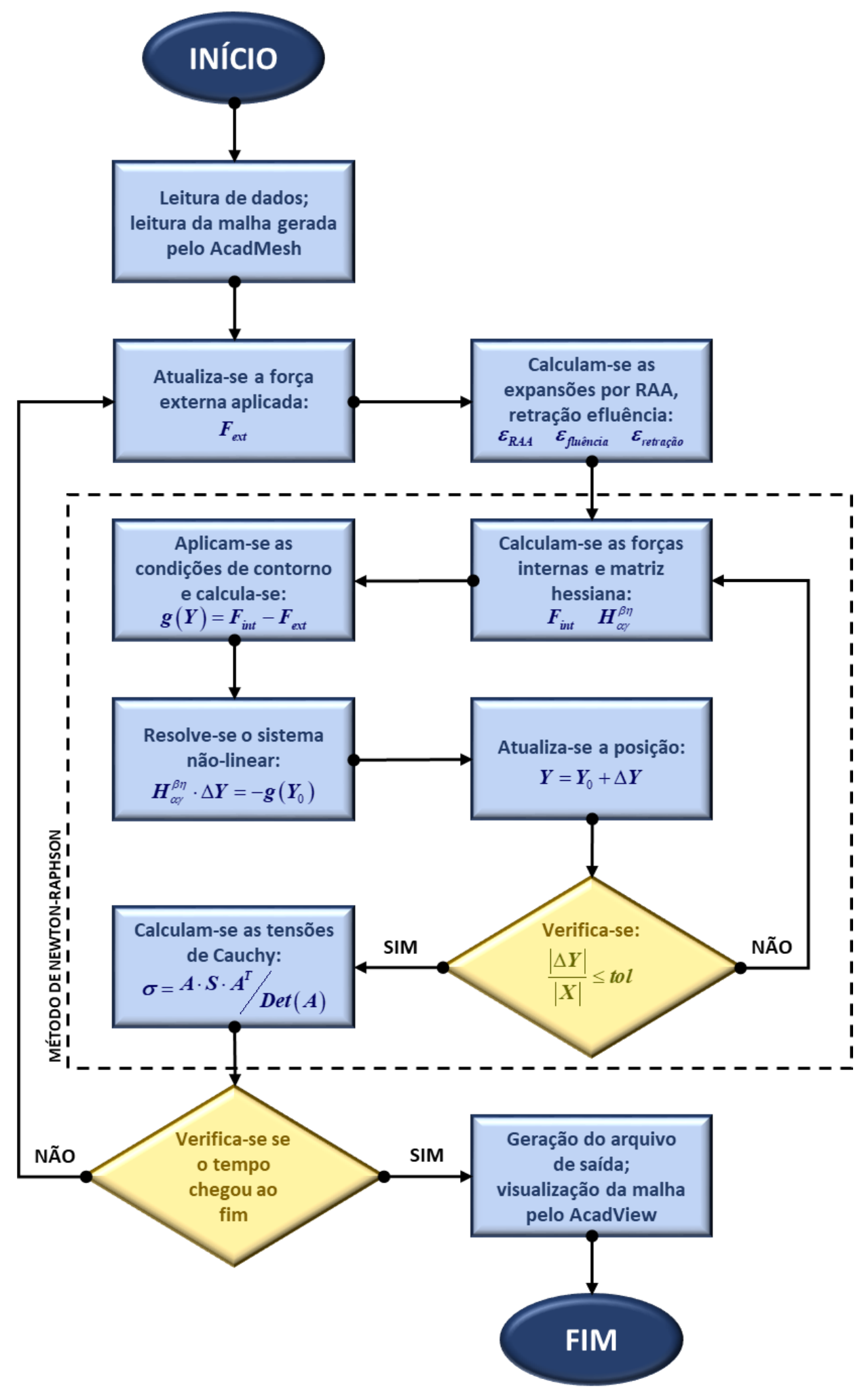




\section{CAPÍTULO 5} RESULTADOS E DISCUSSÕES

Neste capítulo são apresentados os resultados e discussões referentes às modelagens implementadas. 0 primeiro exemplo traz somente a validação do MEF Posicional. 0 segundo mostra a validação da modelagem da RAA, enquanto o terceiro mostra a validação da modelagem da retração e fluência para os três modelos implementados. 0 quarto exemplo é uma aplicação considerando os três fenômenos estudados. E, por fim, o último exemplo se trata de uma análise paramétrica feita para os três fenômenos associados.

\subsection{MEF POSICIONAL}

Este primeiro exemplo tem como objetivo a validação do MEF posicional. Para isto, utilizou-se o trabalho de Mattiasson (1981), que apresentou resultados precisos para estruturas geometricamente não lineares, por meio de integrais elípticas. 0 exemplo em questão se trata de um quadro carregado nos pontos médios de um par de lados opostos, conforme mostrado na Figura 5.1a.

Figura 5.1 - (a) Problema do quadro carregado (b) Malha discretizada do quadro.
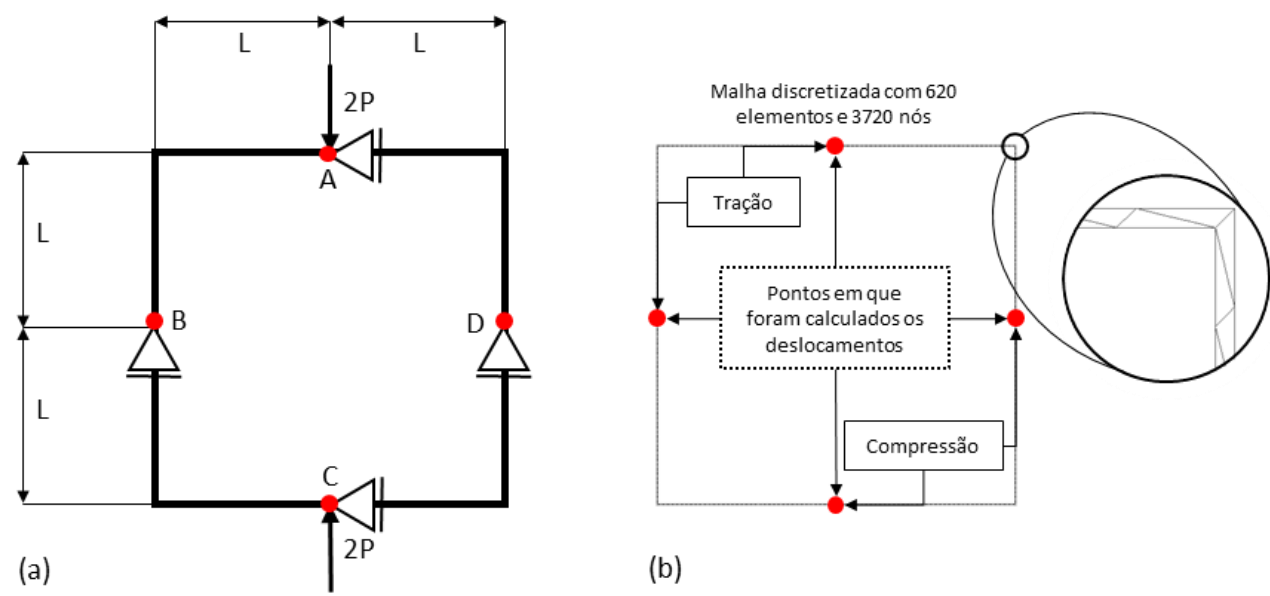

(b)

Para discretização do quadro, foi gerada uma malha com 620 elementos triangulares de aproximação cúbica e 3720 nós (Figura 5.1b), em que os pontos A e B foram utilizados para 
calcular os deslocamentos verticais e horizontais quando o quadro foi submetido à tração, enquanto os pontos C e D quando submetido à compressão. Foram considerados $L=E=I=1, v=0$ e $P=4$. 0 carregamento foi feito em 10 passos de cargas, sendo $0,4 \mathrm{o}$ valor de cada incremento.

A Figura 5.2 traz a estrutura deformada quando submetida às forças P e 2P. Para estes casos calculou-se as diferenças relativas entre as deformações calculadas pelo programa e as calculadas por Mattiasson, demonstrados no Quadro 1. A Figura 5.3 traz o gráfico do parâmetro de carga relacionado às deformações quando o quadro está submetido à compressão, enquanto a Figura 5.4 quando submetido à tração. $u / L$ representa as deformações horizontais e $w / L$ as deformações verticais. Nota-se que, para ambos os gráficos, houve resultados satisfatórios do programa implementado quando comparado aos resultados numéricos calculados por Mattiasson (1981). Assim, os baixos valores das diferenças relativas e os resultados demonstrados pelos gráficos indicam o desempenho eficiente do programa para o cálculo de estruturas não lineares geométricas.

Figura 5.2 - Deformações do quadro carregado à (a) Compressão e (b) Tração.

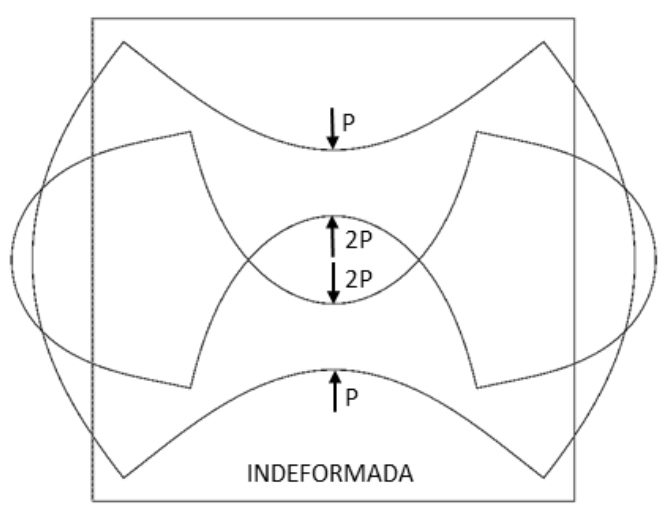

(a)

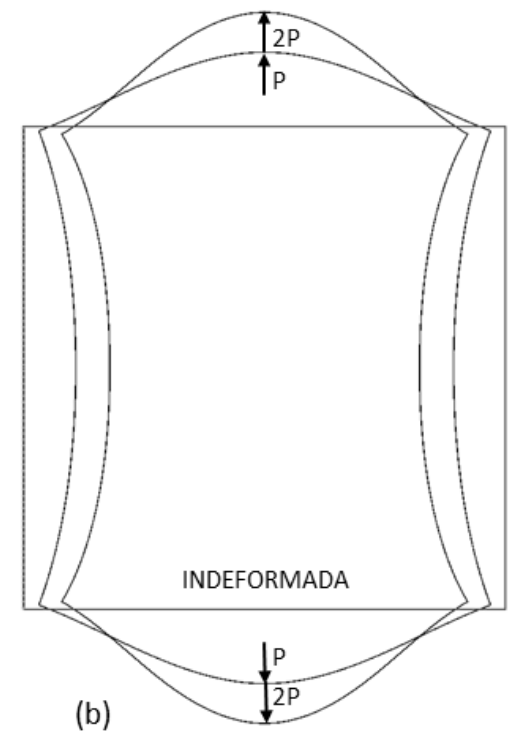

Quadro 1 - Diferenças relativas entre o modelo numérico e os resultados de Mattiasson (1981).

\begin{tabular}{|c|c|c|c|c|}
\hline \multicolumn{7}{|c|}{ DIFERENÇAS RELATIVAS } \\
\hline \multirow{2}{*}{ Deformação } & \multicolumn{2}{|c|}{ Compressão } & \multicolumn{2}{c|}{ Tração } \\
\hline & $\mathbf{P}$ & $\mathbf{2 P}$ & $\mathbf{P}$ & $\mathbf{2 P}$ \\
\hline u/L & $-0,40 \%$ & $0,56 \%$ & $-0,33 \%$ & $-0,15 \%$ \\
\hline v/L & $-0,44 \%$ & $-0,18 \%$ & $0,16 \%$ & $0,28 \%$ \\
\hline
\end{tabular}


Figura 5.3 - Deformações do quadro carregado à compressão.

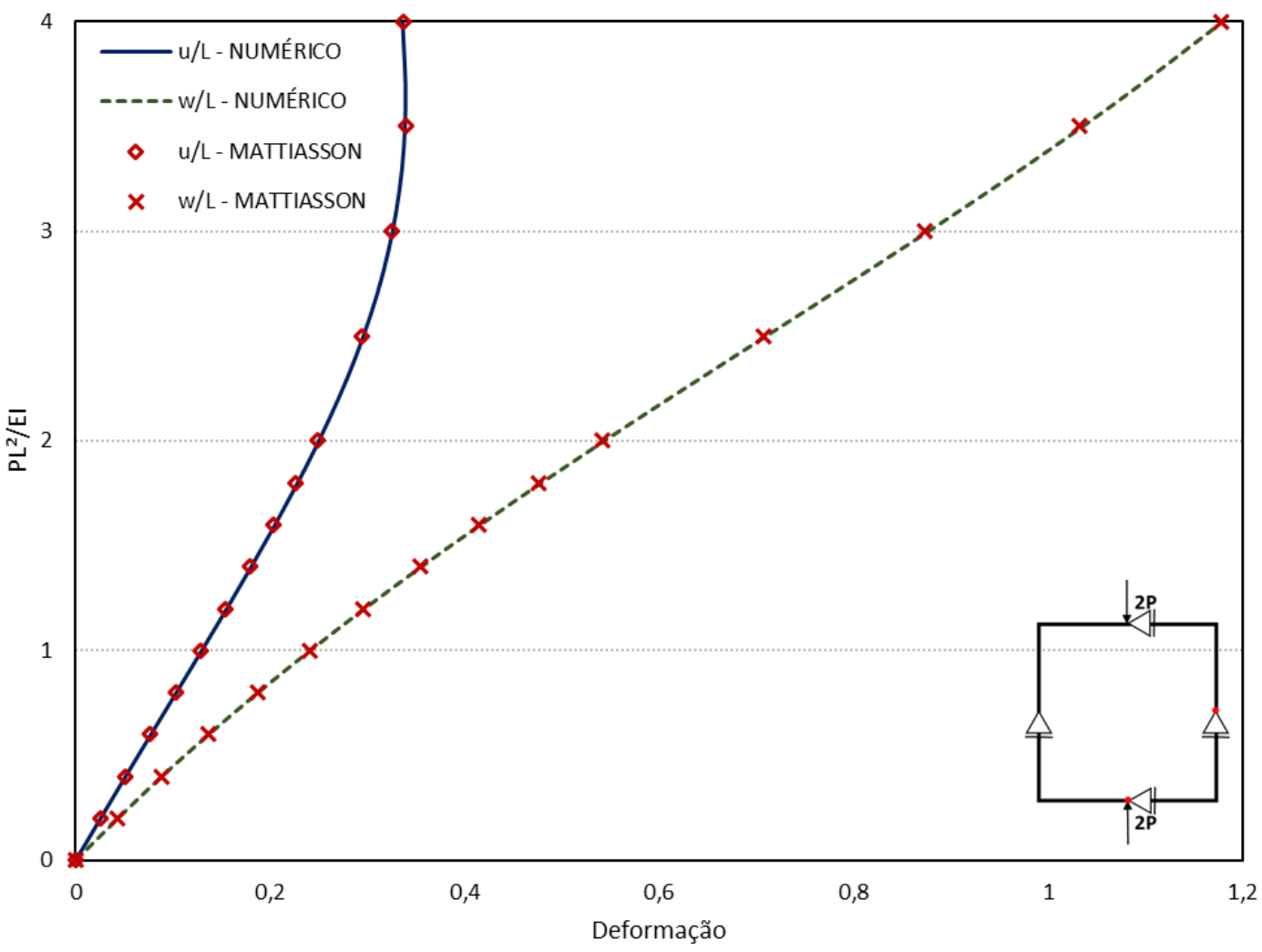

Figura 5.4 - Deformações do quadro carregado à tração.

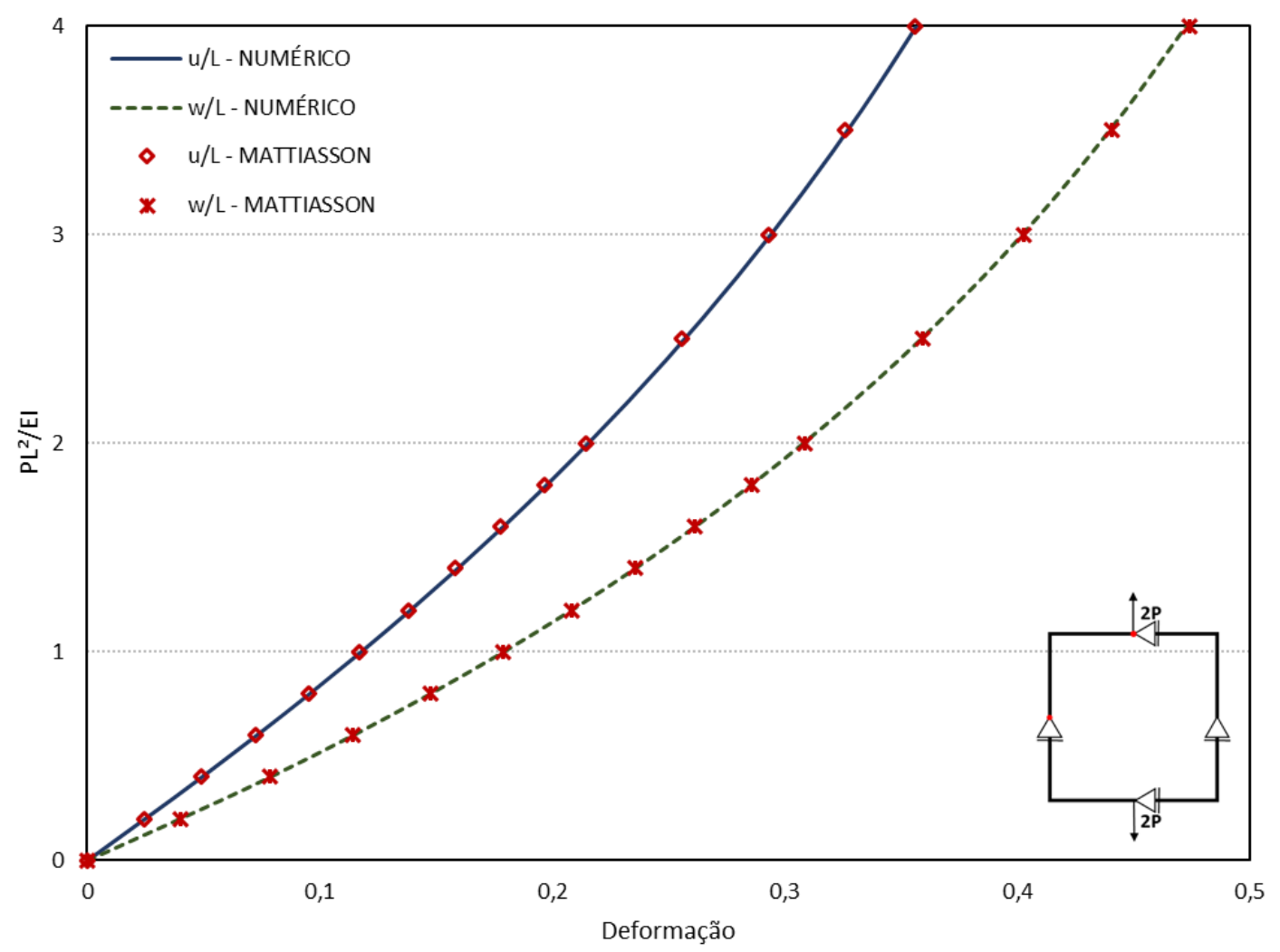




\subsection{REAÇÃo ÁLCALI-AGREGADO}

Para validação da modelagem da reação álcali-agregado, foram utilizados os dados dos trabalhos de Boddy, Hooton \& Thomas (2000) e de Multon \& Toutlemonde (2006).

No trabalho de Boddy, Hooton \& Thomas (2000) foi avaliada a expansão livre por RAA em corpos de prova prismáticos de dimensões 7,5 x 7,5 x $30 \mathrm{~cm}$ (Figura 5.5a), produzido com agregado deletério e cimento altamente alcalino, em ensaios acelerados de degradação. Os corpos de prova foram mantidos a $100 \%$ de umidade, sob temperatura de $38^{\circ} \mathrm{C}$ por um período de 300 dias. Foi considerado $E=2000 \mathrm{KN} / \mathrm{cm}^{2}$ e $v=0,20$.

A fim de representar o prisma foi criada uma malha com 190 elementos triangulares de aproximação cúbica e 919 nós. Na Figura 5.5b indica-se o ponto em que foram medidos os deslocamentos verticais para o cálculo das deformações longitudinais. Para a modelagem deste exemplo, foram considerados tempo de preenchimento de poros $\left(t_{p}\right)$ considerado igual a 53 dias e máxima expansão volumétrica $\left(\varepsilon_{v o l}^{\max }\right)$ igual a 0,001752 .

Figura 5.5 - (a) Esquema do prisma de concreto (b) Malha discretizada do prisma.

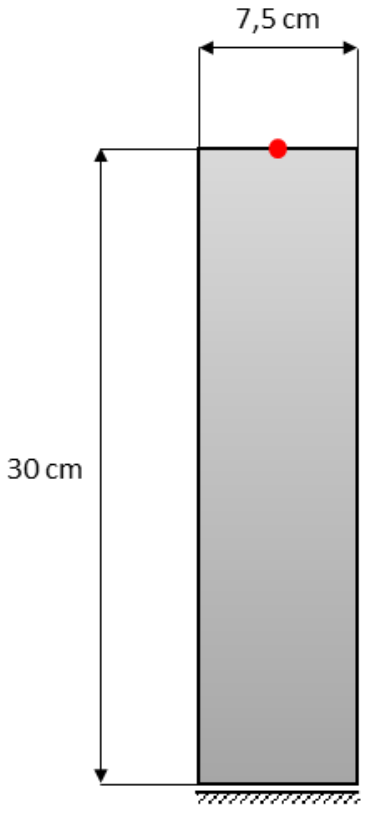

(a)

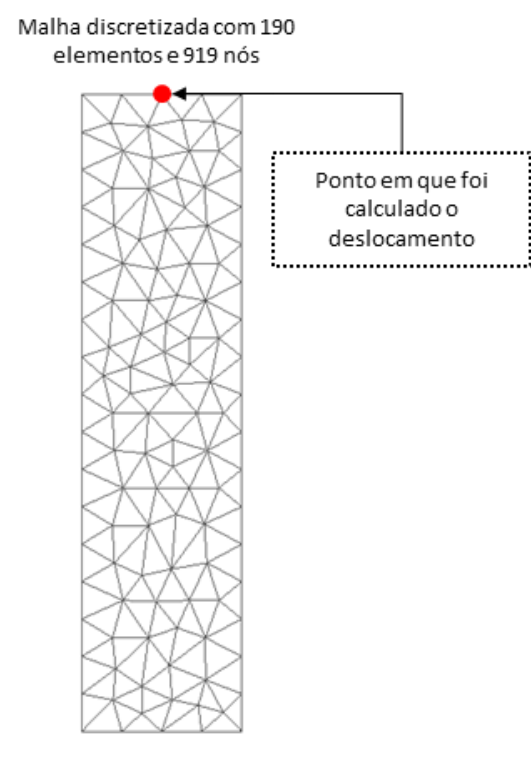

(b)

A Figura 5.6 traz a comparação entre o modelo numérico implementado e os resultados experimentais dos autores para expansão volumétrica. Sabendo que a equação proposta por Carrazedo (2004) considera a expansão apenas a partir do completo preenchimento dos poros, que para este caso se dá aos 53 dias, percebe-se que a partir deste 
momento, a modelagem é condizente com os resultados experimentais, demonstrando a eficiência do modelo.

Figura 5.6 - Comparação entre o modelo numérico e os resultados experimentais para e expansão longitudinal.

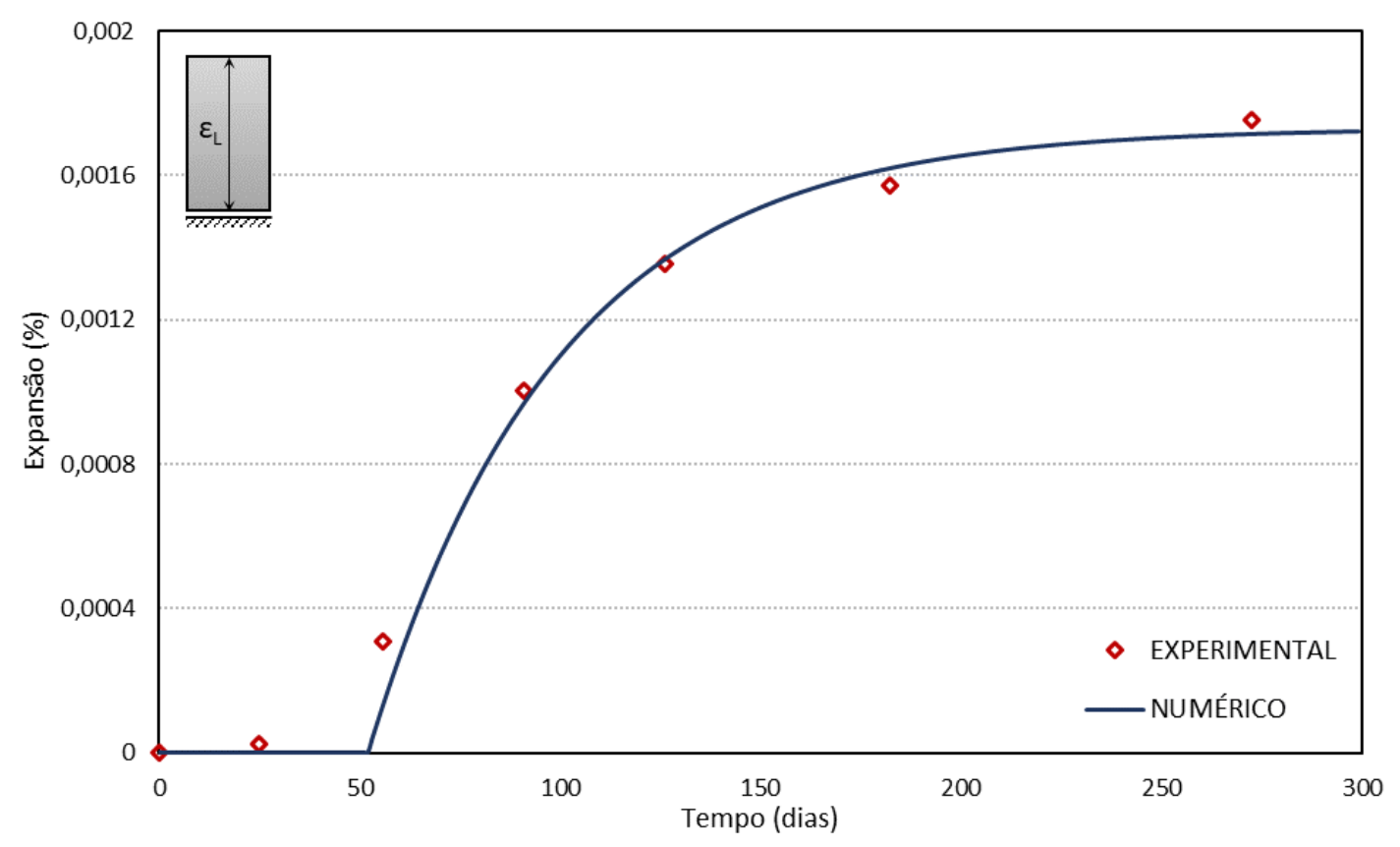

No trabalho de Multon \& Toutlemonde (2006) foram realizadas medições em corpos de prova de concreto sujeitos a vários estados de tensão ao longo das direções radial e longitudinal. Para o experimento foram utilizados corpos de prova de concreto, com módulo de elasticidade de $3720 \mathrm{kN} / \mathrm{cm}^{2}$ e coeficiente de Poisson de 0,22. Após 28 dias de cura, foram aplicados diferentes estados de tensões axiais (0,10 e $20 \mathrm{MPa}$ ) em espécimes cilíndricos, de $130 \mathrm{~mm}$ de diâmetro e $240 \mathrm{~mm}$ de altura (Figura 5.7a), durante 450 dias. Os corpos de prova foram mantidos a uma temperatura de $38^{\circ} \mathrm{C}$ e $100 \%$ de umidade relativa, em ensaios acelerados de degradação.

Figura 5.7 - (a) Esquema do cilindro de concreto (b) Malha discretizada do cilindro.

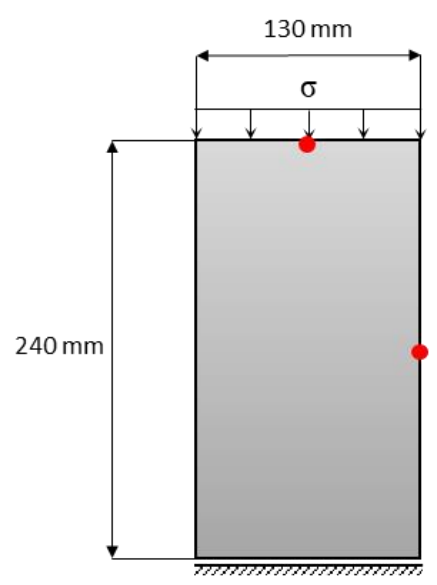

(a)

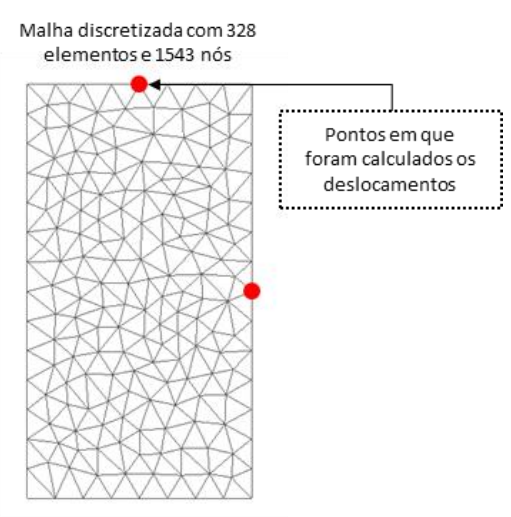

(b) 
O cilindro de concreto foi discretizado com 328 elementos triangulares de aproximação cúbica e 1543 nós (Figura 5.7b). A máxima expansão volumétrica para este exemplo é de 0,000994128 e o tempo de preenchimento dos poros considerado foi de 90 dias. Como este exemplo tem o intuito de avaliar somente a expansão por RAA, foi considerada apenas a expansão livre, isto é, com tensão axial de $0 \mathrm{MPa}$. As tensões de 10 e $20 \mathrm{MPa}$ são consideradas em exemplo posterior.

A Figura 5.8 mostra a correlação entre a expansão modelada neste trabalho e a observada pelos autores no ensaio experimental. A linha em amarelo demonstra a modelagem perfeita, quando os valores obtidos são exatamente iguais aos experimentais, ou seja, $R^{2}=1$. Deste modo, percebe-se que o modelo implementado atende satisfatoriamente a expansão livre por RAA na direção longitudinal, e ainda, sabendo que o modelo empregado não considera a transferência de expansão por RAA da direção restringida para a livre - como visto em Multon e Toutlemonde (2006) - a distinção entre expansões é promovida apenas pelo coeficiente de Poisson, de maneira que, dentro das possibilidades de abrangência deste modelo, ele também atende de modo satisfatório as expansões radiais. A Figura 5.9 mostra os deslocamentos horizontais e verticais do corpo de prova.

Figura 5.8 - Correlação entre as expansões modeladas e observadas.

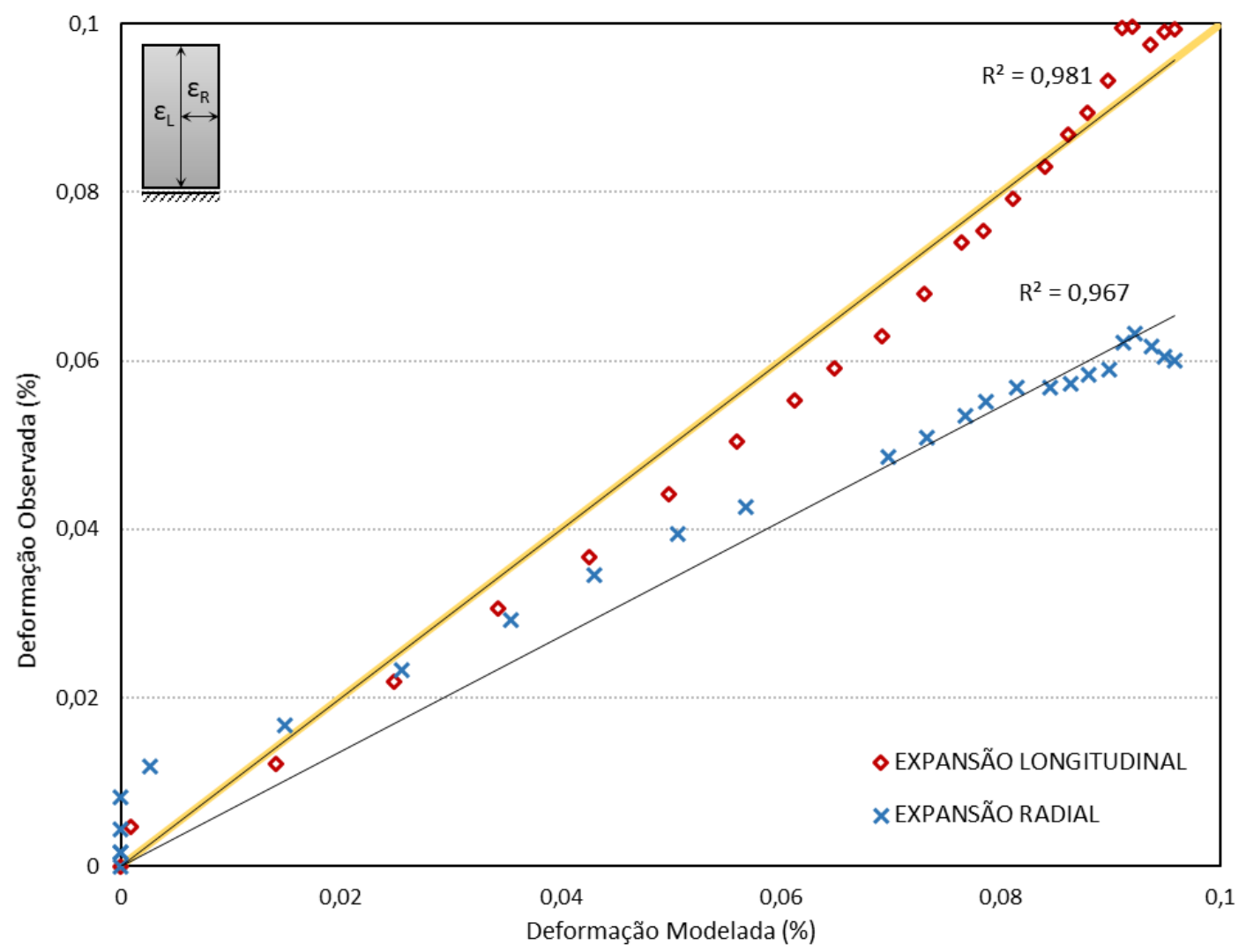


Figura 5.9 - Deslocamentos (a) horizontais (em cm) e (b) verticais (em cm) obtidos aos 450 dias.

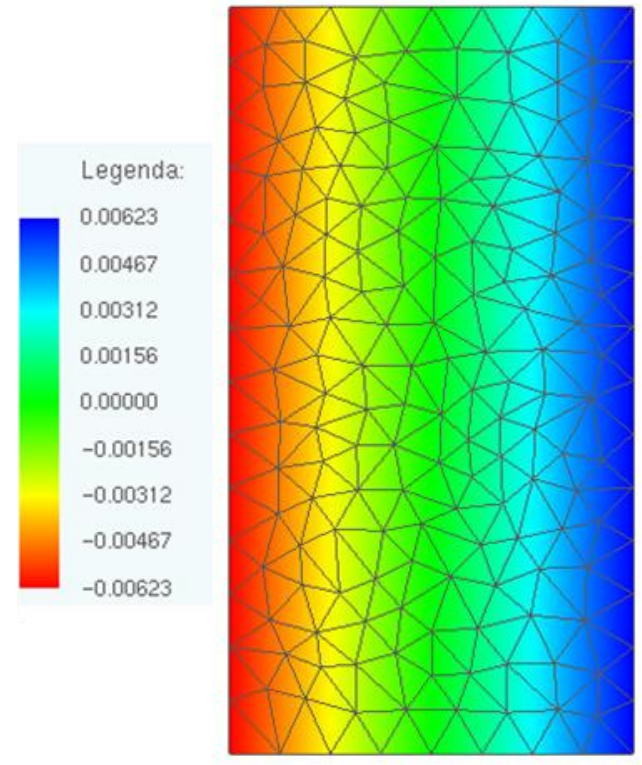

(a)

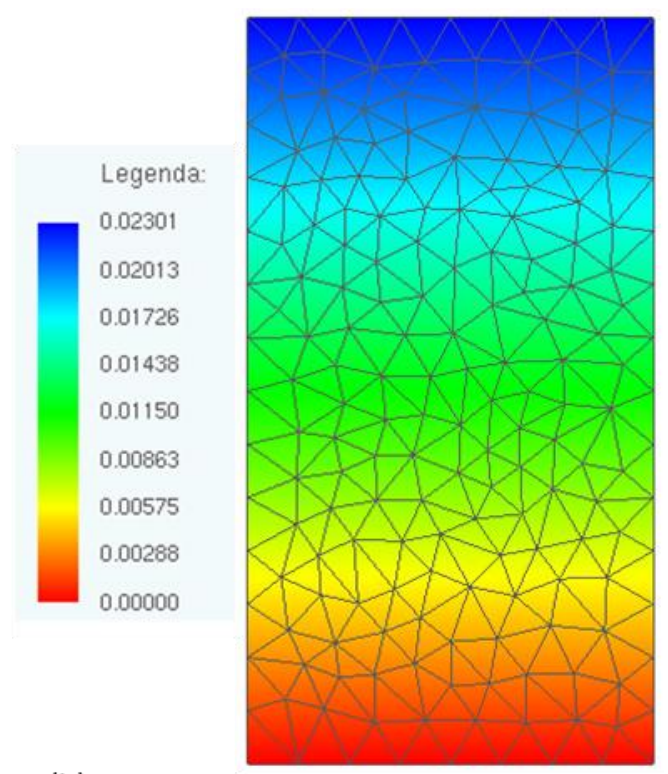

(b)

\subsection{RETRAÇÃO E FLUÊNCIA}

Para validação dos modelos implementados de retração e fluência foi usado o trabalho de Charpin etal. (2018). 0 trabalho foi feito em conjunto com a empresa Électricité de France, que teve como propósito o estudo experimental sobre fluência e retração de um concreto semelhante ao experimentado por uma usina nuclear em operação na França. 0 ensaio se deu com corpos de prova cilíndricos submetidos a compressão uniaxial durante um período de 12 anos. Os autores ressaltam que os resultados são disponibilizados a outros pesquisadores justamente para que possam contribuir com análises e modelos numéricos.

O cilindro de concreto ensaiado possui $16 \mathrm{~cm}$ de diâmetro e $100 \mathrm{~cm}$ de comprimento. No ensaio, os autores usaram sensores LVDT com calibre de comprimento de $50 \mathrm{~cm}$ e $8 \mathrm{~cm}$ para medir, respectivamente, os deslocamentos verticais e horizontais. Esses sensores foram colocados nos pontos indicados em vermelho, conforme demonstra a Figura 5.10a.

Para o modelo numérico, o cilindro foi discretizado com uma malha de 1120 elementos triangulares de aproximação cúbica e 5221 nós, e os deslocamentos foram calculados nos mesmos pontos que o ensaio experimental Figura 5.10b. A fim de simplificar a análise deste exemplo, avaliou-se, somente, os primeiros 1000 dias de ensaio. Conforme indicado no artigo dos autores, foram utilizados como dados: cimento tipo CEM II/AA 42,5 R, agregado calcário, relação volume/superfície igual a 40, relação água/cimento igual a 0,49, relação agregado/cimento igual a 3,146, o consumo de cimento foi de $350 \mathrm{~kg} / \mathrm{m}^{3}$. Os corpos de prova 
foram mantidos a uma temperatura de $20^{\circ} \mathrm{C}$ e $50 \%$ de umidade relativa. A resistência à compressão aos 28 dias foi de $40 \mathrm{MPa}$, o módulo de elasticidade obtido foi de 29,94 GPa e coeficiente de Poisson igual a 0,30 .

Figura 5.10 - (a) Esquema de ensaio do cilindro (b) Malha discretizada do cilindro.

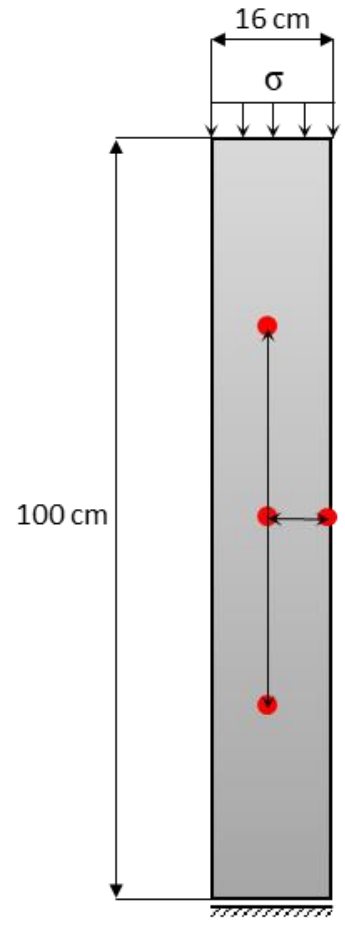

(a)

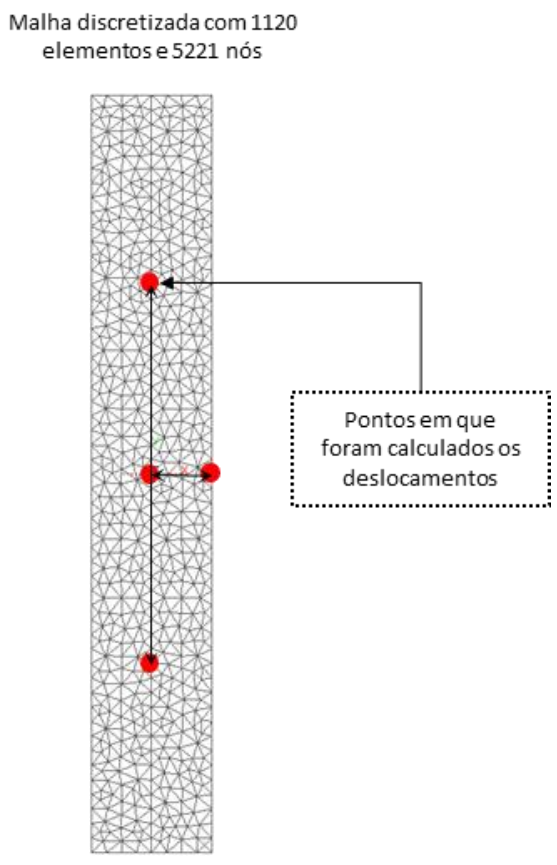

(b)

Os autores realizaram algumas modalidades de ensaio, em que este trabalho utilizou apenas duas. A primeira modalidade se refere a um corpo de prova submetido a uma compressão de $12 \mathrm{MPa}$, com carregamento e secagem aos 90 dias. E na segunda, o cilindro está sujeito a expansão livre, com secagem iniciando nas primeiras $24 \mathrm{~h}$. Destaca-se que devido à umidade ser igual a 50\%, haverá tanto retração quanto fluência por secagem, de modo que este exemplo consegue trabalhar com todas as parcelas envolvidas nas equações de deformação por retração e fluência.

A Figura 5.11 e a Figura 5.12 mostram os resultados da comparação entre os modelos numéricos e os resultados obtidos pelos ensaios experimentais, considerando um desvio de $30 \%$, para as deformações longitudinal e radial, respectivamente, dos corpos de prova submetidos à tensão de $12 \mathrm{MPa}$. Os gráficos estão em escala logarítmica pois a fluência e retração tendem a evoluir como função logarítmica, segundo os autores. Observa-se que, para o cilindro carregado, o modelo B4 apresentou comportamento mais satisfatório quando comparado aos modelos JSCE e FIB, tanto para as deformações longitudinais, quanto radiais. 
Figura 5.11 - Comparação entre os modelos numéricos e os resultados experimentais para deformação longitudinal do cilindro submetido tensão de compressão de $12 \mathrm{MPa}$.

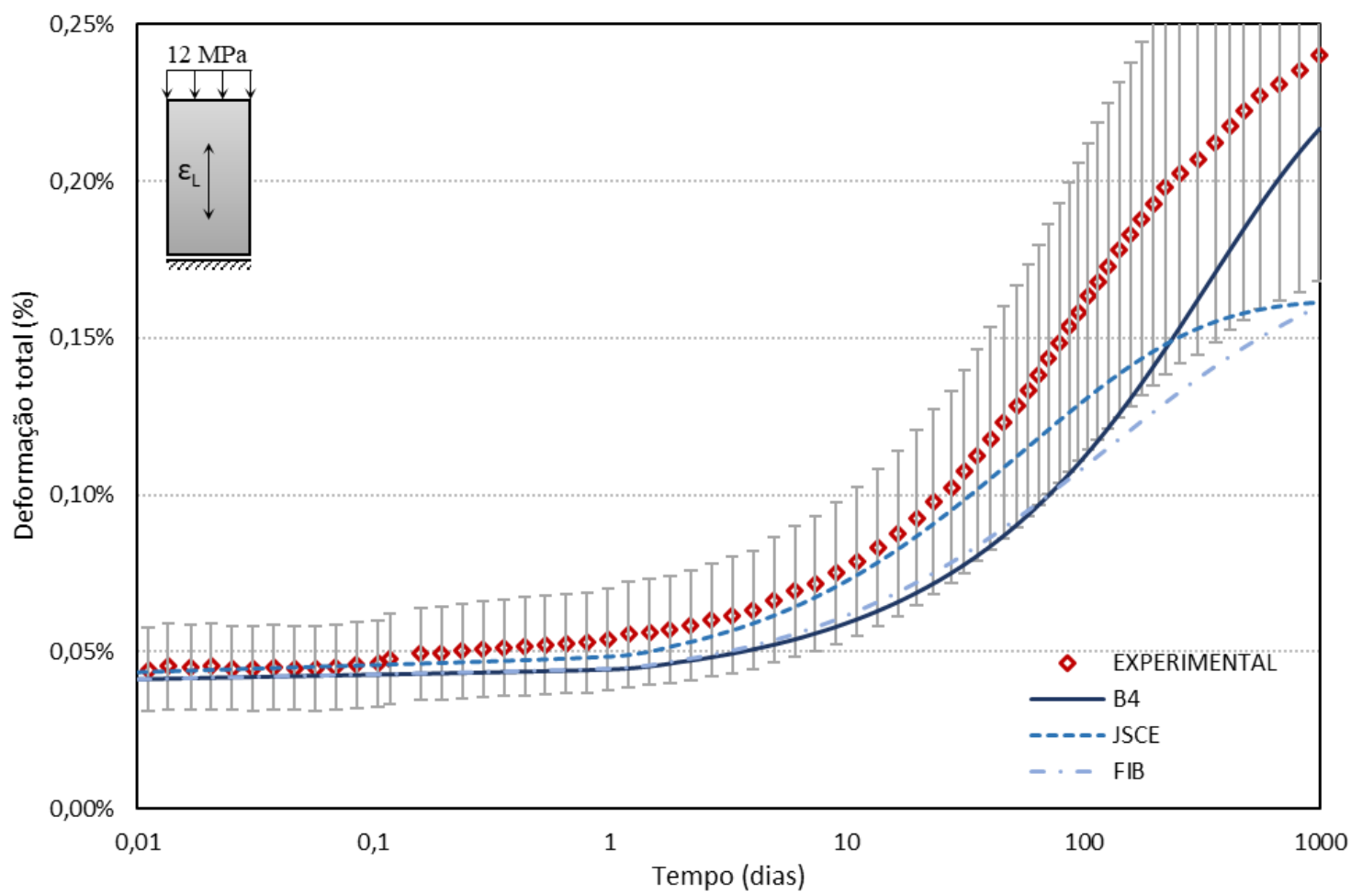

Figura 5.12 - Comparação entre os modelos numéricos e os resultados experimentais para deformação radial do cilindro submetido tensão de compressão de $12 \mathrm{MPa}$.

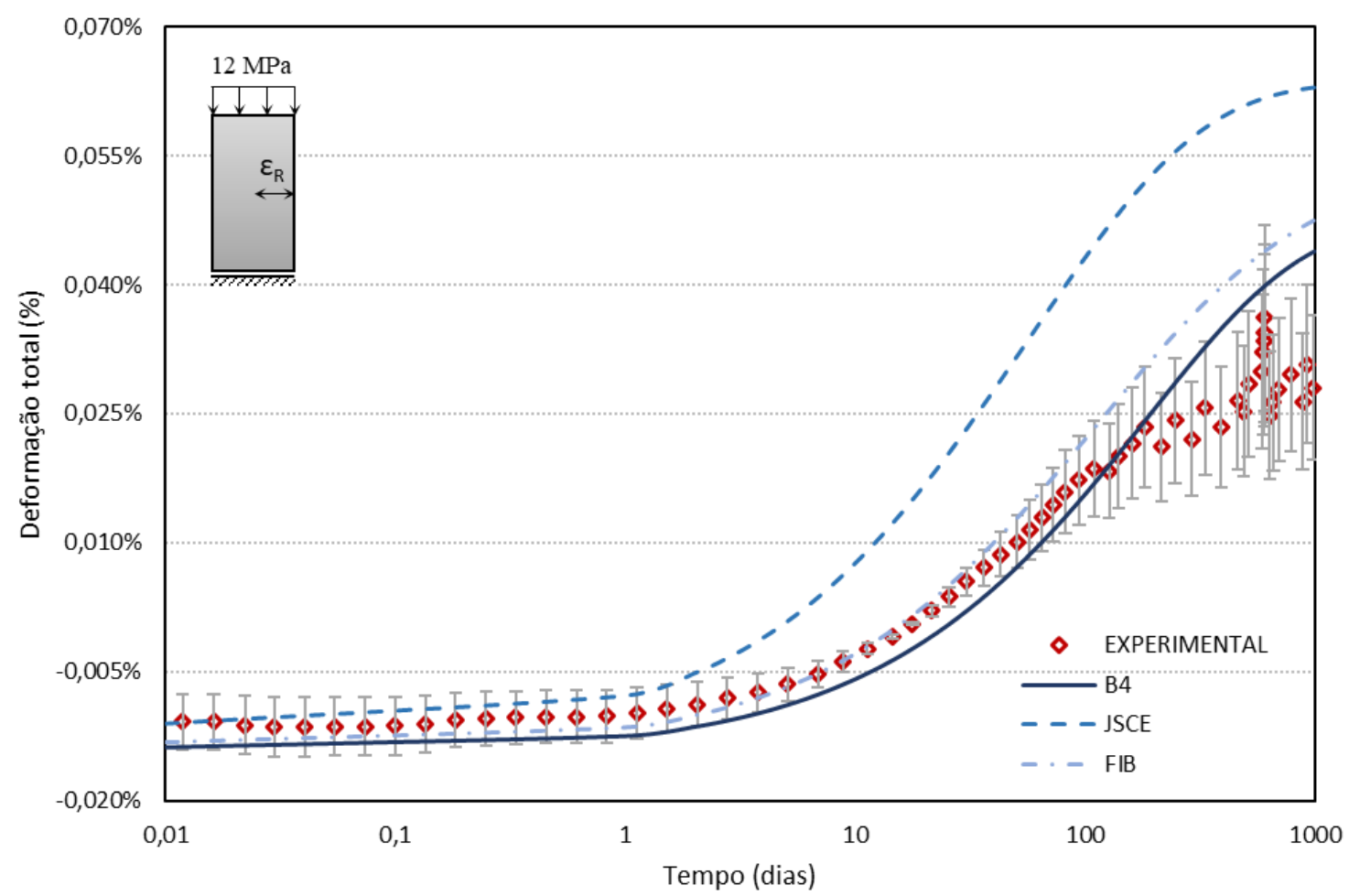


Figura 5.13 - Comparação entre os modelos numéricos e os resultados experimentais para deformação longitudinal do cilindro submetido a expansão livre.

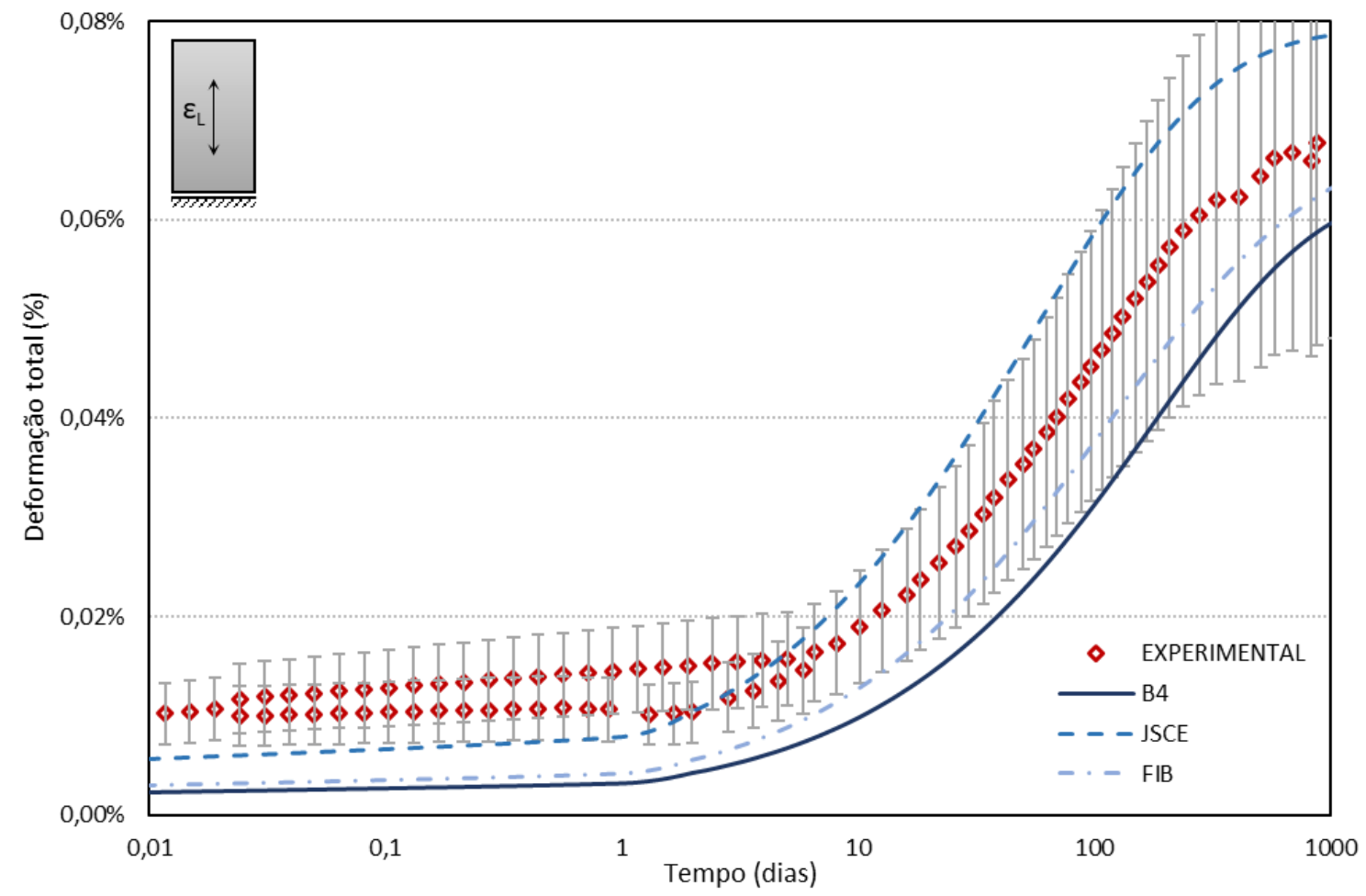

Figura 5.14 - Comparação entre os modelos numéricos e os resultados experimentais para deformação radial do cilindro submetido a expansão livre.

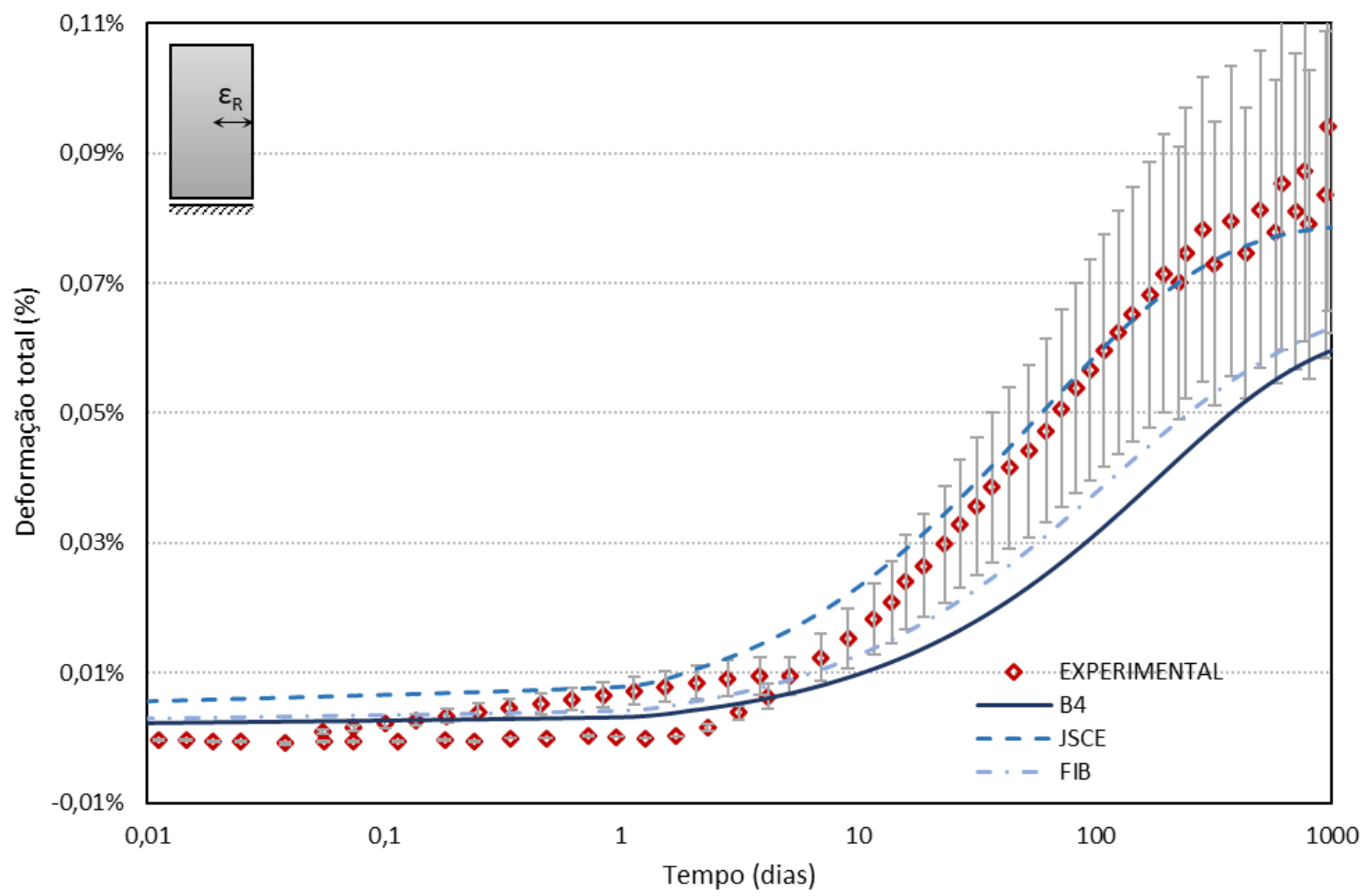


Uma observação importante a ser feita sobre estes modelos, e sobre a qualidade de seus resultados, é que os modelos JSCE e FIB trabalham com relação volume/superfície indicada entre 100 e 300 mm, e 50 e 600 mm, respectivamente. A relação v/s considerada neste exemplo foi de $40 \mathrm{~mm}$, um pouco abaixo do limite do modelo FIB, e consideravelmente abaixo do limite para o modelo JSCE, entretanto está dentro do limite do modelo B4 entre 12 e $120 \mathrm{~mm}$. Esta diferença pode ser uma das razões pelas quais estes dois modelos não apresentaram resultados tão satisfatórios quanto o modelo B4.

A Figura 5.13 e a Figura 5.14 mostram, respectivamente, os resultados para expansão livre longitudinal e radial. Quando avaliados os modelos quanto à expansão livre longitudinal, os três modelos apresentaram comportamento adequado. Entretanto, ao compará-los quanto à expansão livre radial, foi o modelo JSCE que apresentou melhor comportamento.

\subsection{RAA, RETRAÇÃO E FLUÊNCIA}

Neste exemplo foi considerado, novamente, o trabalho de Multon \& Toutlemonde (2006). Conforme já explicado em tópico anterior, os autores fizeram um ensaio experimental de corpos de prova submetidos à compressão de 10 e $20 \mathrm{MPa}$, considerando a expansão por RAA. Além dos dados empregados anteriormente, foram considerados os seguintes dados: cimento tipo CEM I 52,5 R, agregado calcário, relação volume/superfície igual a 32,5 mm, relação água/cimento igual a 0,50, relação agregado/cimento igual a 2,732, consumo de cimento de $410 \mathrm{~kg} / \mathrm{m}^{3}$. Os corpos de prova foram mantidos a uma temperatura de $38^{\circ} \mathrm{C}$ e $100 \%$ de umidade relativa. A resistência à compressão adotada foi de $50 \mathrm{MPa}$, o módulo de elasticidade obtido foi de 37,2 GPa e coeficiente de Poisson igual a 0,22. A máxima expansão volumétrica para este exemplo é de 0,000994128 e o tempo de preenchimento dos poros é de 90 dias

A Figura 5.15 e a Figura 5.16 mostram a comparação entre os modelos numéricos e os resultados dos ensaios experimentais, com desvio de 30\%, para os regimes de tensão de 10 e $20 \mathrm{MPa}$, respectivamente. Para os três modelos implementados, nota-se novamente que o modelo B4 apresentou melhor comportamento quanto a deformação longitudinal para ambos os casos, em que se salienta, mais uma vez, o uso da relação v/s, que neste exemplo é igual a 32,5 mm, inferior aos limites dos modelos JSCE e FIB.

Os modelos apresentaram comportamento um pouco divergente ao do experimental para a deformação radial quando o cilindro estava submetido a tensão de $10 \mathrm{MPa}$. Percebe- 
se, no entanto, que os três modelos apresentaram comportamento coerente para a deformação radial quando o corpo de prova estava submetido à tensão de $20 \mathrm{MPa}$.

Figura 5.15 - Comparação entre os modelos numéricos e os resultados experimentais para deformação do cilindro submetido tensão de compressão de $10 \mathrm{MPa}$.

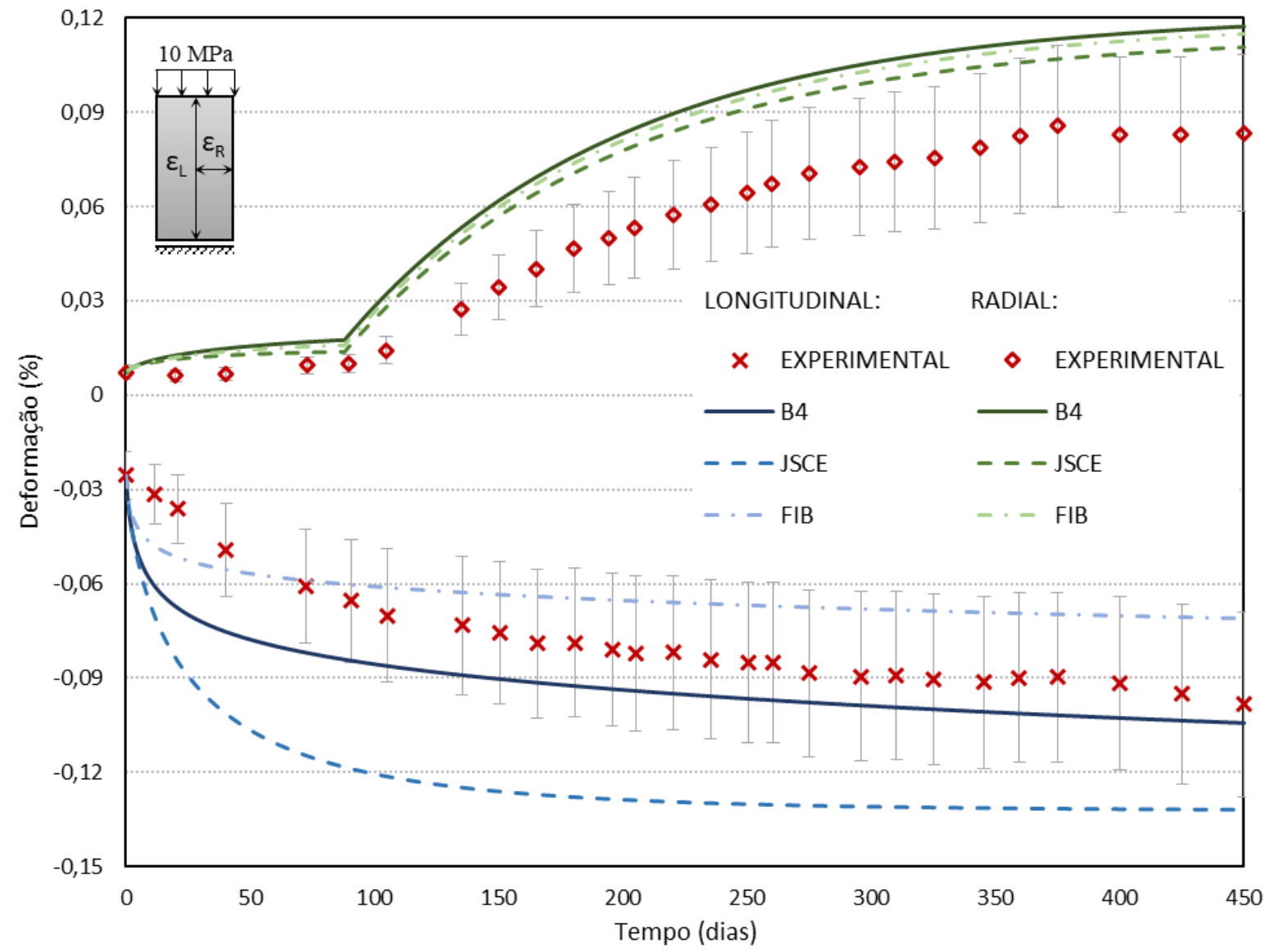

Deve-se enfatizar que o comportamento próximo dos três modelos no caso das deformações radiais decorre do fato de ser a expansão por RAA a preponderante, justamente pela liberdade do corpo de prova em expandir nessa direção. Entretanto, na direção longitudinal, o que governa a intensidade das deformações é a deformação por fluência, devido a intensidade do carregamento. Além da tensão aplicada interferir na intensidade da fluência, ela também suprime a expansão por RAA. E ainda, ao considerar umidade relativa igual a 100\%, não haverá nem retração por secagem nem fluência por secagem.

Outro ponto a ser observado para o caso das deformações radiais, é que durante os primeiros 90 dias, período em que ainda não houve o completo preenchimento dos poros pelos produtos da RAA, a deformação é positiva e crescente. Isto ocorre, pois, sob uma umidade relativa de 100\%, o efeito da retração é inverso ao do usual, de modo que o concreto incha ao invés de retrair. 
Figura 5.16 - Comparação entre os modelos numéricos e os resultados experimentais para deformação do cilindro submetido tensão de compressão de $20 \mathrm{MPa}$.

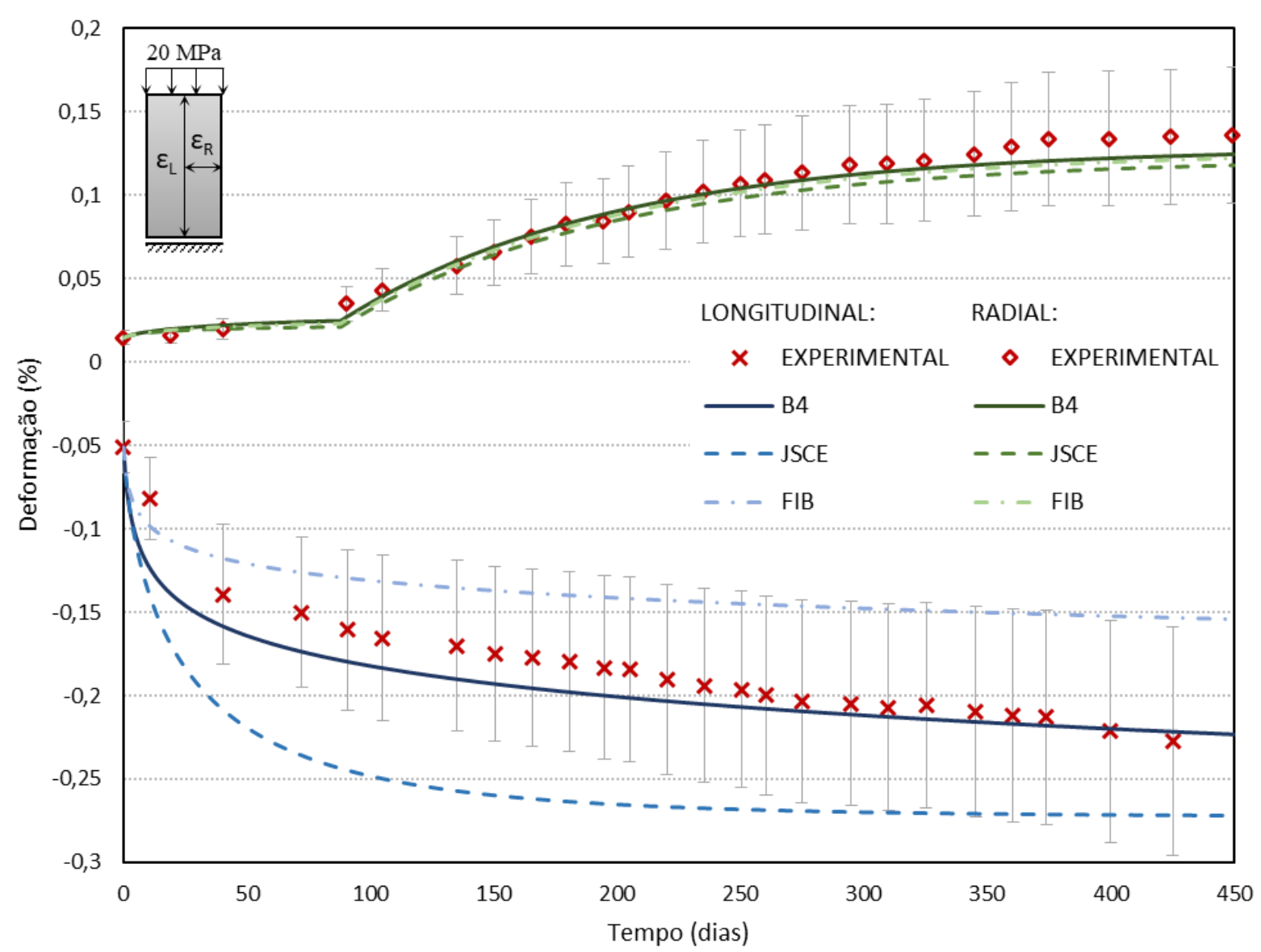

Por meio deste exemplo e do anterior, entende-se que para estes casos estudados, o modelo B4 apresentou melhor comportamento frente aos outros modelos. Uma das possíveis razões que pode contar em favor do modelo, além da já falada relação v/s, é o fato de ele possuir um maior nível de refinamento de parâmetros quanto ao tipo de agregado e cimento.

Considerando, então, apenas o modelo B4, a Figura 5.17 mostra a comparação das deformações longitudinais para cada fenômeno isoladamente e considerando os três fenômenos associados. Verifica-se que, ao considerar a implementação apenas da modelagem da RAA, devido à magnitude da tensão, a expansão causada pela RAA é contida, e somente a deformação relativa à parcela elástica ao longo do tempo é considerada. Ao inserir as deformações relacionadas à retração e à fluência, o modelo passa a descrever coerentemente a curva de deformação durante o período analisado, e percebe-se que a deformação por retração suaviza os efeitos da deformação por fluência, devido ao inchamento do concreto sob a umidade relativa de $100 \%$, melhorando o comportamento da curva de deformação vs tempo. Infere-se, portanto, a necessidade das modelagens da retração e da fluência. 
Figura 5.17 - Comparação das deformações longitudinais considerando cada fenômeno isoladamente.

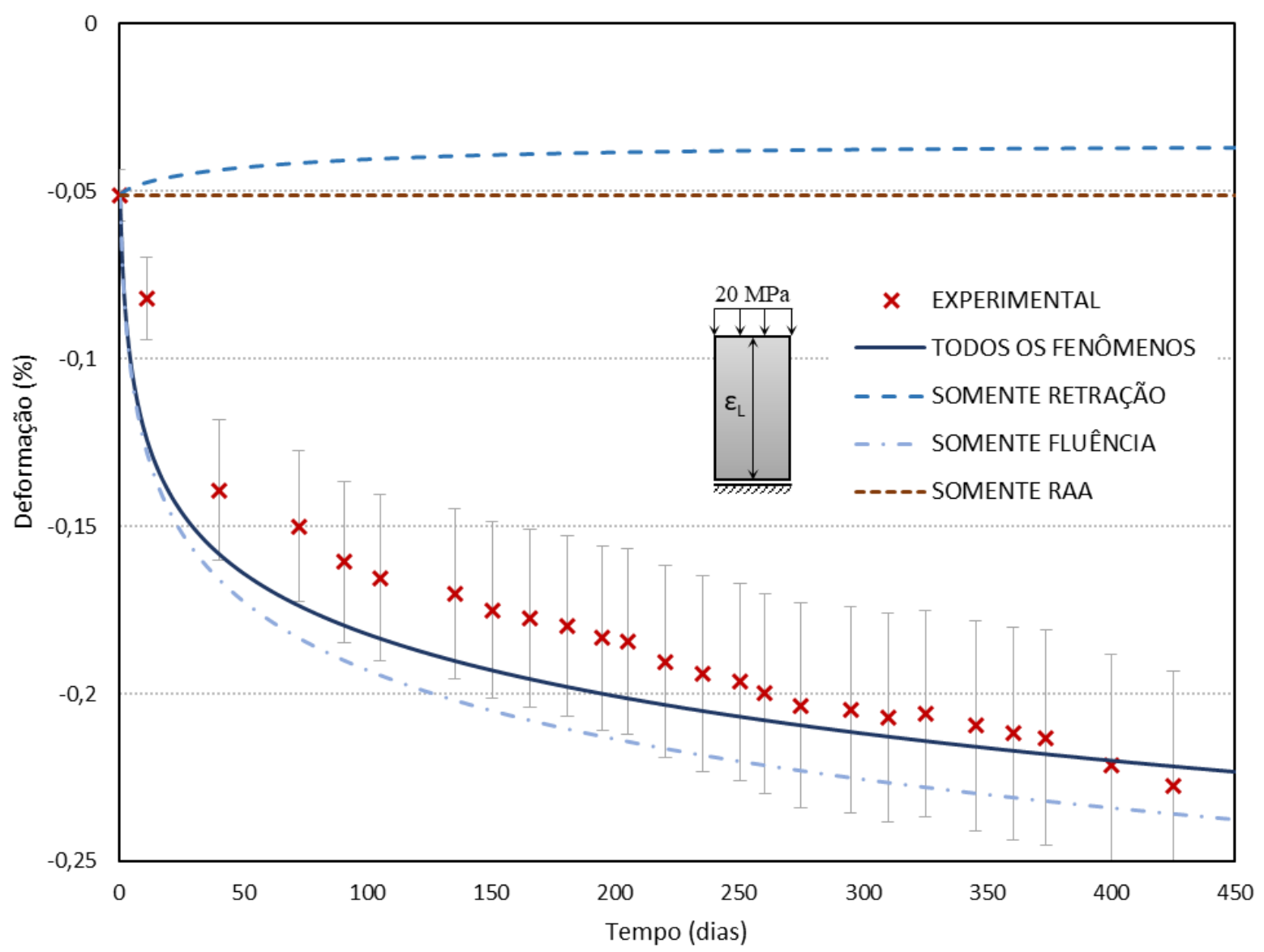

\subsection{ANÁLISE PARAMÉTRICA}

Este exemplo tem como objetivo realizar uma análise de três parâmetros comuns aos três fenômenos, a saber: tensão aplicada, umidade relativa e temperatura ambiente. Foi considerado um corpo de prova cilíndrico de 7,5 cm de diâmetro e $30 \mathrm{~cm}$ de altura, de maneira a utilizar a mesma malha mostrada na Figura 5.5b. Foram considerados como dados: cimento tipo CEM I 42,5 R, agregado calcário, relação volume/superfície igual a 18,75 mm, relação água/cimento igual a 0,50, relação agregado/cimento igual a 3,0, consumo de cimento de 400 $\mathrm{kg} / \mathrm{m}^{3}$. A resistência à compressão aos 28 dias foi de $40 \mathrm{MPa}$, o módulo de elasticidade considerado foi de 29,94 GPa e coeficiente de Poisson igual a 0,20. A máxima expansão volumétrica para este exemplo é de 0,001752 e o tempo de preenchimento dos poros é de 90 dias, e o tempo de análise de 300 dias.

Neste exemplo foi utilizado somente o modelo B4, visto que este apresentou melhor resultado, de modo geral, nos exemplos anteriores. Para a primeira análise os corpos de prova foram considerados mantidos a uma temperatura de $38^{\circ} \mathrm{C}$ e $98 \%$ de umidade relativa, com 
tensões aplicadas variando de 0 a $6 \mathrm{MPa}$. A temperatura de $38^{\circ} \mathrm{C}$ foi escolhida por ser usual em ensaios de RAA, e a umidade relativa de $98 \%$ foi arbitrada para que houvesse os fenômenos de retração por secagem e fluência por secagem. As tensões variam de 0 a $6 \mathrm{MPa}$ para que seja possível perceber a variação da expansão por RAA e a interferência da intensidade do carregamento na fluência.

A Figura 5.18 e a Figura 5.19 mostram, respectivamente, as deformações longitudinais e radiais para diferentes regimes de tensão. Verifica-se que para os primeiros dias, a deformação longitudinal é negativa para todos os casos devido à deformação por fluência. Além disso, com o aumentar da intensidade da tensão aplicada, a expansão por RAA é suprimida, tornando a deformação por fluência preponderante.

Figura 5.18 - Deformação longitudinal do concreto sujeito à RAA, retração e fluência sob diferentes regimes de tensão.

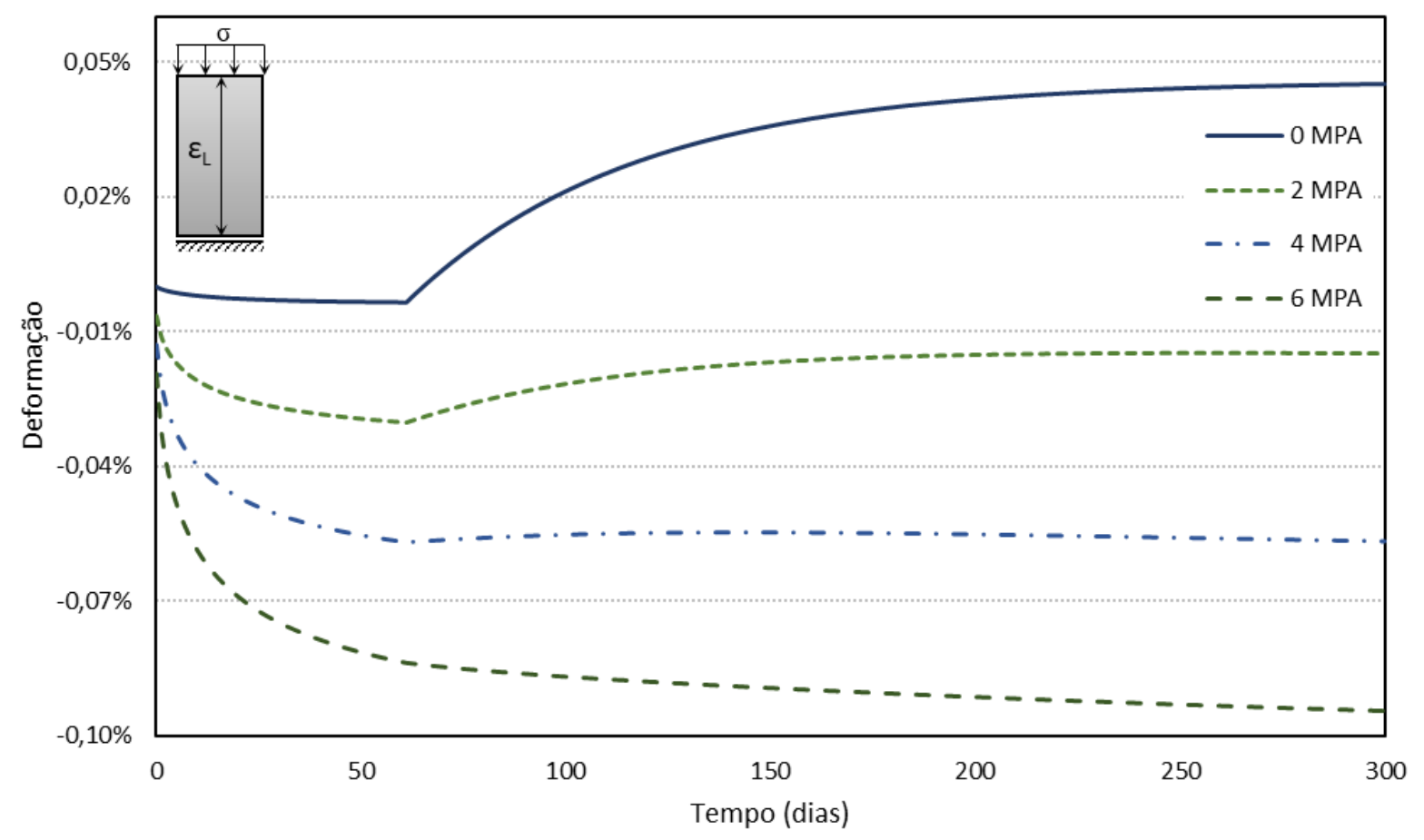

Quando avaliadas as deformações radiais, percebe-se também que as deformações são negativas nos primeiros dias. Isso decorre da deformação por retração, uma vez que não há deformação por fluência pois não há carregamento aplicado nesta direção, e ainda não houve início na expansão por RAA. Devido à liberdade de expansão na direção radial, é a expansão por RAA que governa a intensidade das deformações a partir de seu início, em que o offset apresentado no gráfico ocorre devido à deformação elástica das diferentes tensões atuantes. 
Figura 5.19 - Deformação radial do concreto sujeito à RAA, retração e fluência sob diferentes regimes de tensão.

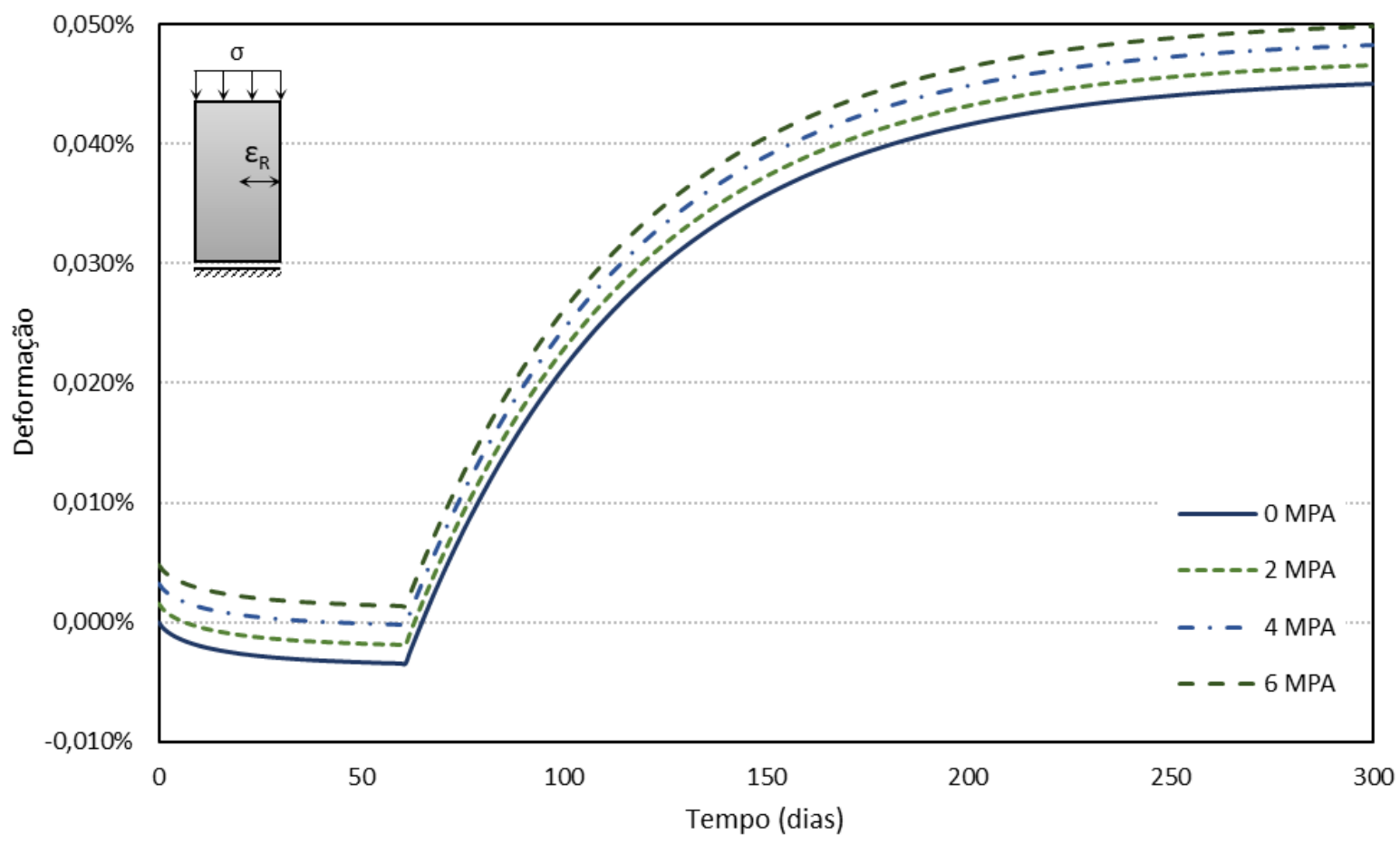

Para a segunda análise os corpos de prova foram considerados mantidos a uma temperatura de $38^{\circ} \mathrm{C}$, sob tensão de compressão de $1 \mathrm{MPa}$, com umidade relativa variando de $80 \%$ a $100 \%$. A tensão de $1 \mathrm{MPa}$ foi escolhida para que fosse possível perceber o efeito da fluência e expansão por RAA.

A Figura 5.20a e a Figura 5.20b mostram, respectivamente, as deformações longitudinais e radiais para este caso. Percebe-se, para ambos os casos, que ao diminuir a umidade relativa ambiente, diminui-se a intensidade da reação álcali-agregado, até esta não ser mais exprimível, o que é notório, visto que a água presente no ambiente é um dos fatores preponderantes para a ocorrência da RAA. Nota-se que as deformações radiais foram superiores às longitudinais para todas as umidades em decorrência de não haver deformação por fluência na direção radial.

É possível verificar ainda a considerável diferença nas deformações para as umidades de 100\% e 98\%, especialmente para o caso da direção longitudinal. Conforme já mencionado antes, a retração possui efeito de inchaço quando se considera umidade igual a $100 \%$, esse efeito foi perceptivelmente intenso, pois para os primeiros dias da deformação longitudinal, a deformação por retração foi superior à da deformação por fluência, de modo a deformação resultante ser positiva. E, ao variar a umidade em apenas $2 \%$, a retração passa a ter efeito contrário, se somando a deformação por fluência, de modo a diminuir a intensidade da 
expansão por RAA. Verifica-se que para a umidade de 90\%, mesmo sendo possível verificar a expansão por RAA, a deformação longitudinal final ainda foi negativa.

Figura 5.20 - Deformação (a) longitudinal e (b) radial do concreto sujeito à RAA, retração e fluência sob diferentes umidades relativas.

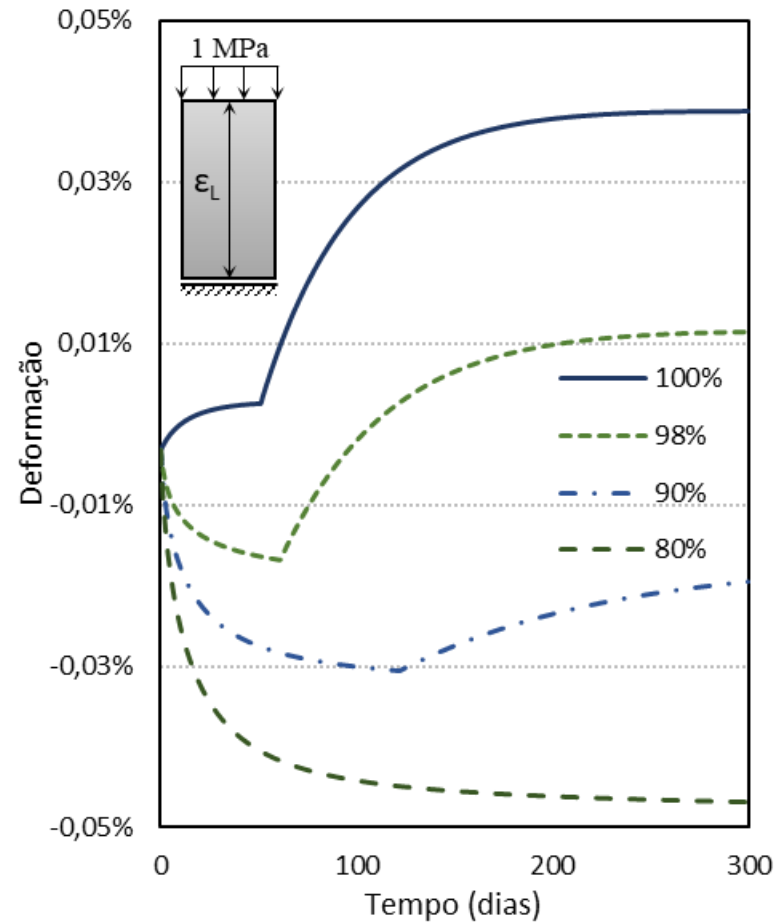

(a)

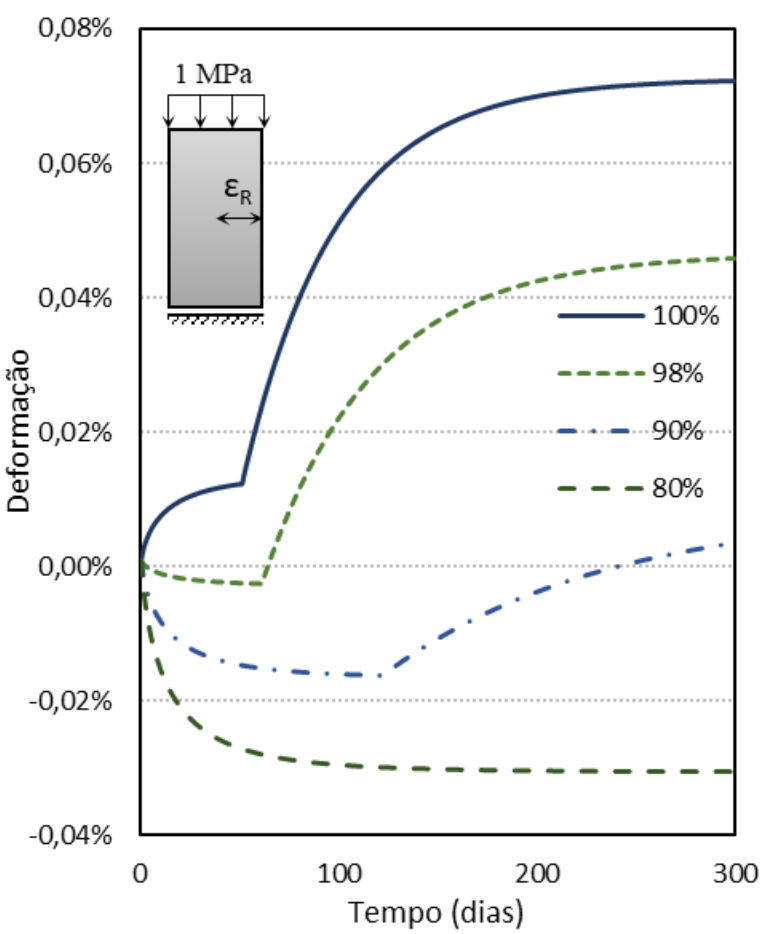

(b)

A última análise considera que os corpos de prova foram mantidos a uma umidade relativa de $98 \%$, sob tensão de compressão de $1 \mathrm{MPa}$, com temperatura variando de $20^{\circ} \mathrm{C}$ a $45^{\circ} \mathrm{C}$. As Figura 5.21a e a Figura 5.21b mostram, respectivamente, as deformações longitudinais e radiais para este caso.

Nota-se a semelhança no comportamento de ambos os gráficos, sendo a principal diferença entre eles a presença da deformação por fluência na direção longitudinal. Percebese, ao analisar os dias iniciais, que a variação de temperatura não afetou de maneira considerável as deformações por fluência e retração. Isto pode ter acontecido pois se considerou uma umidade relativa 98\%, consideravelmente alta, de modo que não houve intensificação da fluência por secagem e retração por secagem. Observa-se que não foi utilizada uma umidade relativa menor justamente para que se pudesse notar a expansão por RAA.

Já se tratando da expansão devido à RAA, verifica-se que o aumento de temperatura antecipa o início da expansão, de modo a aumentar sua intensidade ao longo do período analisado. 
Figura 5.21 - Deformação (a) longitudinal e (b) radial do concreto sujeito à RAA, retração e fluência sob diferentes temperaturas.

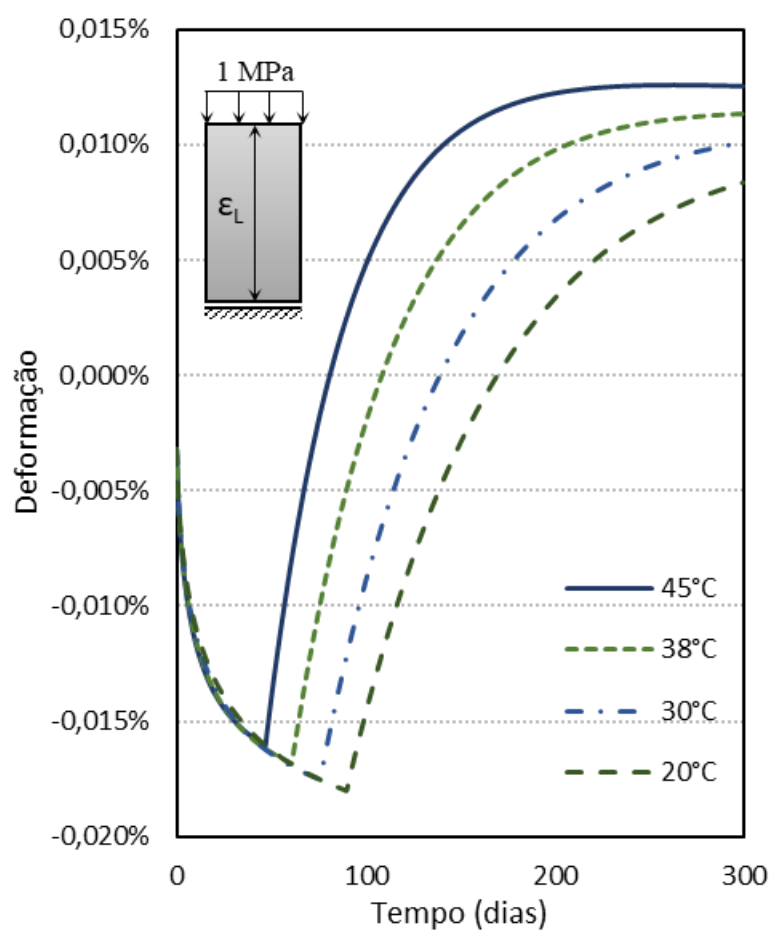

(a)

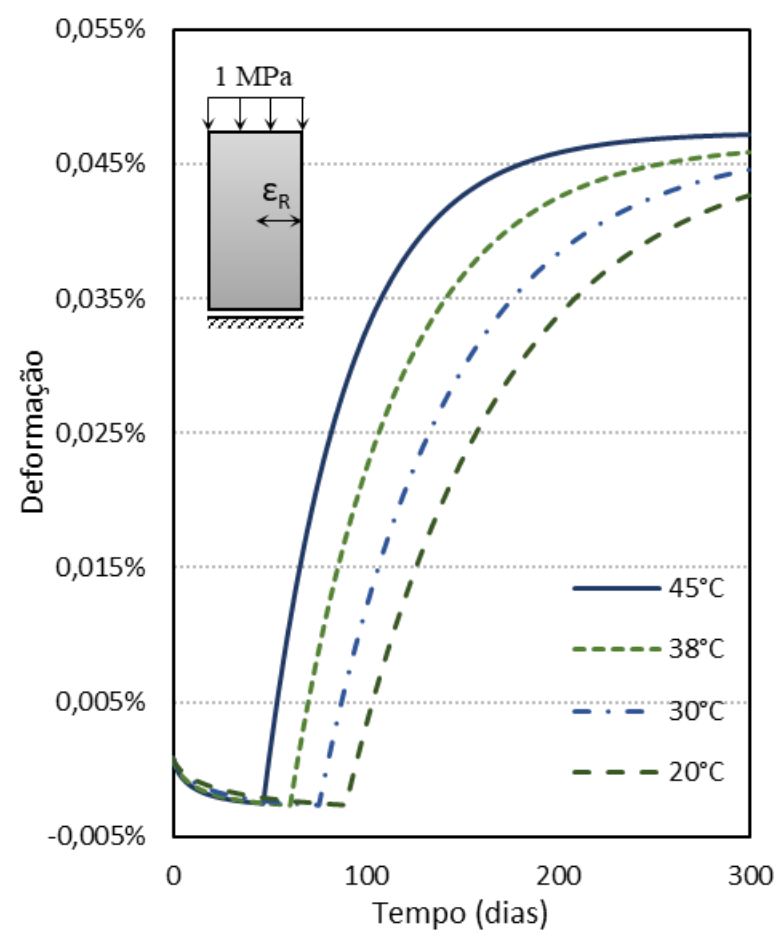

(b) 


\section{CAPÍTULO 6 CONCLUSÕES}

No âmbito da engenharia de estruturas, a reação álcali-agregado, a fluência e a retração do concreto têm instigado uma série de pesquisas ao longo do último século. Entretanto, ainda há muito por investigar no que diz respeito ao fenômeno físico com o intuito de prever as deformações causadas por estes três tipos de deformação. É justamente neste aspecto que surgiu este trabalho, de modo a contribuir na análise numérica das expansões do concreto sujeito à RAA, considerando também as deformações por retração e fluência.

Primeiramente, confirmou-se a eficiência do MEF Posicional para cálculos precisos de deslocamentos quanto à análise não linear geométrica de estruturas sujeitas a regimes de grandes deslocamentos.

Em segundo, foi possível verificar a eficiência do modelo proposto por Carrazedo \& Lacerda (2008) para o cálculo da expansão do concreto sujeito à RAA, especialmente para a expansão volumétrica. Quando calculados as expansões longitudinais e radias de corpos de prova cilíndrico, o modelo novamente demonstrou sua eficiência, apesar de não levar em conta que não há consideração da transferência de expansão da direção restrita à direção livre.

Este trabalho permitiu notar, para os casos analisados, a melhor eficiência do modelo B4 para o cálculo das deformações por retração e fluência quando comparado aos modelos JSCE e FIB. Indagou-se como possibilidade para tal verificação, o fato de o modelo B4 possuir maior refinamento de dados frente aos demais, além de que se levou em consideração a abrangência dos modelos JSCE e FIB no que diz respeito à relação volume/superfície.

Quando analisados a RAA, a retração e a fluência conjuntamente, percebeu-se que o modelo de Carrazedo \& Lacerda (2008) conjugado ao modelo B4 representou satisfatoriamente as deformações do concreto sujeito aos três fenômenos, demonstrando a eficiência da análise computacional para previsão das deformações de estruturas de concreto.

A análise paramétrica deste trabalho permitiu perceber, numericamente, o que já se sabia pela literatura, que a RAA governa a intensidade das deformações na direção livre para 
elementos carregados, mas que é suprimida na direção restringida, até um ponto em que se torna inexpressível.

Constatou-se a forte influência da umidade na expansão por RAA, havendo a diminuição na intensidade da deformação com a diminuição da umidade, até o ponto em que a reação deixa de ocorrer. Verificou-se também a interferência da umidade no fenômeno da retração, mostrando a inversão no comportamento da retração quando houve variação de apenas $2 \%$ na umidade. Foi observado, segundo os modelos numéricos empregados, que o fenômeno tem efeito de inchamento sob $100 \%$ de umidade, e efeito retrativo em umidade inferior a 100\%, uma vez que a superfície do elemento estrutural está livre para retrair.

Averiguou-se, por fim, a influência da temperatura nos fenômenos estudados. Para os casos analisados, não houve variação considerável das deformações por retração e fluência ao variar a temperatura, perquiriu-se como motivo o fato de a análise ter sido feita sob umidade de 98\%, um tanto intensa para que houvesse destaque nas deformações por retração por secagem e fluência por secagem. Por fim, notou-se que, para a expansão por RAA, a elevação da temperatura aumentou a velocidade da reação, sendo condizente com o observado na literatura.

\subsection{SUGESTÕES PARA TRABALHOS FUTUROS}

Com base nos resultados e observações oriundas deste trabalho, sugere-se:

i. Avaliar como ocorre a transferência da expansão por RAA da direção restringida para a direção livre de modo a considerar essa transferência na modelagem do fenômeno;

ii. Acoplar a variação da umidade relativa e temperatura ambiente ao longo do tempo, para que a modelagem se torne mais próxima à realidade das estruturas de concreto.

iii. Inserir no modelo a maturação do concreto ao longo do tempo, pois o ganho de rigidez do concreto irá interferir na intensidade das deformações;

iv. Modelar a danificação do concreto, uma vez que a degradação do concreto tende a intensificar as deformações relacionadas aos fenômenos aqui estudados;

v. Considerar a fissuração da matriz cimentícia a partir do agregado de modo que o modelo opere em escala mesoscópica, trazendo maior fidelidade à forma de ocorrência da reação álcali-agregado. 


\section{REFERÊNCIAS}

ABDELLATEF, M.; ALNAGGAR, M.; BOUMAKIS, G.; CUSATIS, G.; DI-LUZIO, G.; WENDNER, R. Lattice Discrete Particle Modeling for coupled concrete creep and shrinkage using Solidification Microprestress Theory. CONCREEP 10: MECHANICS AND PHYSICS OF CREEP, SHRINKAGE, AND DURABILITY OF CONCRETE AND CONCRETE STRUCTURES, Viena, 21-23 Setembro 2015.

ACI 209. Guide for Modeling and Calculating Shrinkage and Creep in Hardened Concrete. Farmington Hills: American Concrete Institute (ACI), 2008.

ASSOCIAÇÃO BRASILEIRA DE NORMAS TÉCNICAS (ABNT). NBR 15577-1: AgregadosReatividade álcali-agregado - Parte 1: Guia para avaliação da reatividade potencial e medidas preventivas para uso de agregados em concreto. Rio de Janeiro: ABNT, 2008.

AYUB, T.; KHAN, S. U.; MEMON, F. A. Mechanical Characteristics of Hardened Concrete with Different Mineral Admixtures: A Review. The Scientific World Journal, v. 2014, p. 1-15, 2014.

BATTAGIN, A. F. Divulgando conhecimento sobre a RAA para sua prevenção. Concreto e Construções, v. 44, n. 83, p. 7-8, 2016.

BAŽANT, Z. P.; BAWEJA, S. Creep and Shrinkage Prediction Model for Analysis and Design of Concrete Structures: Model B3. In: ACI Adam Neville Symposium: Creep and Shrinkage Structural Design Effects. Farmington Hills: American Concrete Institute (ACI), p. 1-83, 2000.

BAŽANT, Z. P.; RILEM. RILEM draft recommendation: TC-242-MDC multi-decade creep and shrinkage of concrete: material model and structural analysis Model B4 for creep, drying shrinkage and autogenous shrinkage of normal and high-strength concretes with multidecade applicability. Materials and Structures, v. 48, n. 4, p. 753-770, 2015.

BAŽANT, Z. P.; STEFFENS, A. Mathematical model for kinetics of alkali-silica reaction in concrete. Cement and Concrete Research, v. 30, p. 419-428, 2000. 
BAŽANT, Z. P.; YU, Q.; LI, G.-H. Excessive Long-Time Deflections of Prestressed Box Girders. I: Record-Span Bridge in Palau and Other Paradigms. Journal of Structural Engineering, v. 138, p. 676-686, 2012.

BEKTAS, F.; TURANLI, L.; TOPAL, T.; GONCUOGLU. M. C. Alkali reactivity of mortars containing chert and incorporating moderate-calcium fly ash. Cement and Concrete Research, v. 34, p. 2209-2214, 2004.

BÉRUBÉ, M. A.; DUCHESNE, J.; DORION, J. F.; RIVEST, M. Laboratory assessment of alkali contribution by aggregates to concrete and application to concrete structures affected by alkali-silica reactivity. Cement and Concrete Research, v. 32, n. 8, p. 1215-1227, 2002.

BODDY, A. M.; HOOTON, R. D.; THOMAS, M. D. A. The effect of product form of silica fume on its ability to control alkali-silica reaction. Cement and Concrete Research, v.30, n. 7, p. 1139$1150,2000$.

BROEKMANS, M. A. T. M. The alkali-silica reaction: mineralogical and geochemical aspects of some Dutch concretes and Norwegian mylonites. PhD. Thesis in University of Utrecht. 2002.

BR0OKS, J. J. Influence of mix proportions, plasticizers and superplasticizers on creep and drying shrinkage of concrete. Magazine of Concrete Research, v. 41, n. 148, p. 145-153, 1989.

CAPRA, B.; BOURNAZEL, J. P. Modeling of induced mechanical effects of alkali aggregate reactions. Cement and Concrete Research, v. 28, p. 251-260, 1998.

CARASEK, H.; CASCUDO, O.; CAETANO, G. Contribuição à previsão de danos para estruturas de concreto atacadas pela reação álcali-sílica. Concreto e Construções, v. 44, n. 83, p. 30-38, 2016.

CARRAZEDO, R. Modelagem Numérica da Expansão do Concreto devido à Reação ÁlcaliAgregado. Dissertação (Mestrado em Engenharia Civil) - Programa de Pós Graduação em Métodos Numéricos em Engenharia. Universidade Federal do Paraná. Curitiba, p. 104. 2004.

CARRAZEDO, R.; LACERDA, L. A. Parametric model for the analysis of concrete expansion due to alkali-aggregate reaction. The Journal of Strain Analysis for Engineering Design, v. 43, p. 325$335,2008$. 
CARRAZEDO, R.; SANCHES, R. A. K.; LACERDA, L. A.; DIVINO, P. L. Concrete Expansion Induced by Alkali-Silica Reaction in a Small Arch Dam. International Journal of Civil Engineering, v. 16, p. 289-297, 2018.

CHARLES-GIBERGUES, A.; HORNAIN, H. La durabilité des bétons face aux réactions de gonflement endogènes. In: OLLIVIER, J. P.; VICHOT, A. La Durabilité des Bétons - Bases scientifiques pour la formulation de bétons durables dans leur environnement. 2. ed. Paris: Presses de l'École nationale des ponts et chaussées, 2008.

CHARLWOOD, R. G. A review of alkali-aggregate reactions in hydro-electric plants and dams. Hydropower Dams, n. 1, p. 73-80, 1994.

CHARPIN, L.; PAPE, Y. L.; COUSTABEAU, É.; TOPPANI, É.; HEINFLING, G.; BELLEGO, C. L.; MASSON, B.; MONTALVO, J.; COURTOIS, A.; SANAHUJA, J.; REVIRON, N. A 12 year EDF study of concrete creep under uniaxial and biaxial loading. Cement and Concrete Research, v. 103, p. 140-159, 2018.

CODA, H. B. Análise não-linear geométrica de sólidos e estruturas: uma formulação posicional baseada no MEF. Tese para concurso de professor titular. São Carlos, 2003.

CODA, H. B.; GRECO, M. A. A simple FEM formulation for large deflection 2D frame analysis based on position description. Computer Methods in Applied Mechanics and Engineering, v. 193, n. 33-35, p. 3541-3557, 2004.

CODA, H. B.; PACCOLA, R. R. An alternative positional FEM formulation for geometrically nonlinear analysis of shells: curved triangular isoparametric elements. Computational Mechanics, v. 40, p. 185-200, 2007.

COLLINS, R. J.; BAREHAM, P. D. Alkali-silica reaction: suppression of expansion using porous aggregate. Cement and Concrete Research, v. 17, n. 1, p. 89-96, 1987.

COMI, C.; PEREGO, U. Anisotropic Damage Model for Concrete Affected by Alkali-Aggregate Reaction. International Journal of Damage Mechanics, v. 20, n. 4, p. 598-617, 2011.

CONSTANTINER, D.; DIAMOND, S. Alkali release from feldspars into pore solutions. Cement and Concrete Research, v. 33, p. 549-554, 2003.

DESCHENES, D. J. ASR/DEF-Damaged bent caps : shear tests and field implications. Master of Science in Engineering - The University of Texas. Austin, p. 295. 2009. 
DUNANT, C. F.; SCRIVENER, K. L. Micro-mechanical modelling of alkali-silica-reactioninduced degradation using the AMIE framework. Cement and Concrete Research, v. 40, n. 4, p. 517-525, 2010.

DYER, T. A Durabilidade do Concreto. Rio de Janeiro: Editora Ciência Moderna, 2015.

FIB. Model Code 2010. 65. ed. Lausanne: International Federation for Structural Concrete (fib), v. 1, 2012.

FOURNIER, B.; BÉRUBÉ, M. A. Alkali-aggregate reaction in concrete: a review of basic concepts and engineering implications. Canadian Journal of Civil Engineering, v. 27, n. 2, p. 167-191, 2000.

FRIEDEL, L. F. O. Análise de estruturas planas reforçadas com fibras ativas viscoelásticas e matriz com modelo constitutivo hiperelástico: aplicações gerais em engenharia e biomecânica. Dissertação (Mestrado) - Escola de Engenharia de São Carlos, Universidade de São Paulo. São Carlos. 2016.

GARDNER, N. J. Comparison of prediction provisions for drying shrinkage and creep of normal-strength concretes. Canadian Journal of Civil Engineering, v. 31, n. 5, p. 767-775, 2004.

GARDNER, N. J.; LOCKMAN, M. J. Design provisions for drying shrinkage and creep of normalstrength concrete. ACI Materials Journal, v. 98, p. 159-167, 2001.

GILLOTT, J. E. Alkali-aggregate reactions in concrete. Engineering Geology, v. 9, p. 303-326, 1975.

GLASSER, L. S. D.; KATAOKA, N. The chemistry ok alkali-aggregate reaction. Cement and Concrete Research, v. 11, n. 1, p. 1-9, 1981.

GRECO, M.; CODA, H. B. Positional FEM formulation for flexible multi-body dynamic analysis. Journal of Sound and Vibration, v. 290, p. 1141-1174, 2006.

GRIMAL, E.; SELLIER, A.; PAPE, Y. L.; BOURDAROT, E. Creep, Shrinkage, and Anisotropic Damage in Alkali-Aggregate Reaction Swelling Mechanism-Part I: A Constitutive Model. ACI Materials Journal, v. 105, n. 3, p. 227-235, 2008.

GUDMUNDSSON, G.; ÁSGEIRSSON, H. Some investigation of alkali aggregate reaction. Cement and Concrete Research, v. 5, p. 211-220, 1975. 
HASPARYK, N. P. Investigação de concretos afetados pela reação álcaliagregado e caracterização avançada do gel exsudado. Tese (Doutor em Engenharia Civil), Universidade Federal do Rio Grande do Sul. Porto Alegre. 2005.

HASPARYK, N. P. Reação álcali-agregado no concreto. In: ISAIA, C. G. Concreto: ciência e tecnologia. São Paulo: IBRACON, Cap. 27, p. 933-1001, 2011.

HEYMSFIELD, E.; DESCHENES, R.; HALE, W. M.; KUSS, M. L. Alkali-Silica Reaction Identification and Remediation at Northwest Arkansas Regional Airport. Journal of Performance of Constructed Facilities, v. 30, n. 4, p. 1-9, 2016.

HOBBS, D. W. Alkali-Silica Reaction in Concrete. London: Thomas Telford Ltd, 1988.

HOBBS, D. W. The alkali-silica reaction - a model for predicting expansion in mortar. Magazine of Concrete Research, v. 33, n. 117, p. 208-220, 1981.

HOLZAPFEL, G. A. Nonlinear Solid Mechanics - A Continuum Approach for Engineering. Chichester: John Wiley \& Sons, 2000.

HUBLER, M. H.; WENDNER, R.; BAŽANT, Z. P. Comprehensive Database for Concrete Creep and Shrinkage: Analysis and Recommendations for Testing and Recording. ACI Materials Journal, v. 112, p. 547-558, 2015.

JENSEN, V. Alkali-silica reaction damage to Elgeseter Bridge, Trondheim, Norway: a review of construction, research and repair up to 2003. Materials Characterization, v. 53, n. 2-4, p. 155-170, 2004.

JENSEN, A. D.; CHATTERJI, S.; CHRISTENSEN, P.; THAULOW, N. Studies of alkali-silica reaction - part II effect of air-entrainment of expansion. Cement and Concrete Research, v. 14, p. 311$314,1984$.

JOSHAGHANI, A.; BALAPOUR, M.; RAMEZANIANPOUR, A. A. Effect of controlled environmental conditions on mechanical, microstructural and durability properties of cement mortar. Construction and Building Materials, v. 164, p. 134-149, 2018.

JSCE. Standard Specifications for Concrete Structures - 2007. Design. Tokyo: Japan Society of Civil Engineers (JSCE), v. 15, 2010. 
KUPERMAN, S. C. Considerações sobre fluência de concretos. Téchne - Revista de Tecnologia da Construção, v.125, p. 58-63, 2007.

KZAM, A. K. L. Análise da instabilidade estrutural global e local pelo MEF posicional com determinação de pontos críticos na trajetória de equilíbrio. Tese de Doutorado - Escola de Engenharia de São Carlos, Universidade de São Paulo. São Carlos. 2016.

LÉGER, P.; CÔTÉ, P.; TINAWI, R. Finite element analysis of concrete swelling due to alkaliaggregate reactions in dams. Computers \& Structures, v. 60, n. 4, p. 601-611, 1996.

LEONHARDT, F.; MÖNNING, E. Construções de Concreto. Princípios Básicos do Dimensionamento de Estruturas de Concreto Armado. 2a. ed. Rio de Janeiro: Interciência Ltda., v. I, 1977.

LINDGÅRD, J.; ANDIÇ-ÇAKIR, Ö.; FERNANDES, I.; RøNNING, T. F.; THOMAS, M. D. A. Alkalisilica reactions (ASR): Literature review on parameters influencing laboratory performance testing. Cement and Concrete Research, v. 42, p. 223-243, 2012.

LINDGÅRD, J.; NIXON, P. J.; BORCHERS, I.; SCHOUENBORG, B.; WIGUM, B. J.; HAUGEN, M.; ÅKESSON, U. The EU "PARTNER" Project-European standard tests to prevent alkali reactions in aggregates: Final results and recommendations. Cement and Concrete Research, v. 40, p. 611-635, 2010.

MADUREIRA, E. L. Simulação numérica do comportamento mecânico de elementos de concreto armado afetados pela reação álcali-agregado. Tese (Doutorado) - Universidade Federal do Pernambuco - UFPE. Recife. 2007.

MATTIASSON, K. Numerical results from large deflection beam and frame problems analysed by means of elliptic integrals. International Journal for Numerical Methods in Engineering, v. 17 , p. $145-153,1981$.

MAZLOOM, M.; RAMEZANIANPOUR, A. A.; BROOKS, J. J. Effect of silica fume on mechanical properties of high-strength concrete. Cement and Concrete Composites, v. 26, n. 4, p. 347-357, 2004.

MEHTA, P. K.; MONTEIRO, P. J. M. Concreto. Microestrutura, Propriedades e Materiais. 2a. ed. São Paulo: IBRACON, 2014. 
MULTON, S.; CYR, M.; SELLIER, A.; DIEDERICH, P.; PETIT, L. Effects of aggregate size and alkali content on ASR expansion. Cement and Concrete Research, v. 40, p. 508-516, 2010.

MULTON, S.; CYR, M.; SELLIER, A.; LEKLOU, N.; PETIT, L. Coupled effects of aggregate size and alkali content on ASR expansion. Cement and Concrete Research, v. 38, p. 350-359, 2008.

MULTON, S.; TOUTLEMONDE, F. Effect of applied stresses on alkali-silica reaction induced expansions. Cement and Concrete Research, v. 36, p. 912-920, 2006.

NEVILLE, A. M.; BROOKS, J. J. Tecnologia do Concreto. Porto Alegre: Bookman, 2013.

NGUYEN, V. P.; STROEVEN, M.; SLUYS, L. J. Multiscale failure modeling of concrete: Micromechanical modeling, discontinuous homogenization and parallel computations. Computer Methods in Applied Mechanics and Engineering, v. 201, p. 139-156, 2012.

NOVOZHILOV, V. V. Foundations of the nonlinear theory of elasticity. Rochester: Graylock Press, 1953.

OBERHOLSTER, R. E. Alkali reactivity of silicious rock aggregates: Diagnosis of the reaction, testing of cement and aggregate and prescription of preventive measures. Proceeding of the 6th International Conferance Alkalies in Concrete - Research and Practice. Copenhagen, 1983. OGDEN, R. W. Non-linear elastic deformation. New York: Dover Publication, 1997.

ÓLAFSSON, H. The effect of relative humidity and temperature on alkali expansion of mortar bars. In: Proceedings of the 7th International Conference on Concrete Alkali-Aggregate Reaction. Ottawa, 1986.

OLIVEIRA, J. R. S. Modelagem da expansão do concreto devido à RAA com decaimento do módulo de elasticidade. Dissertação (Mestre em Ciências) - Universidade Federal do Paraná UFPR. Curitiba. 2013.

PACCOLA, R. R.; CODA, H. B. AcadView, versão 3. Laboratório de Informática e Mecânica Computacional da Escola de Engenharia de São Carlos da Universidade de São Paulo. São Carlos, 2005.

PAN, J.; FENG, Y. T.; JIN, F.; ZHANG, C. Numerical prediction of swelling in concrete arch dams affected by alkali-aggregate reaction. European Journal of Environmental and Civil Engineering, v. 17, n. 4, p. 231-247, 2013. 
PAPPALARDO JR, A.; PAULETTI, R. M. O.; PIMENTA, P. M. Simulação numérica da reação álcaliagregado em barragens de concreto. Revista Mackenzie de Engenharia e Computação, v. 1, n. 1, p. 181-199, 2000.

PASCON, J. P. Sobre modelos constitutivos não lineares para materiais com gradação funcional exibindo grandes deformações: implementação numérica em formulação não linear geométrica. Tese (Doutorado) - Departamento de Engenharia de Estruturas, Escola de Engenharia de São Carlos, Universidade de São Paulo. São Carlos, 2012.

PIEDADE NETO, D.; FAGÁ JR., R.; PACCOLA, R. R. AcadMesh2D. Laboratório de Informática e Mecânica Computacional da Escola de Engenharia de São Carlos da Universidade de São Paulo. São Carlos, 2012.

PIETRUSZCZAK, S. On the mechanical behaviour of concrete subjected to alkali-aggregate reaction. Computers \& Structures, v. 58, n. 6, p. 1093-1097, 1996.

PIETRUSZCZAK, S.; JIANG, J.; MIRZA, F. A. An elastoplastic constitutive model for concrete. International Journal of Solids and Structures , v. 24, n. 7, p. 705-722, 1988.

PIGNATELLI, R. Modeling of degradation induced by alkali-silica reaction in concrete structures. Tesi di Dottorato - Ingegneria Strutturale, Sismica e Geotecnica. Politecnico di Milano. Milano, p. 163. 2012.

POLETTO, F. A. B. Análise da Fluência em Vigas de Concreto Armado Simplesmente Apoiadas Usando o Método dos Elementos Finitos. Dissertação (Mestrado em Engenharia Civil) Programa de Pós-Graduação em Engenharia Civil. Universidade Tecnológica do Paraná. Curitiba, p. 191. 2015.

POSTERLLI, M. C. Modelagem da expansão devido à reação álcali-agregado de concreto armado reforçado com fibras. Dissertação (Mestrado em Engenharia Civil - Estruturas) - Escola de Engenharia de São Carlos - Universidade de São Paulo. São Carlos. 2017.

PROENÇA, S. P. B. Análise não-linear de Estruturas. Notas de Aula (Não-linearidade geométrica). Departamento de Estruturas (SET), Escola de Engenharia de São Carlos Universidade de São Paulo. São Carlos. 2006.

PROVOST, F.; FAWCETT, T. Data Science for Business. 1a. ed. Sebastopol: O’Reilly Media, 2013. 
RILEM. RILEM TC 191-ARP: 'Alkali-reactivity and prevention-assessment, specification and diagnosis of alkali-reactivity', RILEM recommended test method AAR-1: detection of potential alkali-reactivity of aggregates-petrographic method. Materials and Structures, v. 36, p. 480496, 2003.

RÜSCH, H. Concreto armado e protendido - propriedades dos materiais e dimensionamento. Rio de Janeiro: Campus, 1981.

SALOMÃO, R. C. Análise da Influência do Campo Higrométrico sobre a Reação Álcali-Agregado. Dissertação (Mestrado em Engenharia Civil - Estruturas) - Escola de Engenharia de São Carlos - Universidade de São Paulo. São Carlos, 2017.

SAMPAIO, M. S. M. Análise não linear geométrica de cascas laminadas reforçadas com fibras. Tese (Doutorado) - Escola de Engenharia de São Carlos - Universidade de São Paulo. São Carlos, 2014.

SAOUMA, V. E.; MARTIN, R. A.; HARIRI-ARDEBILI, M. A.; KATAYAMA, T. A mathematical model for the kinetics of the alkali-silica chemical reaction. Cement and Concrete Research, v. 68, p. 184-195, 2015.

SCRIVENER, K. L. Importance of microstructural understanding for durable and sustainable concrete. Concrete Repair, Rehabilitation and Retrofitting II, p. 13-20, 2009.

SHAYAN, A. The pessimum effect in an accelerated mortar bar test using $1 \mathrm{M} \mathrm{NaOH}$ solution at $80^{\circ} \mathrm{C}$. Cement and Concrete Composites, v. 14, p. 249-255, 1992.

SILVEIRA, J. F. A. A expansão do concreto em barragens afetadas pela RAA e a importância das tensões confinantes. In: Simpósio sobre reatividade álcali-agregado em estruturas de concreto. Goiânia, 1997.

ST JOHN, D. A.; POOLE, A. B.; SIMS, I. Concrete Petrography-A Handbook of Investigative Techniques. U. K.: Arnold Publisher, 1998.

STANTON, T. E. Expansion of concrete through reaction between cement and aggregates. Proceedings of ASCE, v. 66, n. 10, p. 1781-1811, 1940.

STRAUSS, A.; VIDOVIC, A.; ZAMBON, I.; GROSSBERGER, H. Monitoring Information and Probabilistic-Based Prediction Models for the Performance Assessment of Concrete Structures. Journal of Performance of Constructed Facilities, v. 30, n. 4, p. 1-16, 2016. 
TANG, M.-C. The Story of the Koror Bridge. Zürich: International Association for Bridge and Structural Engineering (IABSE), 2014.

TIECHER, F. Reação álcali-agregado: avaliação do comportamento de agregados do sul do Brasil quando se altera o cimento utilizado. Dissertação (Mestrado em Engenharia Civil) Universidade Federal do Rio Grande do Sul. Porto Alegre, 2006.

TIMOSHENKO, S.; GOODIER, J. N. Theory of Elasticity. 2a. ed. New York: McGraw-Hill, 1951.

TROXELL, G. E.; RAPHAEL, J. M.; DAVIS, R. E. Long-Time Creep and Shrinkage Tests of Plain and Reinforced Concrete. Proceedings of ASTM International, v. 58, p. 1101-1120, 1958.

VILLAÇA, S. F.; GARCIA, L. F. T. Introdução à teoria da elasticidade. Rio de Janeiro: COPPE/UFRJ, 1998.

WENDNER, R.; HUBLER, M. H.; BAŽANT, Z. P. Statistical justification of model B4 for multidecade concrete creep using laboratory and bridge databases and comparisons to other models. Materials and Structures, v. 48, p. 815-833, 2015.

WU, T.; TEMIZER, I.; WRIGGERS, P. Multiscale hydro-thermo-chemo-mechanical coupling: Application to alkali-silica reaction. Computational Materials Science, v. 84, p. 381-395, 2014.

ZHANG, M. H.; MALHOTRA, V. M. Characteristics of a thermally activated alumino-silicate pozzolanic material and its use in concrete. Cement and Concrete Research, v. 25, n. 8, p. 17131725, 1995.

ZHANG, C.; WANG, A. Q.; TANG, M. S.; WU, B. Q.; ZHANG, N. S. Influence of aggregate size and aggregate size grading on ASR expansion. Cemente and Concrete Research, v. 29, n. 9, p. 13931396, 1999. 